\title{
Lean NOx Trap Catalysis for Lean Natural Gas Engine Applications
}

\section{September 2007}

\author{
Prepared by \\ James E. Parks II, John M. E. Storey, Aaron M. Williams, H. Douglas \\ Ferguson III, James Tassitano, Senthil Ponnusamy, Tim J. Theiss \\ (Oak Ridge National Laboratory)
}

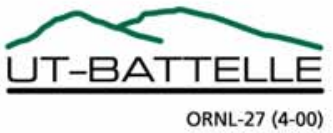




\section{DOCUMENT AVAILABILITY}

Reports produced after January 1, 1996, are generally available free via the U.S. Department of Energy (DOE) Information Bridge.

Web site http://www.osti.gov/bridge

Reports produced before January 1, 1996, may be purchased by members of the public from the following source.

National Technical Information Service

5285 Port Royal Road

Springfield, VA 22161

Telephone 703-605-6000 (1-800-553-6847)

TDD 703-487-4639

Fax 703-605-6900

E-mail info@ntis.fedworld.gov

Web site http://www.ntis.gov/support/ordernowabout.htm

Reports are available to DOE employees, DOE contractors, Energy Technology Data Exchange (ETDE) representatives, and International Nuclear Information System (INIS) representatives from the following source.

Office of Scientific and Technical Information

P.O. Box 62

Oak Ridge, TN 37831

Telephone 865-576-8401

Fax 865-576-5728

E-mail reports@adonis.osti.gov

Web site http://www.osti.gov/contact.html

This report was prepared as an account of work sponsored by an agency of the United States Government. Neither the United States government nor any agency thereof, nor any of their employees, makes any warranty, express or implied, or assumes any legal liability or responsibility for the accuracy, completeness, or usefulness of any information, apparatus, product, or process disclosed, or represents that its use would not infringe privately owned rights. Reference herein to any specific commercial product, process, or service by trade name, trademark, manufacturer, or otherwise, does not necessarily constitute or imply its endorsement, recommendation, or favoring by the United States Government or any agency thereof. The views and opinions of authors expressed herein do not necessarily state or reflect those of the United States Government or any agency thereof. 
ORNL/TM-2007/140

\title{
LEAN NOX TRAP CATALYSIS FOR LEAN NATURAL GAS ENGINE APPLICATIONS
}

\author{
Prepared by \\ James E. Parks II, John M. E. Storey, Aaron M. Williams, H. Douglas Ferguson III, James \\ Tassitano, Senthil Ponnusamy, Tim J. Theiss \\ Oak Ridge National Laboratory \\ Oak Ridge, TN 37831-6283 \\ Under support from the \\ Advanced Reciprocating Engine Systems Program \\ Office of Electricity Delivery \& Energy Reliability \\ U.S. Department of Energy
}

Date Published: September 2007

Department of Energy (DOE) Proposal Number 1883-S821-A1

Prepared Under DOE Contract \#DE-AC05-00OR22725

between

Department of Energy Oak Ridge Operations Office

and

UT-Battelle, LLC 


\section{CONTENTS}

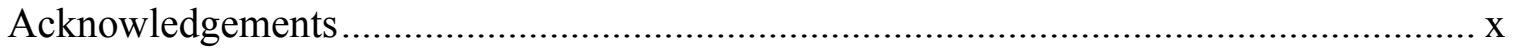

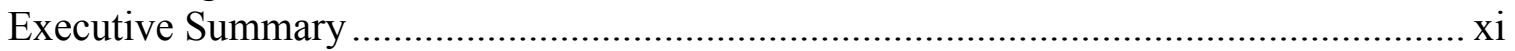

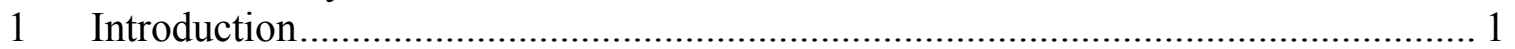

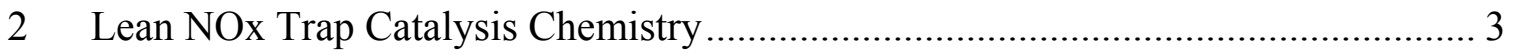

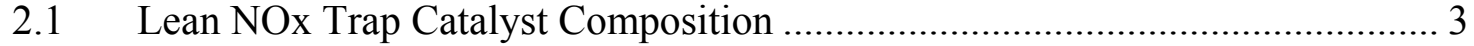

2.2 Sorption-Regeneration Cycle.................................................................. 4

2.3 Natural Gas Utilization for Lean NOx Trap Regeneration ............................... 8

3 Lean NOx Trap Catalyst System and Engine Platform ..................................... 10

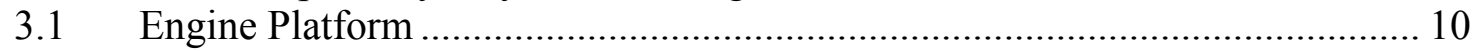

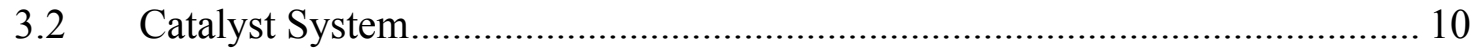

3.3 Data Acquisition and Exhaust Species Analysis ..................................... 12

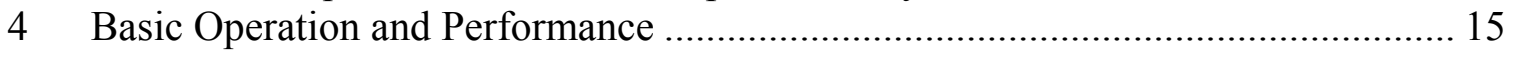

5 Optimization of Performance............................................................................ 20

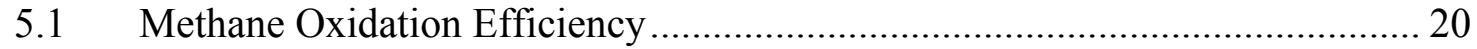

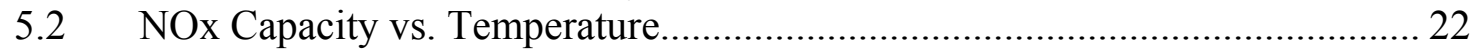

5.3 NOx Capacity vs. NOx Rate ....................................................................... 23

6 Lean NOx Trap Regeneration with Natural Gas................................................... 26

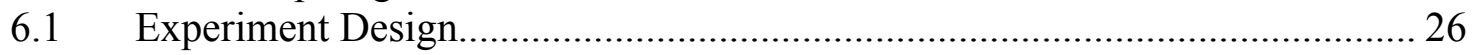

6.2 NOx Reduction and Fuel Penalty ......................................................... 26

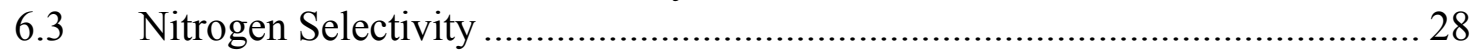

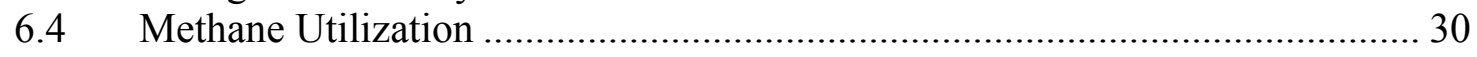

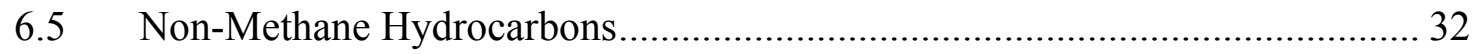

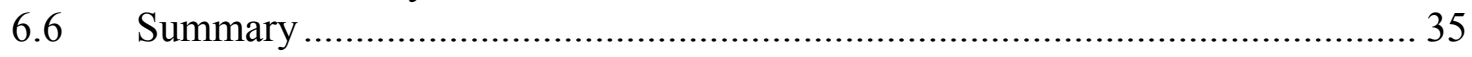

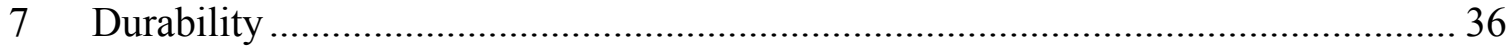

7.1 Catalyst Degradation Mechanisms ............................................................ 36

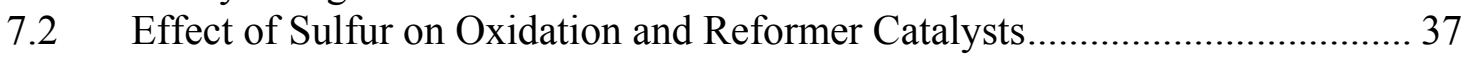

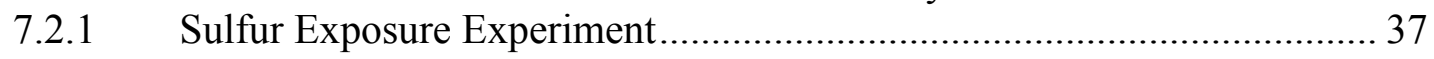

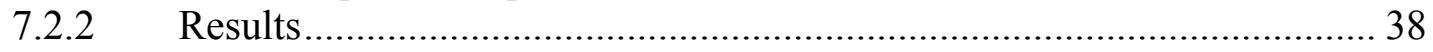

7.2.3 Discussion: Implications of the Results ............................................. 42

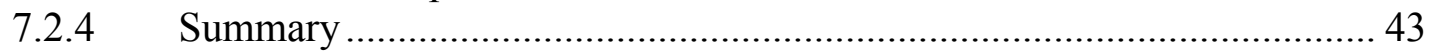

7.3 Mitigation of Sulfur Effects on Lean NOx Trap Catalysts ............................. 43

7.3.1 Sorbate Reapplication Procedure ......................................................... 44

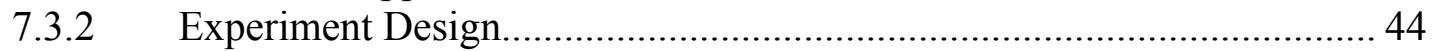

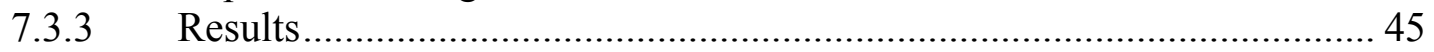

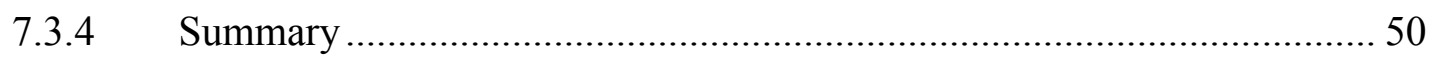

8 Application of Lean NOx Trap Catalysis for Natural Gas Applications ................. 51

8.1 ISO 8178 Emission Test Cycle ................................................................. 51

8.2 Details of Modal Data ................................................................................. 52

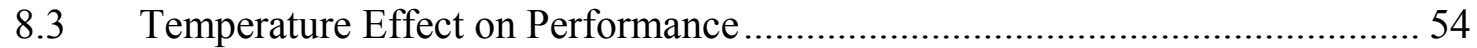

9 Future of Lean NOx Trap Catalysis for Reciprocating Engines............................. 57

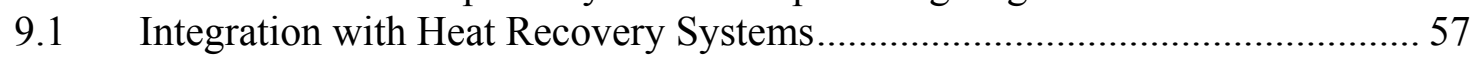

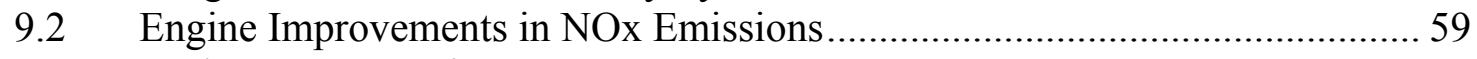

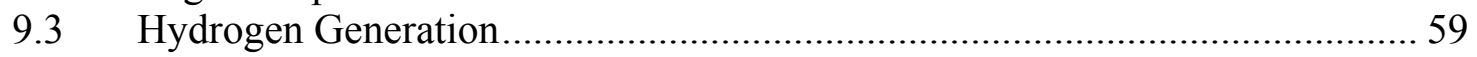

9.4 Opportunities for Catalyst Cost Reduction .............................................. 60 


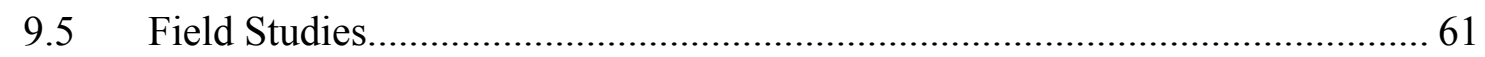

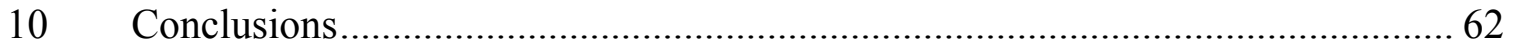

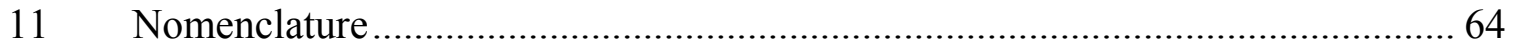

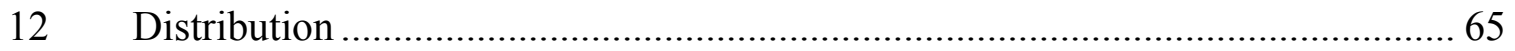

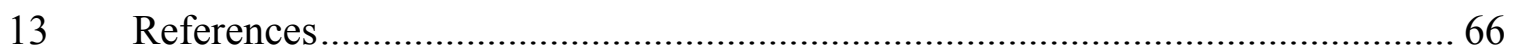




\section{FIGURES}

Figure 0 -1. Utilization of methane in the lean NOx trap catalyst system.......................xii Figure 0-2. NOx capacity as a function of temperature before sulfur poisoning (Pre S), after sulfur poisoning (Post S), and after sorbate reapplication (New K)..................

Figure 2-1. Free energy diagram of the chemical states of the alkali/alkaline earth based

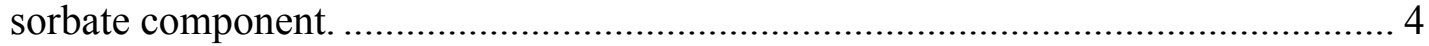

Figure 2-2. Schematic of the finely dispersed catalyst components during a sorptionregeneration cycle. ....................................................................................... 5

Figure 2-3. Scanning electron micrograph of the surface of a lean NOx trap catalyst...... 6 Figure 2-4. Photo of the catalysts used in the study showing the monolithic cell structure.

Figure 2-5. Diagram of the lean NOx trap catalyst process along the flow axis of a

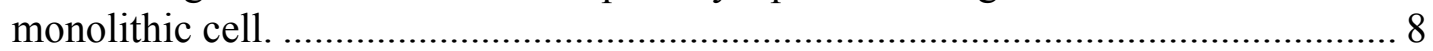

Figure 2-6. Catalyst geometry in the lean NOx trap catalyst system............................ 9

Figure 3-1. Lean NOx trap catalyst system. .............................................................. 11

Figure 3-2. Photograph of lean NOx trap catalyst system in the engine cell.................. 12

Figure 3-3. Schematic of exhaust gas analysis system.............................................. 14

Figure 4-1. NOx concentration as a function of time during lean NOx trap cycling. ..... 15

Figure 4-2. Conversion of NOx concentration to NOx mass emission level................... 17

Figure 4-3. Mass-based NOx emissions showing lean NOx trap catalyst NOx reduction

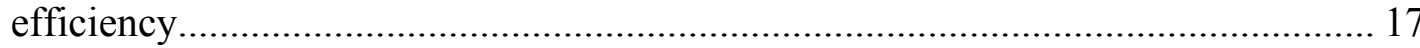

Figure 4-4. Excess air ratio, fuel flow rate, and catalyst temperatures during lean NOx

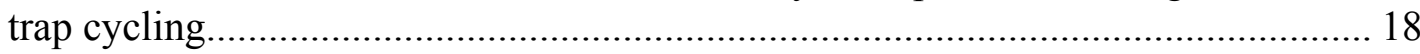

Figure 5-1. $\mathrm{CH}_{4}$ oxidation efficiency of the oxidation catalyst as a function of catalyst temperature.

Figure 5-2. NOx performance, fuel penalty, and reductant production as a function of

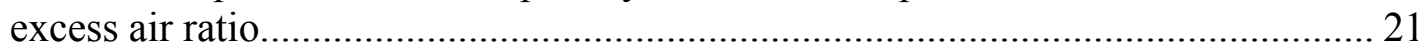

Figure 5-3. NOx storage capacity as a function of LNT catalyst temperature............... 23

Figure 5-4. LNT performance as a function of engine conditions............................... 25

Figure 6-1. NOx reduction efficiency as a function of excess air ratio $(\lambda)$ during

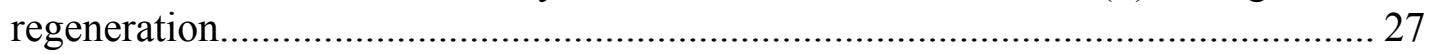

Figure 6-2. Fuel penalty as a function of excess air ratio $(\lambda)$ during regeneration.......... 27

Figure 6-3. Catalyst temperatures as a function of engine load................................... 28

Figure 6-4. Example raw data showing $\mathrm{NH}_{3}$ and $\mathrm{N}_{2} \mathrm{O}$ measured at Oxi Cat In, Oxi Cat Out, Ref Cat Out, and LNT Out sample positions in the catalyst system. The 60second period of the signals is due to the 60 -second lean-rich cycle for lean NOx trap operation; one tick on the $\mathrm{x}$-axis label represents 60 seconds.

Figure 6-5. $\mathrm{N}_{2} \mathrm{O}$ (a) and $\mathrm{NH}_{3}$ (b) peak concentration measured at the LNT Out position as a function of minimum excess air ratio during regeneration.

Figure 6-6. Example raw data showing (a) $\mathrm{CH}_{4}$, (b) $\mathrm{O}_{2}$, (c) $\mathrm{CO}$, and (d) $\mathrm{H}_{2}$ measured at Oxi Cat In, Oxi Cat Out, Ref Cat Out, and LNT Out sample positions in the catalyst system. The 60-second period of the signals is due to the 60 -second lean-rich cycle for lean NOx trap operation; one tick on the x-axis label represents 60 seconds.... 31

Figure 6-7. Exhaust species data obtained at (a) Oxi Cat In, (b) Oxi Cat Out, (c) Ref Cat Out, and (d) LNT Out sample positions. The x-axis for all plots is time in seconds 
with a range of $0-60$. The $y$-axis represents concentration and is the same scale for

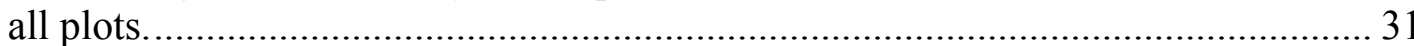

Figure 6-8. Integrated reductant peaks obtained at catalyst temperatures of (a) $420^{\circ} \mathrm{C}$, (b) $500^{\circ} \mathrm{C}$, and (c) $560^{\circ} \mathrm{C}$. Note the different scale for the y-axis in each plot.............. 32

Figure 6-9. Example raw data showing (a) $\mathrm{C}_{2} \mathrm{H}_{4}$ and (b) $\mathrm{CH}_{4}$ measured at Oxi Cat In, Oxi Cat Out, Ref Cat Out, and LNT Out sample positions in the catalyst system. The 60 -second period of the signals is due to the 60 -second lean-rich cycle for lean NOx trap operation; one tick on the $\mathrm{x}$-axis label represents 60 seconds. 33

Figure 6-10. Example raw data showing (a) $\mathrm{C}_{2} \mathrm{H}_{6}$ and (b) $\mathrm{C}_{3} \mathrm{H}_{8}$ measured at Oxi Cat In, Oxi Cat Out, Ref Cat Out, and LNT Out sample positions in the catalyst system. The 60 -second period of the signals is due to the 60 -second lean-rich cycle for lean NOx trap operation; one tick on the $\mathrm{x}$-axis label represents 60 seconds.................. 34 Figure 7-1. $\mathrm{CO}$ and $\mathrm{H}_{2}$ as a function of time and cycles before, during, and after

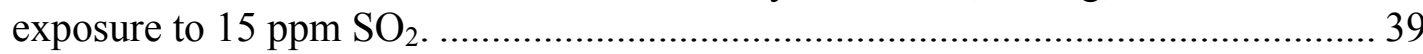

Figure 7-2. $\mathrm{CO}$ and $\mathrm{H}_{2}$ as a function of time and cycles before, during, and after

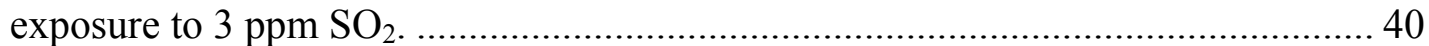

Figure 7-3. Recovery of $\mathrm{H}_{2}$ downstream of the reformer catalyst after exposure to $\mathrm{SO}_{2} .41$ Figure 7-4. Comparison of pre- $\mathrm{SO}_{2}$, post- $\mathrm{SO}_{2}$, and post-recovery reductant concentrations for 3-, 15-, and 40-ppm $\mathrm{SO}_{2}$ exposure experiments; peak reductant concentrations shown for (a) Oxi Cat Out CO, (b) Oxi Cat Out $\mathrm{H}_{2}$, (c) Ref Cat Out $\mathrm{CO}$, and (d) Ref Cat Out $\mathrm{H}_{2}$.

Figure 7-5. Comparison of pre- $\mathrm{SO}_{2}$, post- $\mathrm{SO}_{2}$, and post-recovery reductant concentrations for 460 and $520^{\circ} \mathrm{C}$ catalyst temperatures for $40-\mathrm{ppm} \mathrm{SO}_{2}$ exposure; peak reductant concentrations shown for (a) Oxi Cat Out CO, (b) Oxi Cat Out $\mathrm{H}_{2}$, (c) Ref Cat Out CO, and (d) Ref Cat Out $\mathrm{H}_{2}$.

Figure 7-6. NOx sorption profiles for the lean NOx trap catalyst before and after sulfur exposure and after new sorbate has been applied. The shaded regions represent regeneration phases.

Figure 7-7. Cycle average NOx reduction efficiency for four operational modes over the course of the study.

Figure 7-8. Peak NOx reduction efficiency for four operational modes over the course of

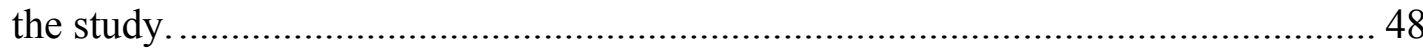

Figure 7-9. NOx reduction efficiency as a function of temperature before and after sulfur exposure and after new sorbate application.......................................................... 49

Figure 7-10. Peak NOx reduction efficiency as a function of temperature before and after sulfur exposure and after new sorbate application.................................................. 49

Figure 7-11. NOx storage capacity as a function of temperature before and after sulfur exposure and after new sorbate application........................................................ 50

Figure 8-1. Fueling rate and excess air ratio for engine loads measured during the ISO 8178 test cycle............................................................................................... 52

Figure 8-2. NOx concentration (a), exhaust flow (b), and NOx mass emission rate (c) for the five modes of the ISO 8178 test cycle............................................................... 53

Figure 8-3. Engine out and system out NOx measured during the ISO 8178 emission test

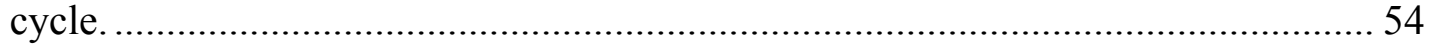

Figure 8-4. Catalyst temperature (a) and system out NOx (b) from three different

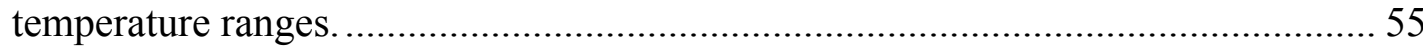


Figure 8-5. ISO 8178 emission test cycle results vs. catalyst temperature.

Figure 9-1. Schematic of waste heat recovery positions from an engine-catalyst system.

Figure 9-2. NOx reduction efficiency and thermal efficiency as heat recovery is varied.

Figure 9-3. Optimization of system performance by separation of partial oxidation and reforming catalysts from the lean NOx trap catalysts........................................ 59

Figure 9-4. Schematic of engine and lean NOx trap system with common $\mathrm{H}_{2}$ source..... 60 Figure 9-5. NOx storage capacity as a function of catalyst temperature for lean NOx trap catalysts with different Pt content 


\section{TABLES}

Table 1. ISO 8178 Type D2 emission test cycle results. ...............................................

Table 1-1. ARES Program Goals................................................................................ 1

Table 3-1. Engine Specifications. ............................................................................... 10

Table 4-1. Flow Rate Through Catalyst Leg During Regeneration.................................. 16

Table 7-1. Mechanisms of Catalyst Deactivation (Source: Bartholomew ${ }^{23}$ )................... 36

Table 8-1. ISO 8178 Emission Test Cycle Type D2 ………......................................... 51

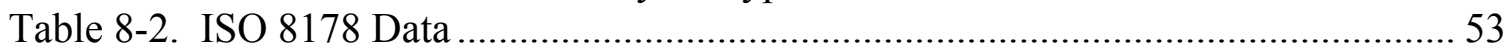

Table 8-3. ISO 8178 Emission Test Cycle Results vs. Catalyst Temperature.................. 54 


\section{Acknowledgements}

This work is a part of the U.S. Department of Energy (DOE) Advanced Reciprocating Engine System (ARES) Program within the Office of Electricity Delivery \& Energy Reliability. The ARES program, under the leadership of Ron Fiskum, is in cooperation with industrial representatives from Caterpillar, Cummins, and Waukesha. The leadership of Ron Fiskum (DOE), Gordon Gerber (Caterpillar), Dave Montgomery (Caterpillar), Edward J. Lyford-Pike (Cummins), Axel zur Loye (Cummins), Link Brandon (Cummins), David Watson (Waukesha), Robert Stachowicz (Waukesha), and Jim Drees (Waukesha), is gratefully acknowledged. Oak Ridge National Laboratory (ORNL) would like to acknowledge EmeraChem LLC for supply of the catalysts for the project. H. Douglas Ferguson III, James Tassitano, and Senthil Ponnusamy performed work under a subcontract with Oak Ridge Associated Universities. Aaron M. Williams performed work through collaboration with the University of Tennessee, Knoxville for his Masters degree under the direction of David "Butch" Irick of the Department of Mechanical, Aerospace, and Biomedical Engineering. ORNL is managed by UT-Battelle LLC for the U.S. Department of Energy under subcontract DE-AC05-00OR22725. 


\section{Executive Summary}

Lean NOx trap catalysts have been studied as a means to reduce NOx emissions from leanburn natural gas reciprocating engines commonly used in distributed power generation. The research was supported by the Advanced Reciprocating Engine Systems (ARES) program of the U.S. Department of Energy. Industrial partners in the ARES program are Caterpillar, Cummins, and Waukesha. A primary goal of the ARES program is to achieve $<0.1 \mathrm{~g} / \mathrm{bhp}-\mathrm{hr}$ NOx emissions by 2010 .

Research was conducted on a Cummins 8.3-liter lean natural gas engine on an engine dynamometer at Oak Ridge National Laboratory. A lean NOx trap catalyst system installed on the exhaust system of the engine successfully demonstrated NOx emission levels below 0.1 $\mathrm{g} / \mathrm{bhp}$-hr. Furthermore, NOx emission levels as low as $0.08 \mathrm{~g} / \mathrm{bhp}$-hr were demonstrated in the ISO 8178 Type D2 emission test cycle commonly used for power generation applications (see Table 1). NOx emissions were reduced by over $90 \%$ from the emission levels emitted by the engine. Natural gas fuel from the supply line to the engine was used as the fuel to enable NOx reduction in lean exhaust; fuel penalties (fuel use for the catalyst system relative to the engine fuel use) for the ISO 8178 test modes were between $1.4 \%$ and $3.8 \%$.

Table 1. ISO 8178 Type D2 emission test cycle results.

\begin{tabular}{|c|c|c|c|c|c|c|c|c|}
\hline Mode & $\begin{array}{c}\text { Engine } \\
\text { Load } \\
(\%)\end{array}$ & $\begin{array}{l}\text { Engine } \\
\text { Out NOx } \\
(\mathrm{g} / \mathrm{hr})\end{array}$ & $\begin{array}{c}\text { System } \\
\text { Out NOx } \\
(\mathrm{g} / \mathrm{hr})\end{array}$ & $\begin{array}{l}\text { Engine } \\
\text { Out NOx } \\
\text { (g/bhp-hr) }\end{array}$ & $\begin{array}{l}\text { System } \\
\text { Out NOx } \\
\text { (g/bhp-hr) }\end{array}$ & $\begin{array}{c}\text { NRE* } \\
(\%)\end{array}$ & $\begin{array}{c}\text { Fuel } \\
\text { Penalty } \\
(\%)\end{array}$ & $\begin{array}{l}\text { LNT Catalyst } \\
\text { Temperature } \\
\left({ }^{\circ} \mathrm{C}\right)\end{array}$ \\
\hline 1 & 100 & 253.4 & 28.6 & 1.05 & 0.12 & 88.7 & 3.8 & 512.2 \\
\hline 2 & 75 & 139.8 & 11.2 & 0.77 & 0.06 & 92.0 & 2.2 & 498.9 \\
\hline 3 & 50 & 74.8 & 3.6 & 0.61 & 0.03 & 95.3 & 1.4 & 469.4 \\
\hline 4 & 25 & 175.0 & 8.2 & 2.95 & 0.14 & 95.2 & 2.7 & 439.6 \\
\hline 5 & 10 & 44.4 & 1.7 & 1.89 & 0.07 & 96.4 & 3.2 & 364.6 \\
\hline \multicolumn{4}{|c|}{ Weighted Result } & 1.11 & 0.08 & 94.2 & 2.3 & 459.5 \\
\hline
\end{tabular}

*NRE $=$ NOx Reduction Efficiency

Several critical aspects of the lean NOx trap catalyst technology were investigated for lean natural gas reciprocating engine applications. Research activities ranged from fundamental mechanisms involved in catalyst operation to studies of catalyst performance relative to ARES goals established by the ARES industrial representatives for commercial systems. Key findings include:

- Natural gas fuel can be used as the catalyst reductant. Natural gas containing high methane content can be used to regenerate the lean NOx trap catalyst and to reduce stored NOx to $\mathrm{N}_{2}$. Partial oxidation and reforming of the natural gas into $\mathrm{CO}$ and $\mathrm{H}_{2}$ species is required to enable catalyst regeneration. Valved exhaust systems enable catalyst regeneration to occur with low fuel penalties and dismiss the need for changes in engine operation.

- The reformer catalyst is a cost-effective component of the catalyst system. A study of the exhaust chemistry during the lean NOx trap catalyst regeneration cycle showed that both the partial oxidation and reforming catalysts contribute to the production of $\mathrm{CO}$ and $\mathrm{H}_{2}$ for catalyst regeneration. Thus, optimal utilization of the methane in natural gas for lean NOx trap catalyst regeneration incorporates the functionality of both catalysts. A summary of the methane utilization through the lean NOx trap catalyst system during the regeneration process is shown in Figure 0-1. 


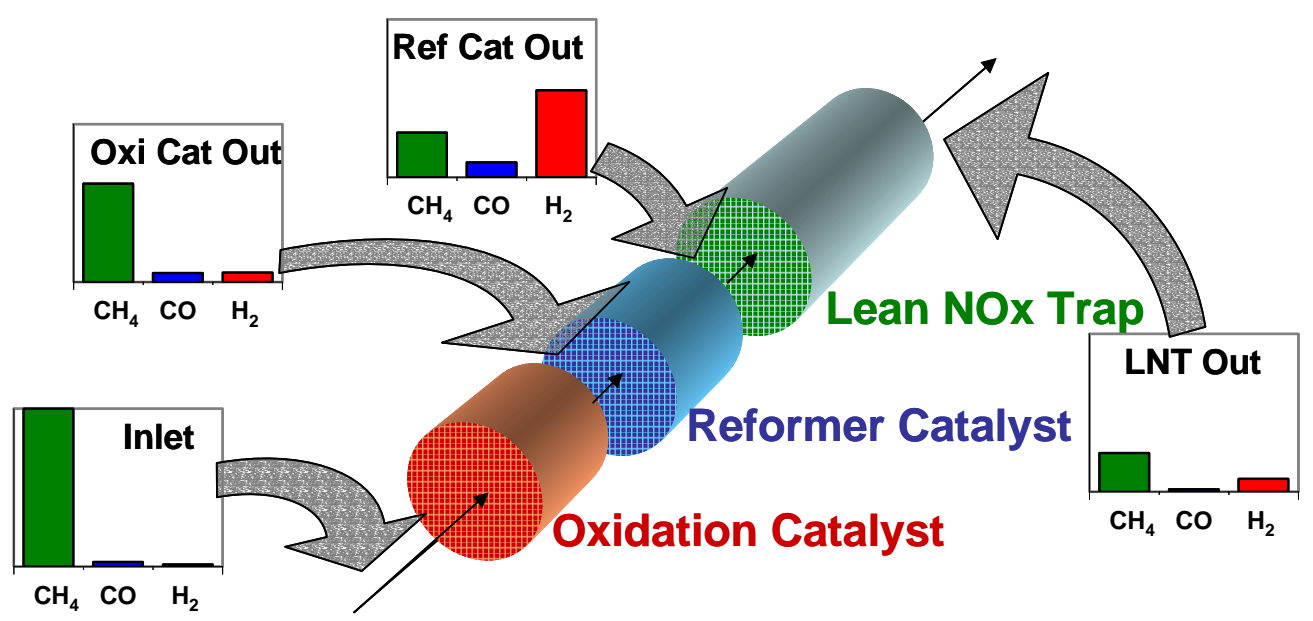

Figure 0-1. Utilization of methane in the lean NOx trap catalyst system.

- Recovery from sulfur poisoning of the oxidation and reforming catalysts occurs under normal lean-rich cycling operation. Sulfur poisoning of the oxidation and reforming catalysts can occur for elevated levels of sulfur in the exhaust; however, normal lean-rich cycling operation of the catalysts with typical sulfur content in fuel removes sulfur compounds and recovers lost performance.

- Sorbate reapplication is a low cost means of managing sulfur poisoning of the lean NOx trap catalysts. Sulfur poisoning is a well known degradation mechanism in lean NOx trap catalysis. Recovery of lost performance due to sulfur poisoning of the lean NOx trap catalysts was demonstrated with a technique where the active sorbate component of the catalysts is removed and reapplied by servicing the catalyst in an aqueous-based solution (see Figure 0-2). The technique enables mitigation of sulfur poisoning in practice through a low cost service process.

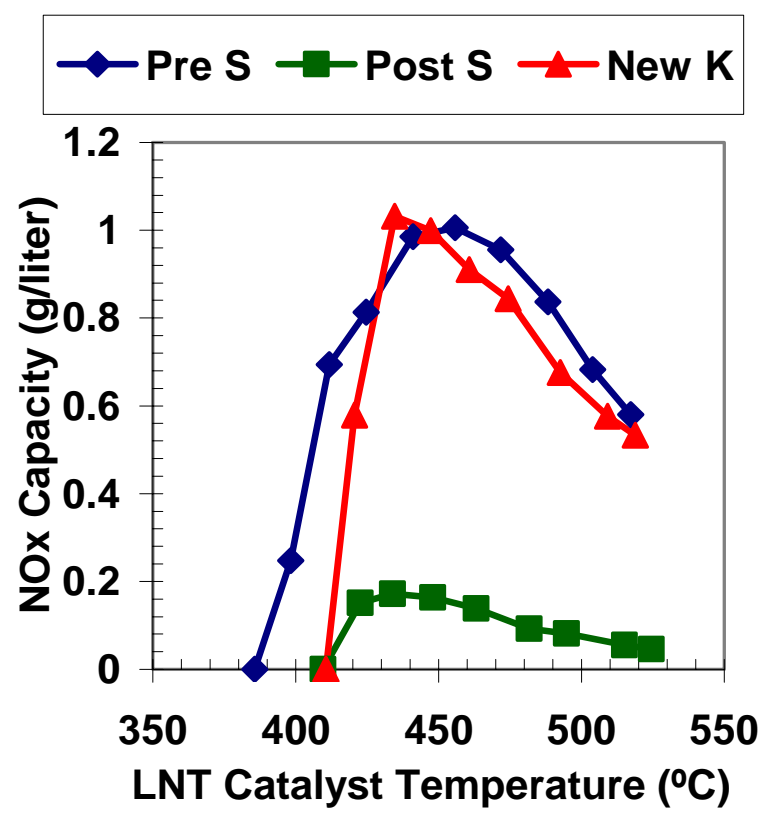

Figure 0-2. NOx capacity as a function of temperature before sulfur poisoning (Pre S), after sulfur poisoning (Post S), and after sorbate reapplication (New K). 
- Thermal management and system integration design will be critical to commercial success. Catalyst performance was sensitive to temperature. Optimal performance for the system was achieved by balancing the need for higher temperatures to enable methane partial oxidation with the preference of lower temperatures for increased NOx storage capacity. Achieving the optimal balance will require careful system integration design and control.

The results from the laboratory studies conclude that lean NOx trap catalysis is a promising technology for control of NOx emissions from lean natural gas reciprocating engines. Further work is required to demonstrate the technology on full size systems in field studies which will help establish more accurate measures for key parameters such as fuel penalty and degradation rate. Advancements in the lean NOx trap technology are still occurring and should help reduce capital costs associated with the catalysts. Furthermore, advancements in engine technology should be mutually beneficial to the lean NOx trap technology as the technology becomes more cost effective with reduced engine out NOx levels. System integration with heat recovery should provide opportunities to reduce cost and improve performance of the lean NOx trap catalyst as well as improve the total efficiency of the power generation system. 


\section{Introduction}

Distributed energy is an approach for meeting energy needs that has several advantages. Distributed energy improves energy security during natural disasters or terrorist actions, improves transmission grid reliability by reducing grid load, and enhances power quality through voltage support and reactive power. In addition, distributed energy can be efficient since transmission losses are minimized. One prime mover for distributed energy is the natural gas reciprocating engine generator set. Natural gas reciprocating engines are flexible and scalable solutions for many distributed energy needs. The engines can be run continuously or occasionally as peak demand requires, and their operation and maintenance is straightforward. Furthermore, system efficiencies can be maximized when natural gas reciprocating engines are combined with thermal energy recovery for cooling, heating, and power applications.

Expansion of natural gas reciprocating engines for distributed energy is dependent on several factors, but two prominent factors are efficiency and emissions. Efficiencies must be high enough to enable low operating costs, and emissions must be low enough to permit significant operation hours, especially in non-attainment areas where emissions are stringently regulated. To address these issues the U.S. Department of Energy and the California Energy Commission launched research and development programs called Advanced Reciprocating Engine Systems (ARES) and Advanced Reciprocating Internal Combustion Engines (ARICE), respectively. Fuel efficiency and low emissions are two primary goals of these programs. The work presented here was funded by the ARES program and, thus, addresses the ARES 2010 goals of 50\% thermal efficiency (fuel efficiency) and $<0.1 \mathrm{~g} / \mathrm{bhp}-\mathrm{hr}$ emissions of oxides of nitrogen (NOx). A summary of the goals for the ARES program is given in Table 1-1. ARICE 2007 goals are 45\% thermal efficiency and $<0.015 \mathrm{~g} / \mathrm{bhp}-\mathrm{hr}$ NOx.

Table 1-1. ARES Program Goals

\begin{tabular}{|c|c|l|}
\hline ARES Program Goal & Goal for 2010 & Lean NOx Trap Technology \\
\hline High Efficiency & $>50 \%$ Thermal Efficiency & Enable lean (efficient) operation \\
\hline Environment & $<0.1 \mathrm{~g} / \mathrm{bhp}-\mathrm{hr}$ NOx & $\begin{array}{l}\text { High ( }>90 \% \text { ) NOx reduction } \\
\text { efficiency }\end{array}$ \\
\hline Fuel Flexibility & Adaptability to Dual Fuel & $\begin{array}{l}\text { Natural gas fuel reductant (no } \\
\text { secondary reductant storage) }\end{array}$ \\
\hline Cost of Power & $10 \%$ Less than Current (2003) & Target low life-cycle costs \\
\hline $\begin{array}{c}\text { Availability, Reliability, } \\
\text { and Maintainability }\end{array}$ & Equal to Current (2003) & $\begin{array}{l}\text { Target durable catalysts and } \\
\text { catalytic processes }\end{array}$ \\
\hline
\end{tabular}

Several approaches for improving the efficiency and emissions of natural gas reciprocating engines are being pursued. Approaches include: stoichiometric engine operation with exhaust gas recirculation and three-way catalysis ${ }^{1}$, advanced combustion modes such as homogeneous charge compression ignition ${ }^{2}$, and extension of the lean combustion limit with advanced ignition concepts $^{3,4,5,6}$ and/or hydrogen mixing ${ }^{7}$. The research presented here addresses the technical approach of combining efficient lean spark-ignited natural gas combustion with low emissions obtained from a lean NOx trap catalyst aftertreatment system. This approach can be applied to current lean engine technology or advanced lean engines that may result from related efforts in lean limit extension. Furthermore, the lean NOx trap technology has synergy with hydrogenassisted lean limit extension since hydrogen is produced from natural gas during the lean NOx trap catalyst system process. The approach is also applicable to other lean engines such as diesel engines, natural gas turbines, and lean gasoline engines; other research activities have focused on those applications. ${ }^{8,9,10,11,12,13}$ Some commercialization of the technology has occurred for automotive applications (both diesel and lean gasoline engine vehicles) and natural gas turbines 
for stationary power. The research here specifically addresses barriers to commercialization of the technology for large lean natural gas reciprocating engines for stationary power.

The report presented here is a comprehensive collection of research conducted by Oak Ridge National Laboratory (ORNL) on lean NOx trap catalysis for lean natural gas reciprocating engines. ${ }^{14,15,16,17}$ The research was performed in the Department of Energy's ARES program from 2003 to 2007 and covers several aspects of the technology. All studies were conducted at ORNL on a Cummins $\mathrm{C} 8.3 \mathrm{G}+$ natural gas engine chosen based on industry input to simulate large lean natural gas engines. Specific technical areas addressed by the research include: NOx reduction efficiency, partial oxidation and reforming chemistry, and the effects of sulfur poisons on the partial oxidation, reformer, and lean NOx trap catalysts. The initial work on NOx reduction efficiency demonstrated that NOx emissions $<0.1 \mathrm{~g} / \mathrm{bhp}-\mathrm{hr}$ (the ARES goal) can be achieved with the lean NOx trap catalyst technology. Subsequent work focused on cost and size optimization and durability issues which addressed two specific ARES areas of interest to industry ("Cost of Power" and "Availability, Reliability, and Maintainability", respectively). Thus, the research addressed the approach of the lean NOx trap catalyst technology toward the ARES goals as shown in Table 1-1. 


\section{Lean NOx Trap Catalysis Chemistry}

Emission control technologies for reciprocating engines have primarily been catalytic in nature due to the constraints of automotive applications which have driven the development. For the stoichiometric combustion gasoline reciprocating engine commonly found in automobiles, three-way catalysts are used to control oxides of nitrogen (NOx), hydrocarbons (HC), and carbon monoxide (CO), simultaneously; thus, the name "three-way" implies the control of three pollutant classes. Effective operation of three-way catalysts occurs only for cases near stoichiometric conditions; here the NOx is reduced by the $\mathrm{HC}$ and $\mathrm{CO}$ reductants. Under conditions lean of stoichiometric combustion, excess oxygen $\left(\mathrm{O}_{2}\right)$ in the exhaust causes the $\mathrm{HC}$ and $\mathrm{CO}$ pollutants to be oxidized without any NOx reduction. Conversely, under conditions rich of stoichiometric combustion, NOx reduction occurs, but there is not enough $\mathrm{O}_{2}$ to fully oxidize the $\mathrm{HC}$ and $\mathrm{CO}$ pollutants.

For engines that operate in conditions lean of stoichiometric combustion, oxidation catalysts are capable of oxidizing the $\mathrm{HC}$ and $\mathrm{CO}$ pollutants, but reduction of $\mathrm{NOx}$ in an $\mathrm{O}_{2}$-rich exhaust environment is challenging. The most common catalytic technology for reducing NOx in lean exhaust is Selective Catalytic Reduction (SCR). In SCR, an ammonia $\left(\mathrm{NH}_{3}\right)$ reductant is metered into the exhaust and reacts with NOx over a catalyst that is "selective" to the $\mathrm{NH}_{3}-\mathrm{NOx}$ reaction; the catalyst is traditionally a vanadium-based catalyst on a $\mathrm{TiO}_{2}$ support. The $\mathrm{NH}_{3}$ can be delivered to the gas stream as a gas or as a liquid in the form of urea which decomposes into $\mathrm{NH}_{3}$ in the exhaust through hydrolysis reactions. SCR is a mature technology that is effective for NOx emission control. Since the SCR catalyst contains no precious metals, catalyst costs are low. A disadvantage of the SCR technology is the requirement to store and handle the $\mathrm{NH}_{3}$ or urea reductant. Another problem is the potential of $\mathrm{NH}_{3}$ slip if reductant supply is not controlled properly; this problem becomes more probable as lower NOx emission levels are attempted with the technology.

Lean NOx trap catalysis is a relatively new approach for control of NOx from lean engines. In lean NOx trap catalysis, the catalyst stores NOx during operation in the $\mathrm{O}_{2}$-rich conditions lean of stoichiometric combustion. Then, after storage accumulates significantly, the catalyst is exposed to a pulse of reductant rich exhaust that releases and reduces the stored NOx to $\mathrm{N}_{2}$. The lean and rich modes of operation are referred to as "sorption" and "regeneration". The operation is cyclic with the regeneration process rendering the catalyst effective for more NOx sorption. The rich exhaust conditions required for the regeneration process can be obtained via a variety of techniques, but the fuel used by the engine is generally the primary reductant source. Thus, a main benefit of lean NOx trap catalysis is the ability to use on-board fuel as the reductant for NOx control thereby eliminating the need for separate storage of a secondary chemical reductant. Another benefit of the technology is the level of emissions control obtained; the technology can achieve very low NOx levels (1-10 ppm) while simultaneously controlling $\mathrm{CO}$ and $\mathrm{HC}$ emissions as well. The two primary disadvantages of lean NOx trap catalysis are cost and sensitivity to sulfur. Catalyst costs are significant since the catalyst contains precious metal components, and the technology is sensitive to sulfur poisoning since sulfur directly competes with NOx storage sites. Both the cost and sulfur poisoning issues are subjects of the research presented here.

\subsection{Lean NOx Trap Catalyst Composition}

The components of a lean NOx trap catalyst are: the washcoat, the precious metal component, and the sorbate component. The washcoat is a high surface area material that supports the active precious metal and sorbate components. Washcoats are generally metal oxides and are typically applied directly to a monolithic support such as cordierite. The precious metal component assists in the oxidation of pollutants and NO during the sorption process, and during the regeneration process, the precious metal component plays a more critical role in facilitating the reduction of 
the stored NOx to $\mathrm{N}_{2}$. The sorbate component is typically an alkali metal or alkaline earth material; nitrate species are formed on the alkali/alkaline when NOx interacts with the material during the sorption phase. Common sorbate materials are potassium $(\mathrm{K})$ and barium $(\mathrm{Ba})$. Often mixtures of alkali/alkaline materials are used to engineer temperature-specific performance into the catalyst.

The lean NOx trap functions according to the thermodynamics of the alkali/alkaline sorbate materials. Since $\mathrm{CO}_{2}$ is in combustion exhaust at percent levels, the sorbate commonly starts as a carbonate moiety. The introduction of $\mathrm{NOx}$ to the alkali/alkaline carbonate species causes $\mathrm{CO}_{2}$ to be emitted and a nitrate species to form in place of the carbonate; thermodynamics favors the nitrate formation over the carbonate. Likewise, for either carbonate or nitrate species, the introduction of sulfur dioxide $\left(\mathrm{SO}_{2}\right)$ results in sulfate species formed by the alkali/alkaline component. A diagram of the free energy of bulk alkali/alkaline earth species is shown in Figure 2-1. Thermodynamics favors nitrates over carbonates and sulfates over nitrates. The reactions are reversible, but energy must be added to the system to return to the carbonate state from either the nitrate or sulfate states. For lean NOx trap catalysis, the energy is added by the reductant fuel and the reaction is catalyzed by the precious metal component on the catalyst.

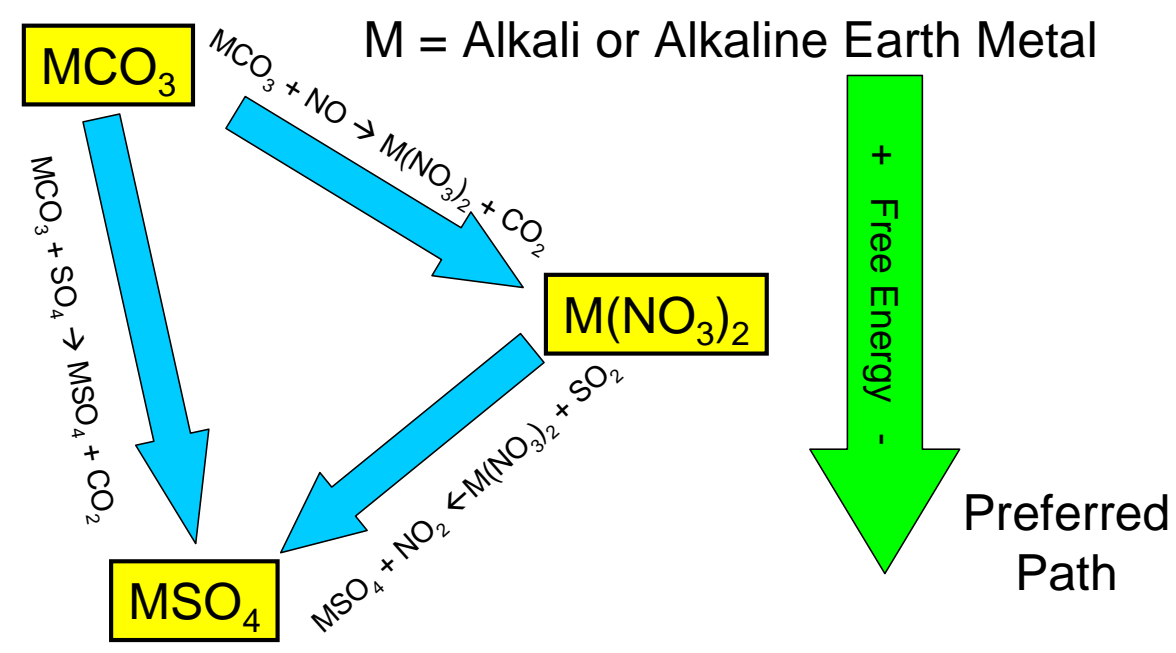

Figure 2-1. Free energy diagram of the chemical states of the alkali/alkaline earth based sorbate component.

\subsection{Sorption-Regeneration Cycle}

Although the free energy shown in Figure 2-1 was calculated for bulk materials, in practice the heterogeneous morphology of the catalyst causes a wide spectrum of free energies as the catalyst surface is characterized by finely dispersed distribution of the active components. Figure 2-2 shows a diagram of the catalyst surface during a sorption-regeneration cycle. In the case shown, the washcoat material is alumina $\left(\mathrm{Al}_{2} \mathrm{O}_{3}\right)$, the precious metal component is platinum $(\mathrm{Pt})$, and the sorbate component is $\mathrm{K}$. The $\mathrm{Pt}$ is finely dispersed over the $\mathrm{Al}_{2} \mathrm{O}_{3}$ washcoat. Typical Pt crystallites can be $1-4 \mathrm{~nm}$ in diameter. The $\mathrm{K}$, originally as $\mathrm{K}_{2} \mathrm{CO}_{3}$, is also finely dispersed but may have a mixture of small and large crystallites as shown. When exposed to lean (oxygencontaining) exhaust in the sorption phase, $\mathrm{NO}$ oxidizes to $\mathrm{NO}_{2}$ on the Pt surface then $\mathrm{NO}_{2}$ interacts with the $\mathrm{K}_{2} \mathrm{CO}_{3}$ to form $\mathrm{KNO}_{3}$ with $\mathrm{CO}_{2}$ gas being emitted. The shift from carbonate to nitrate species can occur for the entire crystallite (as shown for the small crystallite) or only for the outer circumference of a larger crystallite. During the regeneration phase under reducing conditions, the reductants in the exhaust cause the release and reduction of the stored NOx into $\mathrm{N}_{2}$. Hydroxide moieties are likely formed when $\mathrm{H}_{2}$ is the reductant, but ultimately, carbonate 
species are formed as the exhaust is heavily populated with $\mathrm{CO}_{2}$. Specific details of the nanoscale processes involved in lean NOx trap catalysis are still being investigated as the subject of research studies. A recent review of fundamental mechanisms involved in lean NOx trap catalysis is given by Epling et al. ${ }^{18}$ The general chemistry for NOx sorption and regeneration are shown below in equations Equation 2-1 and Equation 2-2, respectively; here potassium (K) again is shown as the active sorbate component. Nitrogen oxide (NO) is oxidized to nitrogen dioxide $\left(\mathrm{NO}_{2}\right)$ by the precious metal in the catalyst, and the carbonate species thermodynamically prefers to form nitrate species in the exhaust. The nitrate species is reduced in a rich atmosphere, and $\mathrm{CO}_{2}$ is adsorbed to form the carbonate species again. A hydroxide species is suspected as an intermediate species in this reaction.

Equation 2-1: $\quad \mathrm{K}_{2} \mathrm{CO}_{3}+\mathrm{NO}+0.5 \mathrm{O}_{2} \rightarrow \mathrm{K}_{2} \mathrm{NO}_{3}+\mathrm{CO}_{2}$

\section{Equation 2-2: $\quad \mathrm{K}_{2} \mathrm{NO}_{3}+\mathrm{H}_{2}+\mathrm{CO}_{2} \rightarrow \mathrm{K}_{2} \mathrm{CO}_{3}+\mathrm{H}_{2} \mathrm{O}$}
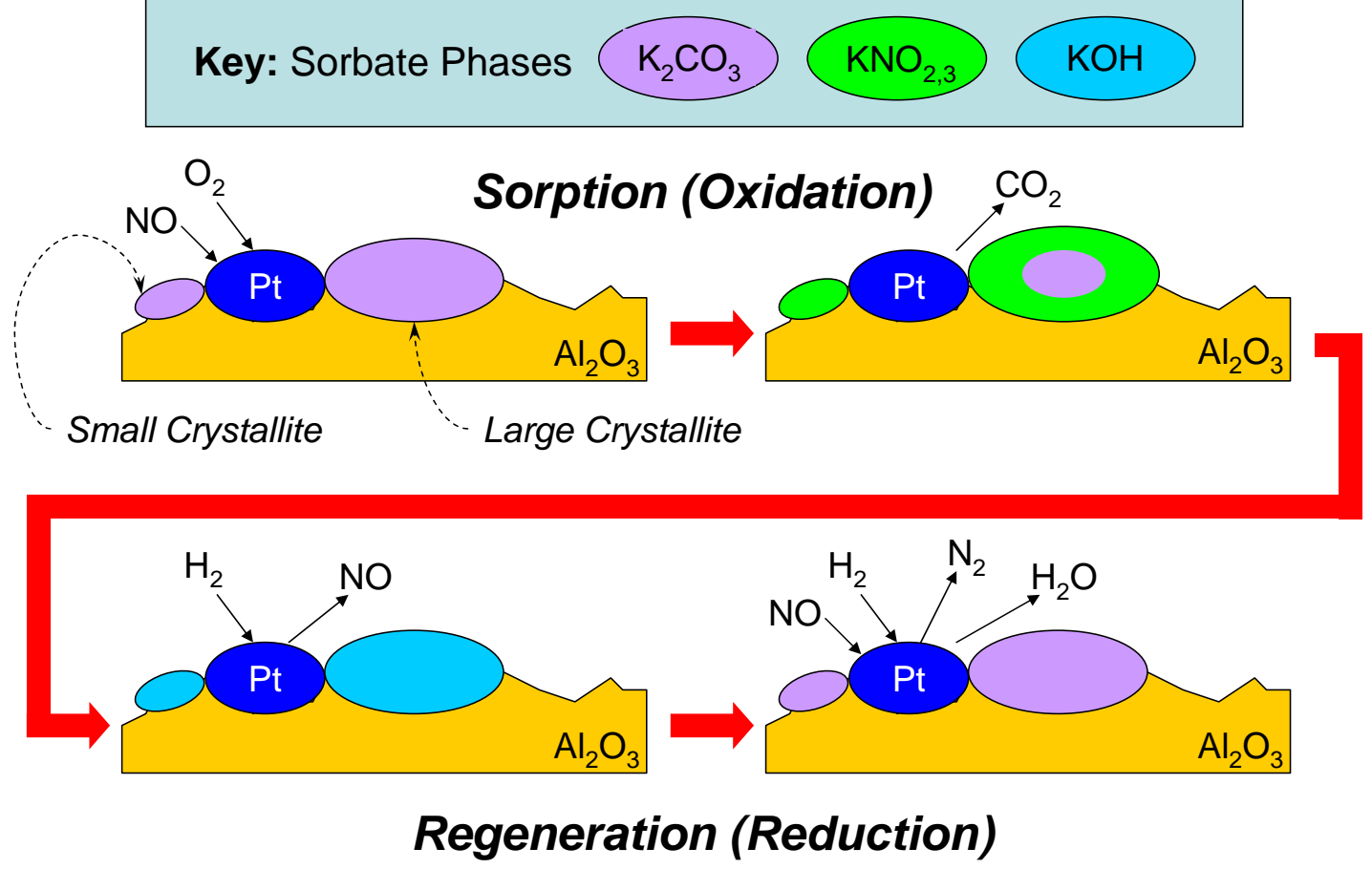

Figure 2-2. Schematic of the finely dispersed catalyst components during a sorption-regeneration cycle.

An image of the lean NOx trap catalyst surface acquired with a scanning electron microscope (SEM) is shown in Figure 2-3. The lean NOx trap imaged is of the same formulation shown in Figure 2-2 $\left(\mathrm{Al}_{2} \mathrm{O}_{3}\right.$ washcoat with $\mathrm{Pt}$ and $\mathrm{K}$-based sorbate component). The image shows the $\mathrm{Al}_{2} \mathrm{O}_{3}$ washcoat with a large number of small $\mathrm{Pt}$ crystallites on the $\mathrm{Al}_{2} \mathrm{O}_{3}$ surface; the $\mathrm{Pt}$ is identified by the small dark objects scattered on the washcoat surface. It is difficult to differentiate between $\mathrm{Al}_{2} \mathrm{O}_{3}$ and $\mathrm{K}_{2} \mathrm{CO}_{3}$ from the image alone, but analysis of $\mathrm{x}$-rays emitted from the electron excitation of the sample allows for relative quantification of the $\mathrm{K}$ content on the sample. The results show that the $\mathrm{K}$ content of the sample varies significantly across the catalyst surface. The analysis results for two highlighted regions ("Positions 008 and 011 ") are shown 
right of the figure. Position 008 has no visually discernible $\mathrm{K}_{2} \mathrm{CO}_{3}$ in the image, but the $\mathrm{x}$-ray analysis shows clearly that $\mathrm{K}$ species exist at that location. Position 008 is likely representative of small sorbate crystallites that are finely dispersed over the $\mathrm{Al}_{2} \mathrm{O}_{3}$. In contrast, Position 011 shows visual evidence of some type of material that does not have Pt on the surface. This crevice in the washcoat likely contains large crystallites of $\mathrm{K}_{2} \mathrm{CO}_{3}$ based on the higher level of $\mathrm{K}$ observed in the x-ray analysis. Although heterogeneous in nature, the lean NOx trap catalysts are engineered to contain specific size distributions of precious metal and sorbate components. By controlling dispersion of these active components, catalyst manufacturers can control the performance properties of the catalyst.

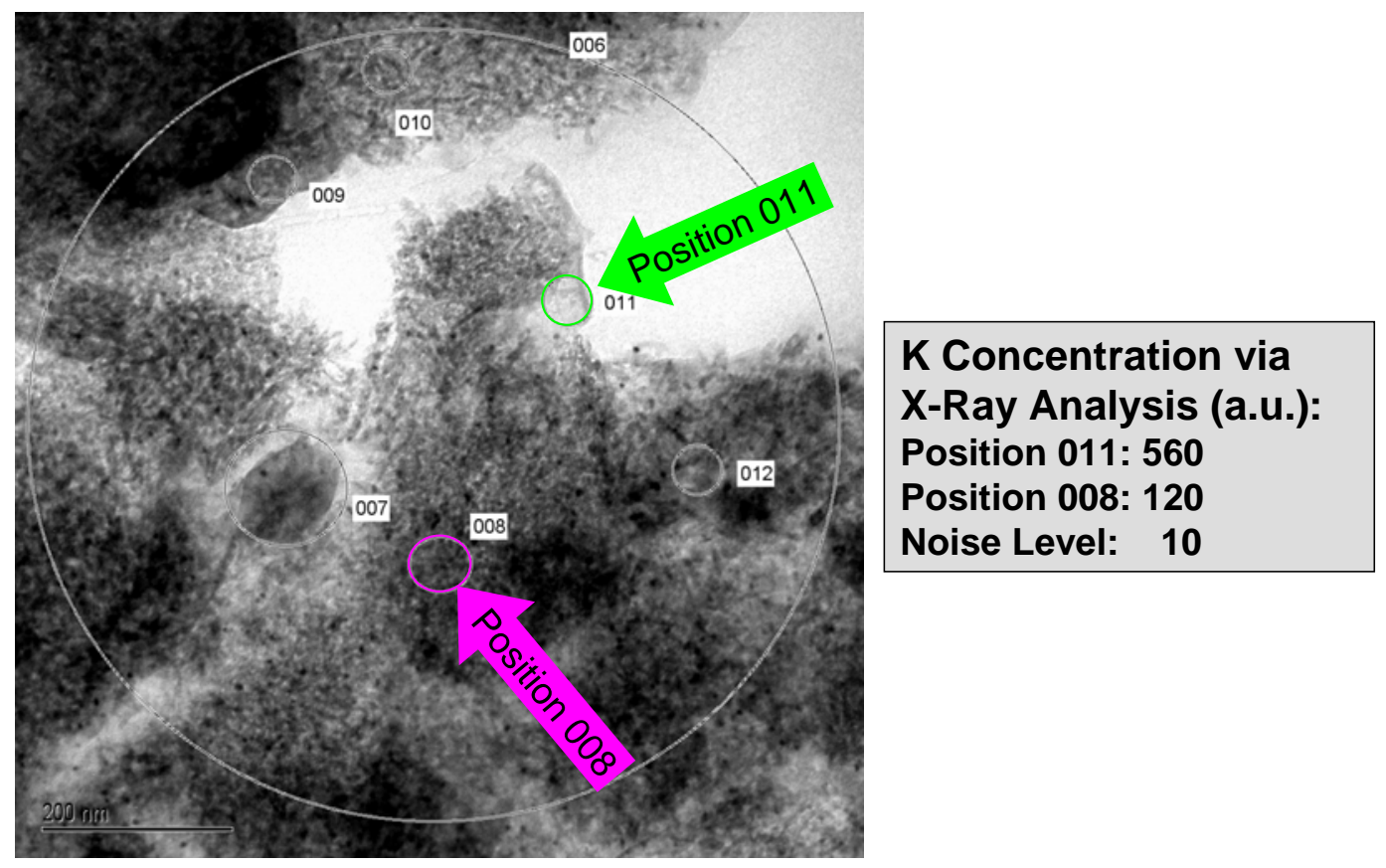

Figure 2-3. Scanning electron micrograph of the surface of a lean NOx trap catalyst. ${ }^{19}$

Although the lean NOx trap catalyst functions on a nanoscale, the actual catalyst device is much larger. The catalyzed washcoat is coated to a monolith for practical use in reciprocating engine applications. The monoliths used for this study were made of cordierite (Corning) and contained $300 \mathrm{cpsi}$ (cells per square inch). Each monolith cell has a square geometry originally, but the coating process tends to add curvature to the cell corners. The cordierite monolith allows the catalysis processes to be implemented with little backpressure to the engine (as compared with catalyzed bead systems) and with low thermal expansion which enables the active catalytic component to remain intact over years of use in the exhaust. An image of the catalysts used for this study is shown in Figure 2-4; methane oxidation, reforming, and lean NOx trap catalysts are shown (color variations are due to differences in the precious metals used for these catalysts). Each catalyst monolith is 9.5 inches $(24.1 \mathrm{~cm})$ in diameter and 6 inches $(15.2 \mathrm{~cm})$ thick. A closer view of the cells in the monolith is shown in the inset. The role of the methane oxidation and reforming catalysts will be detailed below in Section 2.3. 


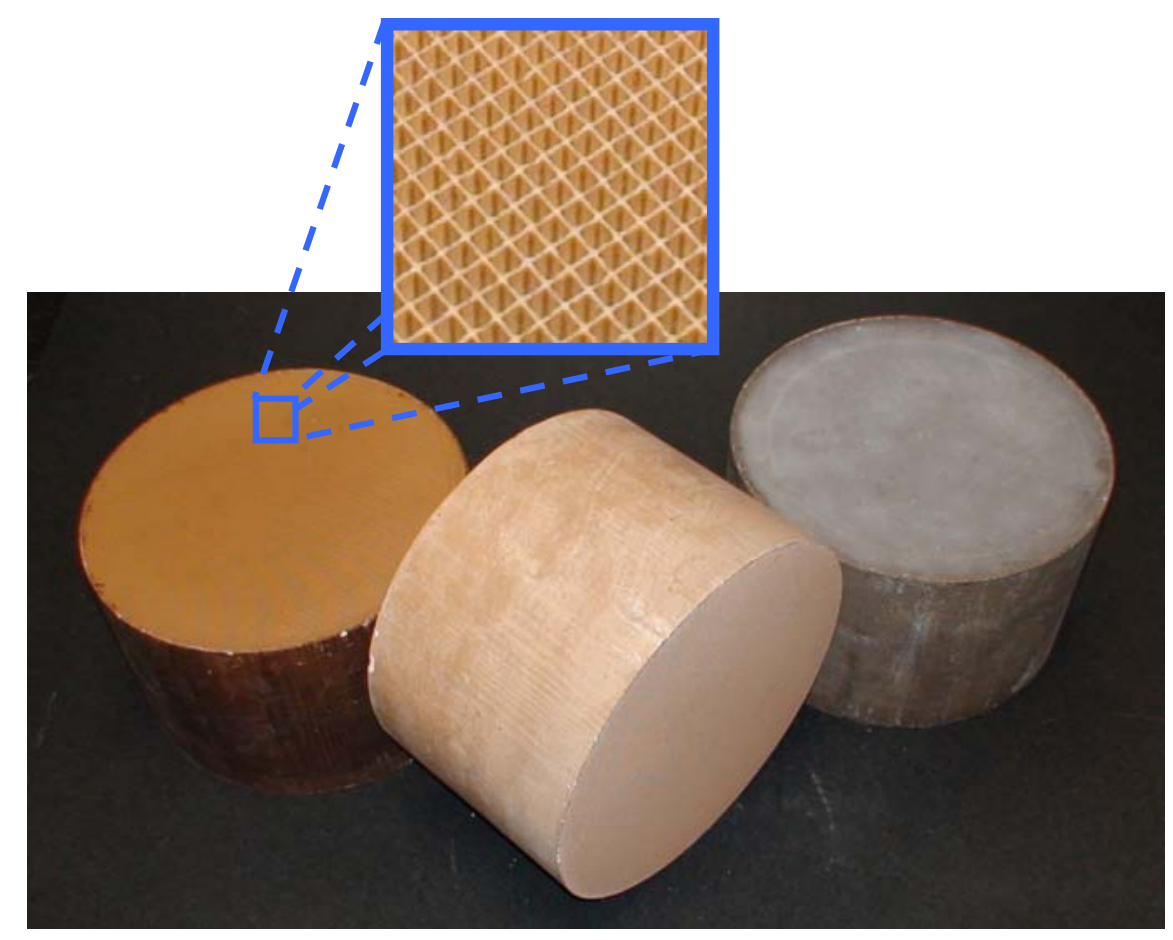

Figure 2-4. Photo of the catalysts used in the study showing the monolithic cell structure.

The functionality of the lean NOx trap catalyst on a macroscale is much different than traditional oxidation catalysts and three-way catalysts. During operation of the catalyst, the actual chemistry of the catalyst changes as the sorbate component changes from carbonate to nitrate forms and vice versa. Furthermore, the NOx concentration in the catalyst is constantly changing as a function of the distance along the flow axis of the catalyst as NOx is continually depleted from the exhaust by the sorbate component. A diagram depicting the changing catalyst chemistry as a function of position along the flow axis is shown in Figure 2-5. A cross sectional view of a single monolithic cell is shown with the catalyst applied to the inner walls of the cell. During the sorption phase, the sorbate components on the upstream side of the catalyst become saturated with NOx and form nitrates rapidly. As exposure to more NOx occurs, sections of the catalyst further downstream become saturated with NOx and form nitrates. Thus, the catalyst tends to change in a plug flow type process. During regeneration, the reverse is true. The upstream sorbate components revert back to carbonate species more rapidly as reductants release the stored NOx. Then, as the regeneration process continues, reductants ultimately reach the downstream parts of the catalyst where the sorbate component is regenerated. 


\section{-(A) Sorption (Oxidizing Atmosphere): Period $=30-120$ sec.}

$2 \mathrm{NO}+\mathrm{O}_{2}+\mathrm{Pt}+\mathrm{K}_{2} \mathrm{CO}_{3}---->2 \mathrm{KNO}_{2,3}+\mathrm{Pt}+\mathrm{CO}_{2}$

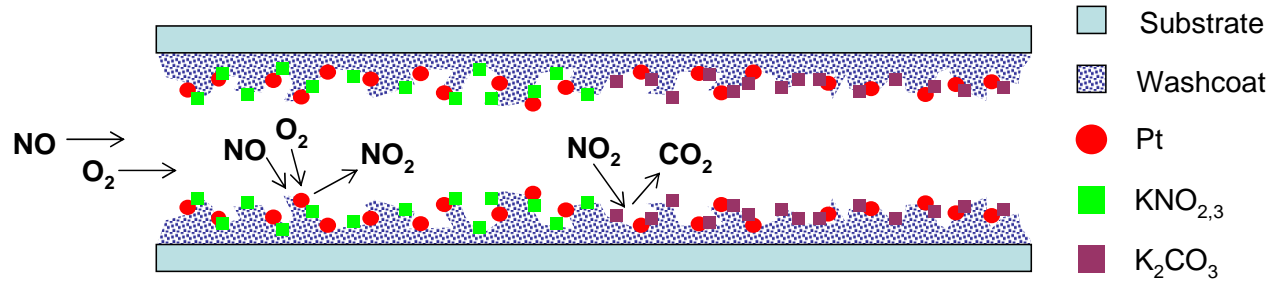

•(B) Regeneration (Reducing Atmosphere): Period = 1-10 sec.

$2 \mathrm{KNO}_{2,3}+\mathrm{Pt}+\mathrm{H}_{2}+\mathrm{CO}_{2}--->2 \mathrm{KOH}+\mathrm{N}_{2}+\mathrm{CO}_{2}+\mathrm{Pt}+\mathrm{H}_{2} \mathrm{O}--->\mathrm{K}_{2} \mathrm{CO}_{3}+\mathrm{N}_{2}+2 \mathrm{H}_{2} \mathrm{O}+\mathrm{Pt}$

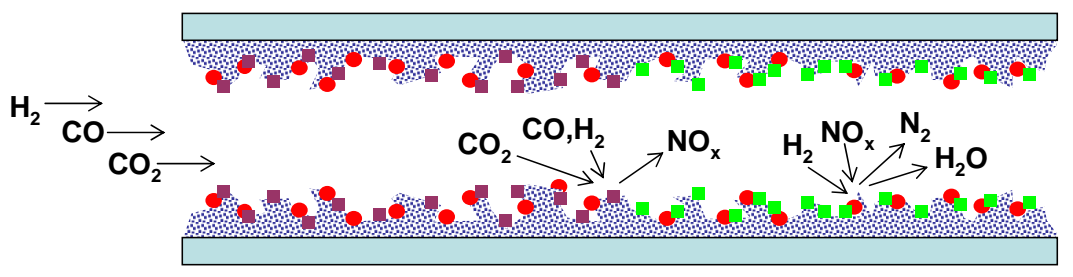

-A-B-A-B-A-B Cycle Repeated

Figure 2-5. Diagram of the lean NOx trap catalyst process along the flow axis of a monolithic cell.

\subsection{Natural Gas Utilization for Lean NOx Trap Regeneration}

To obtain the rich conditions required for regeneration of the NOx trap, the excess oxygen in the exhaust must be combusted with natural gas fuel. There are generally two methods for depleting the oxygen: (1) operating the engine under rich conditions or (2) injecting fuel into the exhaust system upstream of the NOx trap and catalytically combusting the fuel and oxygen. The latter case (2) was used in this study based on industry input that switching between lean and rich combustion modes for large generator-set applications would make power control difficult. Furthermore, in order to reduce the amount of fuel required to regenerate the catalyst, an exhaust system with valves controlling exhaust flow was implemented to reduce the exhaust flow through the catalyst during the regeneration process. ${ }^{11,12,13}$ The lower exhaust flow during regeneration results in a lower oxygen mass flow and thereby, lower fuel requirement. Minimizing fuel use for catalyst regeneration is important since the fuel used for catalyst regeneration provides no useful energy and thus, represents a fuel penalty for the end user. In addition, the lower exhaust flow during regeneration results in a lower space velocity for the catalyst which provides better catalyst performance during regeneration by increasing the total number of gas-surface interactions.

The strategy for obtaining rich exhaust conditions with direct natural gas injection into the exhaust system relies on the capability of the catalyst to combust methane with the oxygen in the exhaust. Methane is the most difficult hydrocarbon to catalytically combust due to the high population of $\mathrm{C}-\mathrm{H}$ bonds in the methane molecule. Lean NOx trap catalysts are not designed for optimal methane combustion efficiency, and in fact, the sorbate component of the lean NOx trap suppresses the oxidation efficiency of the lean NOx trap catalyst. Thus, in order to optimize the methane combustion of the system, oxidation and reformer catalysts were placed upstream of the lean NOx trap to combust methane and generate rich exhaust containing carbon monoxide $(\mathrm{CO})$ and hydrogen $\left(\mathrm{H}_{2}\right)$ to enable efficient regeneration of the lean NOx trap. The catalyst geometry and role of each component is as follows: (1) a methane oxidation catalyst was placed upstream 
to partially oxidize methane in the oxygen-rich exhaust, (2) a reformer catalyst was placed immediately downstream of the methane oxidation catalyst to reform excess $\mathrm{CH}_{4}$ into $\mathrm{CO}$ and $\mathrm{H}_{2}$ and convert $\mathrm{CO}$ into $\mathrm{H}_{2}$ with the water-gas-shift reaction, and (3) the lean NOx trap catalyst was placed downstream where the reductants release and reduce NOx trapped on the catalyst. A diagram of the geometry of the catalysts is shown in Figure 2-6. The order of the catalysts from upstream to downstream is first oxidation catalyst, second reformer catalyst, then third lean NOx trap catalyst.

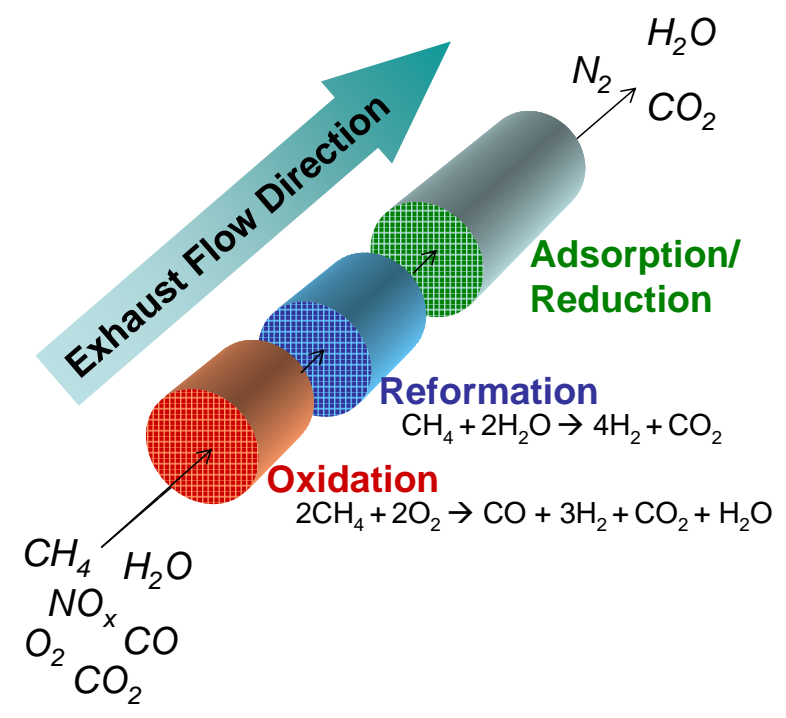

Figure 2-6. Catalyst geometry in the lean NOx trap catalyst system.

The exhaust chemistry that may occur on the catalysts is summarized by the following chemical reactions:

Equation 2-3: $\quad \mathrm{CH}_{4}+2 \mathrm{O}_{2} \rightarrow \mathrm{CO}_{2}+2 \mathrm{H}_{2} \mathrm{O}$

Equation 2-4: $\quad \mathrm{CH}_{4}+0.5 \mathrm{O}_{2} \rightarrow \mathrm{CO}+2 \mathrm{H}_{2}$

Equation 2-5: $\quad \mathrm{CH}_{4}+\mathrm{CO}_{2} \rightarrow 2 \mathrm{CO}+2 \mathrm{H}_{2}$

Equation 2-6: $\quad \mathrm{CH}_{4}+\mathrm{H}_{2} \mathrm{O} \rightarrow \mathrm{CO}+3 \mathrm{H}_{2}$

Equation 2-7: $\quad \mathrm{CO}+\mathrm{H}_{2} \mathrm{O} \rightarrow \mathrm{CO}_{2}+\mathrm{H}_{2}$

Palladium ( $\mathrm{Pd}$ ) is commonly used for methane oxidation, and Rhodium (Rh) is commonly used for reforming processes. Equation 2-3 and Equation 2-4 represent oxidation and partial oxidation of $\mathrm{CH}_{4}$ and are most likely to occur on the Pd-based methane oxidation catalyst. Equation 2-5 and Equation 2-6 are reforming reactions with $\mathrm{CO}_{2}$ and $\mathrm{H}_{2} \mathrm{O}$ that are most likely to occur on the Rh-containing reformer catalyst. In addition, the water-gas-shift reaction shown in Equation 2-7 may occur as well. The main objective of the oxidation and reforming catalysts is to produce $\mathrm{H}_{2}$ and $\mathrm{CO}$ from the methane via these reactions so that efficient regeneration of the lean NOx trap may occur. 


\section{Lean NOx Trap Catalyst System and Engine Platform}

\subsection{Engine Platform}

Experiments were performed on an in-line 6-cylinder 8.3-liter natural gas engine (Cummins Model CG-280, also known as the $\mathrm{C} 8.3 \mathrm{G}+)$ with a peak torque of $1153 \mathrm{Nm}(850 \mathrm{ft}-\mathrm{lb})$ at 1400 $\mathrm{rpm}$ and a peak power of $209 \mathrm{~kW}(280 \mathrm{hp})$ at $2400 \mathrm{rpm}$. Engine specifications are summarized in Table 3-1. The engine was turbocharger assisted, and an intercooler was used for intake temperature control downstream of the turbocharger. Natural gas compressors (Copeland Model SZM22C1A-ABS-XXX) supplied the engine with fuel at 85-95 psig (585-655 kPa); a fuel meter (Micro Motion Model CMF025M009NU) allowed instantaneous measurement of fuel flow. The engine load and speed were controlled by a $600 \mathrm{hp}(450 \mathrm{~kW})$ direct current motoring dynamometer (General Electric Model 42G61). All experiments were performed at $1800 \mathrm{rpm}$ and steady-state conditions to simulate generator-set speeds. Intake air conditions were controlled to approximately $23.9^{\circ} \mathrm{C}\left(75^{\circ} \mathrm{F}\right)$ with a relative humidity of $55 \%$. Intake air flow was measured with a laminar flow element and combined with engine fuel flow measurements to estimate exhaust flow rate.

Table 3-1. Engine Specifications.

\begin{tabular}{|l|c|c|}
\hline Model & Cummins CG-280 \\
\hline Type & 4 Cycle; In-Line 6 Cylinder \\
\hline Bore x Stroke (mm) & $114 \times 135$ \\
\hline Displacement (liter) & 8.3 \\
\hline \multicolumn{3}{|l|}{} \\
\hline \multicolumn{3}{|l|}{} \\
\hline Engine Speed (rpm) & Peak Power & Peak Torque \\
\hline Engine Power (kW) & 2400 & 1400 \\
\hline Engine Torque (Nm) & 209 & 169 \\
\hline Inlet Air Flow (liter/sec) & 831 & 1153 \\
\hline Exhaust Gas Flow (liter/sec) & 293 & 205 \\
\hline Exhaust Gas Temperature* $\left({ }^{\circ} \mathrm{C}\right)$ & 817 & 539 \\
\hline Nominal Fuel Rate (kg/hr) & 643 & 587 \\
\hline
\end{tabular}

*Measured at turbocharger out

\subsection{Catalyst System}

The catalyst system consisted of a two-chamber system with two exhaust brake valves (US Gear) controlling the flow to both chambers. The nominal exhaust pipe diameter was 4 inches $(10.2 \mathrm{~cm})$. One chamber simply consisted of an empty pipe and will be referred to as the "bypass leg". The second chamber contained the oxidation, reformer, and lean NOx trap catalysts and will be referred to as the "catalyst chamber" or "leg". Downstream of the bypass and catalyst legs, the exhaust from the two legs combined again to exit the system. Figure 3-1 shows a diagram of the system.

Since temperature affects catalyst performance, a heat exchanger was added to the engine and catalyst system to control exhaust temperature. The heat exchanger was not available for the initial studies, but was added prior to the studies presented in Sections 7 and 8. During these studies, the catalyst system was installed downstream of an exhaust-to-water heat exchanger. The temperature of the catalyst system could be controlled independent of engine operation by varying the heat dissipation in the exchanger. 
The volumes of catalysts in the catalyst chamber were 7 liters, 7 liters, and 14 liters for the oxidation, reformer, and lean NOx trap catalysts respectively. All catalysts were applied to 300 cpsi cordierite monoliths (Corning) with a $24.1 \mathrm{~cm}(9.5 \mathrm{inch})$ diameter and $15.2 \mathrm{~cm}(6 \mathrm{inch})$ length. The order from upstream to downstream of the catalysts in the catalyst chamber was oxidation, reformer, and then lean NOx trap catalysts. Transition cones were used upstream and downstream of the catalyst chamber to allow exhaust transition to and from the $10.2 \mathrm{~cm}(4 \mathrm{inch})$ diameter exhaust pipe to the larger diameter catalysts.

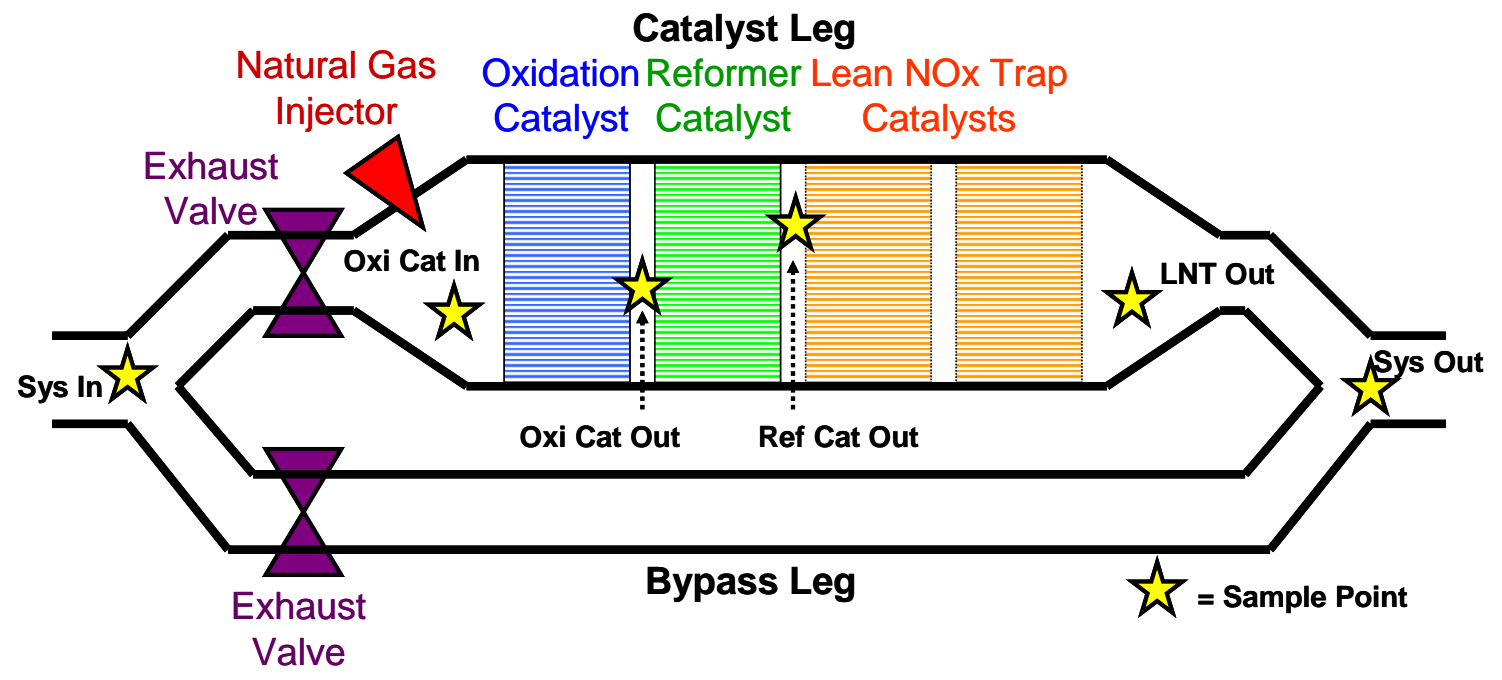

Figure 3-1. Lean NOx trap catalyst system.

Platinum group metals (PGM) including platinum (Pt), palladium (Pd), and rhodium $(\mathrm{Rh})$ were used for all catalysts. The methane oxidation catalyst was a Pd-based formulation with 50 $\mathrm{g} / \mathrm{ft}^{3} \mathrm{Pd}$. The reformer catalyst contained a $\mathrm{Pt} / \mathrm{Rh}$ mixture with $60 \mathrm{~g} / \mathrm{ft}^{3}$ total precious metal loading. Note that although nickel $(\mathrm{Ni})$ catalysts are a common lower-cost catalyst for reforming processes, $\mathrm{Ni}$ catalysts must be maintained in an oxygen-free environment; thus, $\mathrm{Ni}$ is not preferred for this application. The lean NOx trap catalyst contained $100 \mathrm{~g} / \mathrm{ft}^{3} \mathrm{Pt}$. Here the $\mathrm{g} / \mathrm{ft}^{3}$ units describe the mass of metal per volume of space the catalyst occupies (volume of the complete substrate) as typically expressed in the industry. All catalysts were supplied by EmeraChem LLC.

During the study, two different lean NOx trap formulations were used. Both formulations were on $\mathrm{Al}_{2} \mathrm{O}_{3}$ washcoat and contained $100 \mathrm{~g} / \mathrm{ft}^{3} \mathrm{Pt}$. The difference in the formulations was the sorbate component chemistry. During the initial studies, a catalyst with both $\mathrm{Ba}$ and $\mathrm{K}$ sorbate components was used; this formulation was optimized for performance at the natural gas exhaust temperatures. In studies specific to mitigation of sulfur poisoning, a $\mathrm{K}$ only sorbate formulation was used.

It is important to note that sorbate chemistry is critical to the feasibility of the sorbate reapplication procedure which will be discussed in detail below. Different alkali metal and alkaline earth species can be effectively used as the active absorption component of lean NOx trap catalysts; however, the aqueous solubility of the different species is highly dependent on chemistry. Barium (Ba) is a common sorbate component used for lean NOx trap catalysts, but barium carbonate is not very soluble in $\mathrm{H}_{2} \mathrm{O}$. Furthermore, aqueous Ba solutions pose significant health risks. Thus, Ba-based lean NOx trap catalysts are not well suited to sorbate. In contrast, potassium carbonate is very soluble in $\mathrm{H}_{2} \mathrm{O}$ and poses no significant health risks. Thus, lean NOx trap catalysts based on potassium $(\mathrm{K})$ were chosen for the studies that required sorbate reapplication. 
Catalysts were operated by closing the valve to the bypass leg and opening the valve to the catalyst chamber to let exhaust flow through the catalyst leg for the sorption part of the lean NOx trap cycle. Then, the valve to the bypass leg was opened and the valve to the catalyst chamber was closed to allow regeneration of the lean NOx trap. Thus, during regeneration, the majority of engine exhaust passed out the exhaust system untreated. It is important to note that some exhaust leakage past the closed exhaust valves occurred. The leakage rate was dependent on temperature and the pressure differential across the valve. Leakage rates were experimentally measured under a variety of engine conditions by injecting a set rate of $\mathrm{N}_{2}$ into the catalyst chamber with a mass flow controller and measuring the resulting dilution of $\mathrm{O}_{2}$. The exhaust leaking past the valves acted as both the reactant and carrier gas for the fuel injected into the catalyst chamber for catalyst regeneration. Two automotive natural gas injectors (Ford) were mounted on the inlet cone to the catalyst chamber so that fuel could be injected into the catalyst chamber during regeneration; the solenoid injectors were operated with a $75 \mathrm{~Hz} 12 \mathrm{VDC}$ signal with various duty cycles to control flow rate. The fuel supply for the injectors was the same supply for the engine, and the fuel line to the injectors was located downstream of the fuel meter. This allowed measurement of the fuel use for catalyst regeneration since all experiments were performed at steady-state engine conditions. A photograph of the system installed in the engine cell is shown in Figure 3-2.

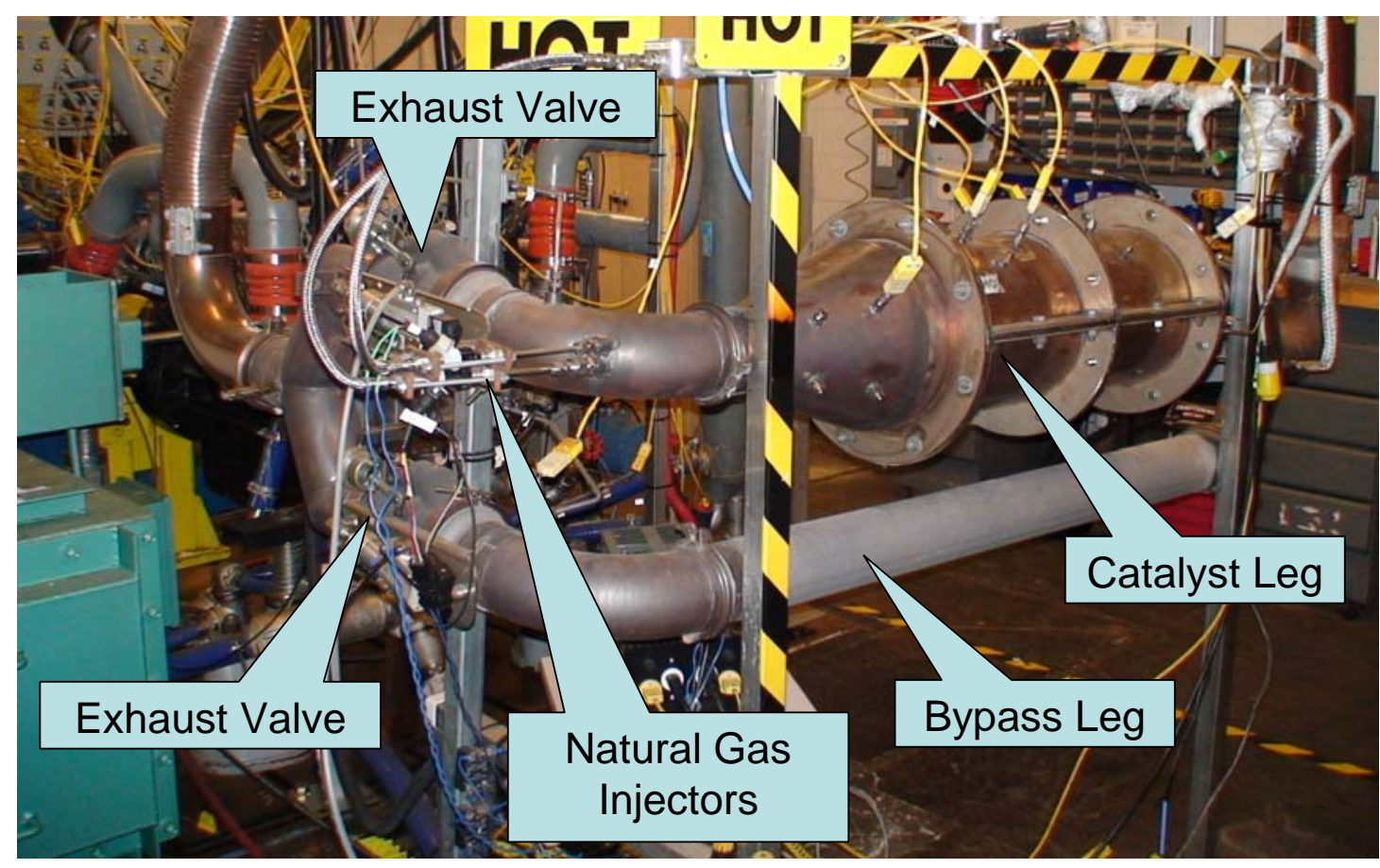

Figure 3-2. Photograph of lean NOx trap catalyst system in the engine cell.

\subsection{Data Acquisition and Exhaust Species Analysis}

Exhaust was sampled for analysis by emissions analyzers at several locations in the exhaust including positions between catalyst monoliths as depicted in Figure 3-1. Exhaust samples were collected at various points in the system as indicated by the abbreviations "Sys In", "Oxi Cat In", "Oxi Cat Out", "Ref Cat Out", "LNT Out", and "Sys Out".

The injector fueling rate and exhaust brake valves were controlled by a computer using data acquisition and control software (National Instruments LabView). A second computer controlled the dynamometer system and logged data from sensors and emissions analyzers. Emissions 
analyzers measured wet NOx as NO or NOx (California Analytical Instruments), dry $\mathrm{O}_{2}$ (Horiba), dry $\mathrm{CO}_{2}$ (Horiba), and dry CO (Horiba). Here "wet" refers to straight exhaust samples, and "dry" refers to exhaust sampled through a chiller to remove $\mathrm{H}_{2} \mathrm{O}$ from the sample stream. A separate chiller sampled exhaust for $\mathrm{SO}_{2}$ measurement by an ultraviolet-adsorption-based analyzer (Ametek). Also, sensors included thermocouples and pressure transducers for temperature and exhaust pressure measurements at various points in the exhaust system. Universal exhaust gas oxygen (UEGO) sensors (ECM) allowed measurement of air-to-fuel ratios in the exhaust.

In addition to the standard emission analyzers used for exhaust speciation, a Fourier transform infrared (FTIR) spectrometer was used to analyze exhaust for $\mathrm{CH}_{4}, \mathrm{CO}_{2}, \mathrm{CO}, \mathrm{H}_{2} \mathrm{O}$, and other species. The FTIR spectrometer was operated in a gas transmission mode with a gas cell of $10 \mathrm{~m}$ pathlength; during data collection, the gas cell was kept at a pressure of 650 torr and a temperature of $120^{\circ} \mathrm{C}$. The resolution of the FTIR spectrometer was $0.5 \mathrm{~cm}^{-1}$. Exhaust samples were diluted with an air dilution tunnel prior to analysis with FTIR in order to avoid $\mathrm{H}_{2} \mathrm{O}$ condensation and reduce the concentration of $\mathrm{CH}_{4}$ and other species for improved accuracy in measurement. The dilution ratio was approximately $35: 1$; the actual dilution ratio was measured often and was kept constant via air flow control by a mass flow controller.

In order to measure the $\mathrm{H}_{2}$ in exhaust samples, a magnetic sector mass spectrometer with a capillary-based sample inlet was utilized. This instrument has been demonstrated for analysis of $\mathrm{H}_{2}$ in diesel exhaust. ${ }^{20}$ In the application presented here, exhaust gas samples were passed through a chiller to remove $\mathrm{H}_{2} \mathrm{O}$ prior to measurement with the mass spectrometer. A 250 micron capillary inserted into the exhaust sample line downstream of the chiller allowed input of the exhaust sample of interest into the vacuum-based mass spectrometer for measurement; vacuum pressures during measurement were typically $5-6 \times 10^{-6}$ torr. The mass spectrometer signal at 2 amu was monitored to measure $\mathrm{H}_{2}$; calibration gas standards were used to calibrate the system.

The combination of standard emission analyzers, FTIR gas cell analysis, and magnetic sector mass spectrometer enable the measurement of the major species of interest for methane partial oxidation and reforming processes. Figure 3-3 shows a schematic of the exhaust analysis system with reference to the analyzers employed and the gas species measured. 


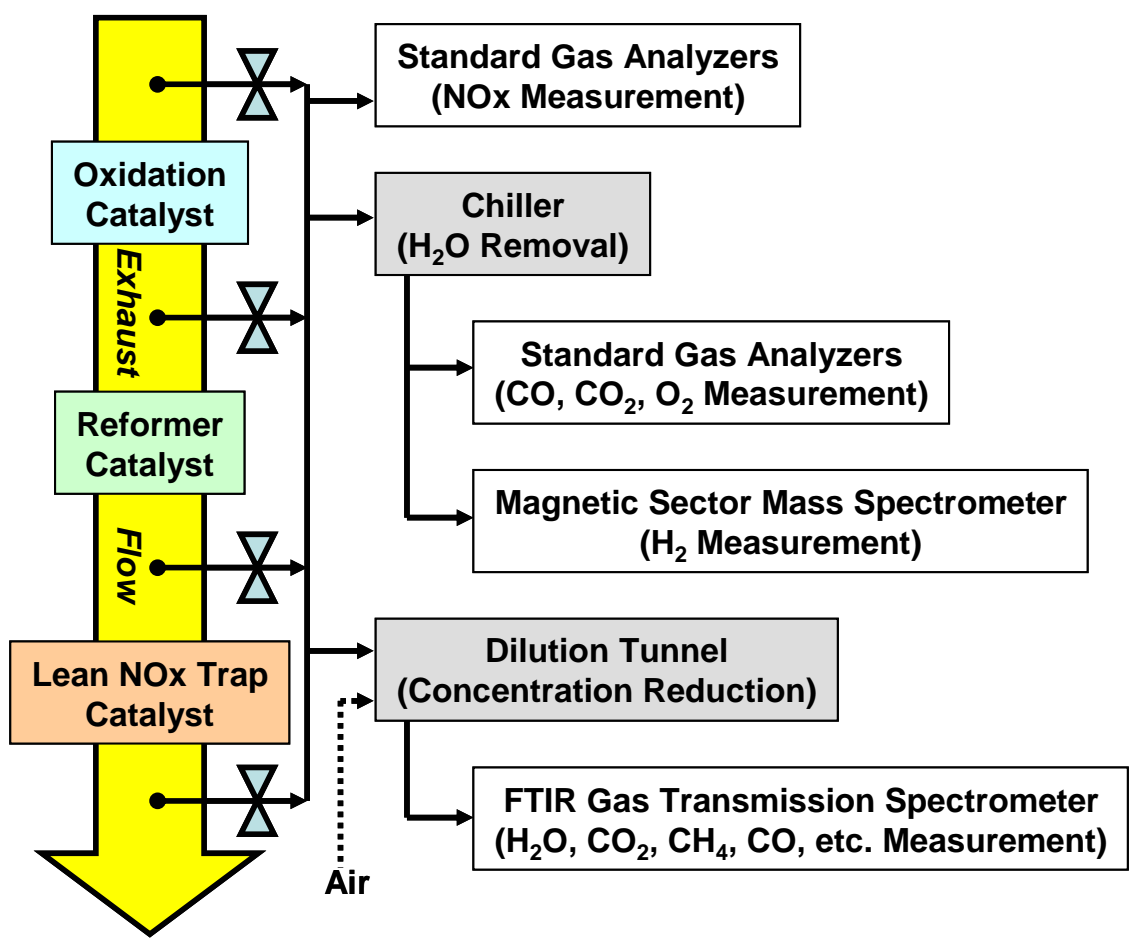

Figure 3-3. Schematic of exhaust gas analysis system. 


\section{Basic Operation and Performance}

Typical performance during operation of the lean NOx trap catalyst system is shown in Figure 4-1; the x-axis (time) for all plots is identical. The engine was operated at $1800 \mathrm{rpm}$ and $50 \%$ load (360 ft-lb and $123 \mathrm{hp}$ or $488 \mathrm{Nm}$ and $92 \mathrm{~kW}$ ) at steady state conditions. The catalyst system was controlled with fixed periods for catalyst sorption and regeneration cycles. The sorption cycle was 60 seconds and the regeneration cycle was 17 seconds total with a 10 second fuel injection. The engine exhaust flow was $289 \mathrm{scfm}(8184 \mathrm{slpm})$, which correlates with a space velocity of $35,000 / \mathrm{hr}$ for the lean NOx trap catalysts during sorption. Four catalyst cycles (sorption plus regeneration) are shown.

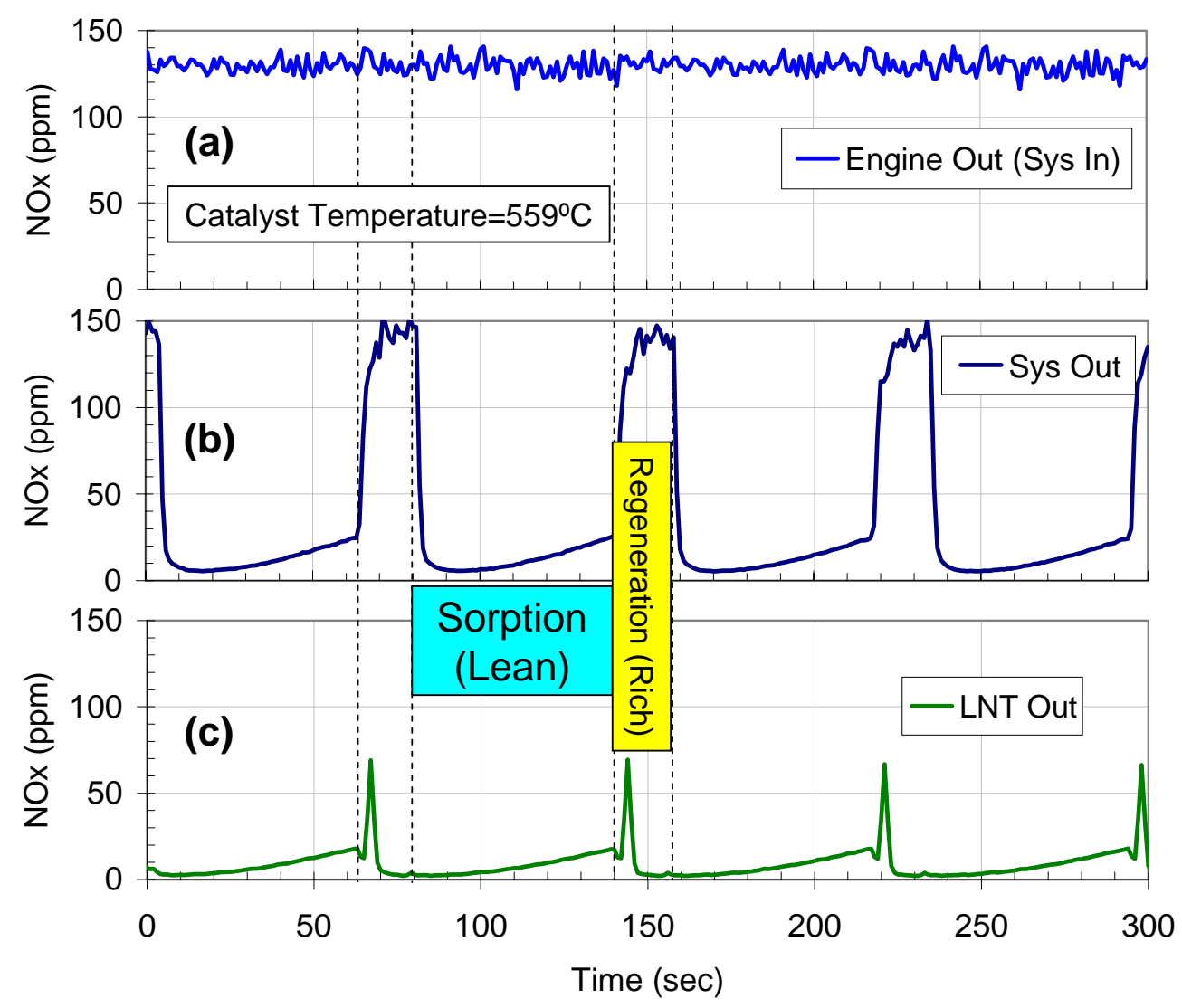

Figure 4-1. NOx concentration as a function of time during lean NOx trap cycling.

Figure 4-1.a. shows the NOx concentration in units of ppm (parts per million, volume) vs. time measured at the Sys In (engine out) position (see Figure 3-1 for notes on sample position). The average engine out NOx level was $\sim 130 \mathrm{ppm}$ and steady. The NOx level measured at the outlet of the catalyst system (Sys Out) varied during the catalyst cycle and represents a mixture of NOx emissions from the catalyst and bypass legs (Figure 4-1.b.). During sorption when the exhaust is treated by the catalyst leg, the NOx levels are dramatically lower than engine out levels, and during regeneration when exhaust flows through the bypass leg, NOx emissions are essentially equal to engine out levels as expected. The NOx level measured immediately downstream of the catalyst (LNT Out) varied during the catalyst cycle as well (Figure 4-1.c.). Immediately after regeneration, NOx levels reached their minimum level of approximately 2 ppm; this represents an instantaneous NOx sorption efficiency of $98 \%$. However, as NOx storage sites fill up, the NOx emissions coming out of the lean NOx trap rise and sorption efficiency decreases. For the case shown here, NOx levels rose to levels of approximately $18 \mathrm{ppm}$. During 
regeneration, a sharp peak in the NOx level coming out of the catalyst at the LNT Out position is observed. Although a peak level of $70 \mathrm{ppm}$ is observed during regeneration at the LNT Out position, the mass flow rate of NOx at this time is low; thus, most of the stored NOx is released and reduced to $\mathrm{N}_{2}$ with only a small fraction of stored NOx being released as NOx.

Since the exhaust analyzers measure NOx concentration instead of NOx mass flow rate, exhaust flow measurements were used to convert the concentration values into mass flow rates which correspond with the units most often used for emission regulations. Total exhaust flow was estimated by adding measurements for intake flow (measured with a Laminar Flow Element) and fuel flow (measured with a Coriolis fuel flow meter). Furthermore, an experiment was performed to measure the exhaust flow rate into the catalyst leg during the regeneration process. The experiment was conducted by adding a known flow of $\mathrm{N}_{2}$ gas to the catalyst leg and monitoring the dilution of $\mathrm{O}_{2}$ measured by the universal exhaust gas oxygen (UEGO) sensor in the catalyst leg. By this method, the exhaust flow leaking past the exhaust brake valve was determined. The leakage rate was a function of the engine load since higher backpressures caused by the higher exhaust flow rates from the engine resulted in a higher pressure differential across the valve and thereby higher leakage flow rates. Measured leakage flow rates are listed in Table 4-1 below. A space velocity corresponding to the flow rates is given as well to show the low flows induced through the catalyst during the regeneration event.

Table 4-1. Flow Rate Through Catalyst Leg During Regeneration.

\begin{tabular}{|c|c|c|}
\hline Engine Load (\%) & Valve Leakage (scfm) & Regeneration SV (/hr) \\
\hline 100 & 39.4 & 4,729 \\
\hline 75 & 27.6 & 3,311 \\
\hline 50 & 17.8 & 2,130 \\
\hline 25 & 7.0 & 836 \\
\hline 10 & 1.3 & 151 \\
\hline
\end{tabular}

Since emission regulations are typically written as mass rates normalized to engine power, data were analyzed to determine the mass emission rate of NOx per time per power with units of $\mathrm{g} / \mathrm{bhp}-\mathrm{hr}$. The mass rate of NOx $\left(\mathrm{m}_{\mathrm{NOx}}\right)$ in $\mathrm{g} / \mathrm{bhp}-\mathrm{hr}$ is calculated with the NOx concentration in ppm $\left(\mathrm{C}_{\mathrm{NOx}}\right)$ and exhaust volumetric flow rate in units of standard liters per hour $\left(\mathrm{V}_{\mathrm{e}}\right)$ as shown in equation (Equation 4-1), where $\mathrm{P}_{\text {out }}$ is the engine power output in $\mathrm{hp}, 46 \mathrm{~g} / \mathrm{mole}$ is the molecular weight of $\mathrm{NO}_{2}$ (emissions regulations typically written with $\mathrm{NOx}$ as $\mathrm{NO}_{2}$ ), and 22.414 liter/mole is the inverse molecular density of an ideal gas at standard conditions.

\section{$\left(\mathrm{C}_{\mathrm{NOx}} / 10^{6}\right)\left(\mathrm{V}_{\mathrm{e}}\right)(46 \mathrm{~g} / \mathrm{mole})$}

Equation 4-1. $\quad \mathbf{m}_{\mathrm{NOx}}=$

\section{(22.414 liter/mole)( $\left.\mathbf{P}_{\text {out }}\right)$}

Figure 4-2 shows graphically the conversion of NOx concentration to NOx mass emission level. In Figure 4-2.a. the NOx concentration and exhaust flow through the catalyst leg of the system are shown as a function of time. The NOx mass emissions calculated using Equation 4-1 gives the NOx emission rate in $\mathrm{g} / \mathrm{bhp}$-hr (Figure 4-2.b.). The profiles of NOx mass rate are similar to the NOx concentration profiles except that the NOx mass rate peaks occurring during regeneration are relatively small compared with engine out mass rates. The exhaust flow rate through the isolated catalyst chamber is only $21 \mathrm{scfm}(603 \mathrm{slpm})$ or $7 \%$ of the total engine exhaust flow, which results in the lower NOx mass rate during regeneration even though NOx concentrations are high. The data demonstrate the high efficiency of the catalyst to reduce the NOx. The average NOx rate measured at the LNT Out position was $0.06 \mathrm{~g} / \mathrm{bhp}$-hr; a minimum level of $0.02 \mathrm{~g} / \mathrm{bhp}-\mathrm{hr}$ was recorded. The average engine out NOx level (not shown) was 0.95 $\mathrm{g} / \mathrm{bhp}-\mathrm{hr}$. Thus, the NOx reduction efficiency of the LNT catalyst was greater than $90 \%$. 

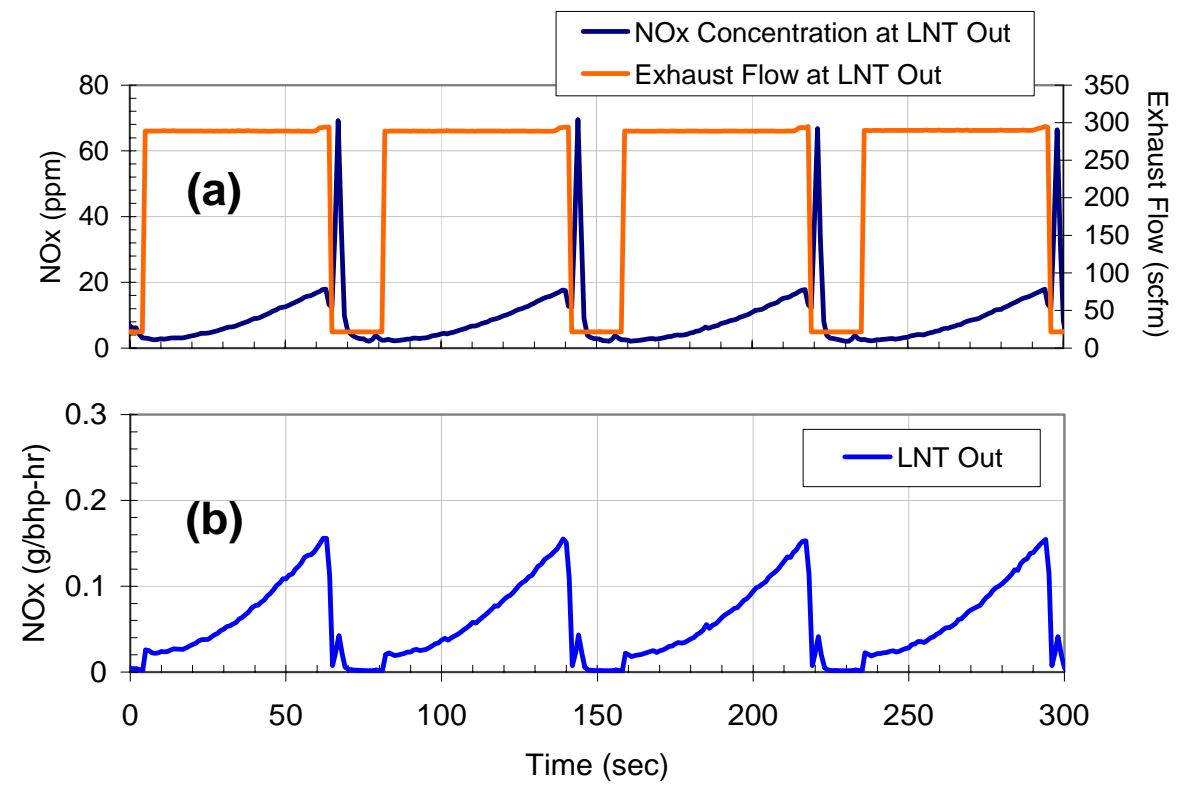

Figure 4-2. Conversion of NOx concentration to NOx mass emission level.

The performance of the lean NOx trap catalyst system is best defined by the mass-based NOx reduction efficiency obtained by the catalyst. Figure 4-3 demonstrates $>90 \%$ NOx reduction efficiency. Engine out and LNT out emissions are shown as a function of time. The average LNT out emissions of $0.06 \mathrm{~g} / \mathrm{bhp}-\mathrm{hr}$ compared with the inlet NOx emission level of $0.95 \mathrm{~g} / \mathrm{bhp}-\mathrm{hr}$ represent a 94\% NOx reduction efficiency average. Furthermore, the $0.06 \mathrm{~g} / \mathrm{bhp}$-hr emission level is below the ARES program target of $0.1 \mathrm{~g} / \mathrm{bhp}-\mathrm{hr}$ NOx.

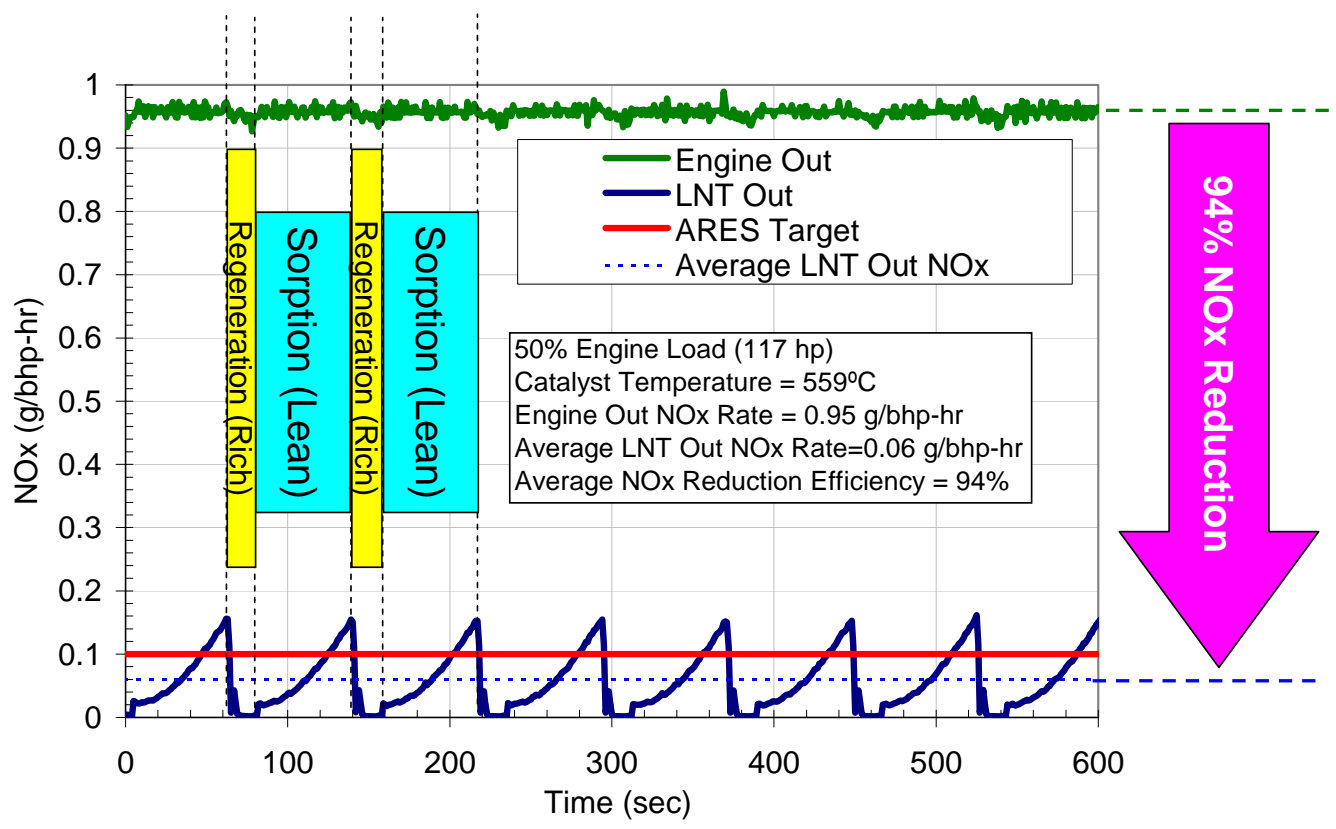

Figure 4-3. Mass-based NOx emissions showing lean NOx trap catalyst NOx reduction efficiency.

It is important to note that during regeneration, the NOx emissions at position Sys Out are equal to the engine out emissions at position Sys In. Therefore, although the LNT catalyst is greater than $90 \%$ efficient at reducing NOx, a catalyst system with only one chamber of LNT 
catalyst is not capable of obtaining NOx reduction efficiencies greater than $90 \%$ continuously. An additional LNT catalyst chamber placed in the Bypass Leg (see Figure 3-1) would result in a two-chamber catalyst system with the capability of continuously reducing NOx from engine exhaust. In order to maximize testing flexibility, a one-chamber system was used for testing, and results will focus on the NOx reduction efficiency of the LNT catalyst, which subsequently can be used to predict the performance of different multi-chamber LNT catalyst systems.

NOx reduction efficiency is highly dependent on the control parameters of the lean NOx trap catalyst operation. High NOx reduction efficiencies $(>90 \%)$ are only attainable when the sorption phase is ended before high levels of NOx slip through the catalyst occur. Furthermore, the amount of fuel injected into the catalyst system during the regeneration phase must be sufficient to reduce the amount of stored NOx and regenerate the catalyst to enable NOx storage in the following cycle. The critical control parameters for regeneration were the minimum excess air ratio $(\lambda)$ and the amount of time fuel was injected to control $\lambda$. Figure 4-4.a. shows the $\lambda$ measured in the catalyst chamber with an UEGO sensor over the catalyst cycle; $\lambda$ is the ratio of the actual air-to-fuel ratio to the stoichiometric air-to-fuel ratio as shown in Equation 4-2. A stoichiometric air-to-fuel ratio of 17.2 was used for the calculation based on the natural gas mixture. Lean operation $(\lambda>1)$ occurs during the sorption cycle as expected. When fuel is injected into the catalyst chamber in conjunction with valve operation to isolate the catalyst chamber from the main exhaust flow, rich conditions $(\lambda<1)$ are obtained. When the injected natural gas is combusted over the oxidation catalyst, exhaust with depleted oxygen and excess reductants results, and subsequently, catalyst regeneration (NOx release and reduction) occurs.

\section{Actual Air-to-Fuel Ratio}

Equation 4-2 $\lambda=$

Stoichiometric Air-to-Fuel Ratio
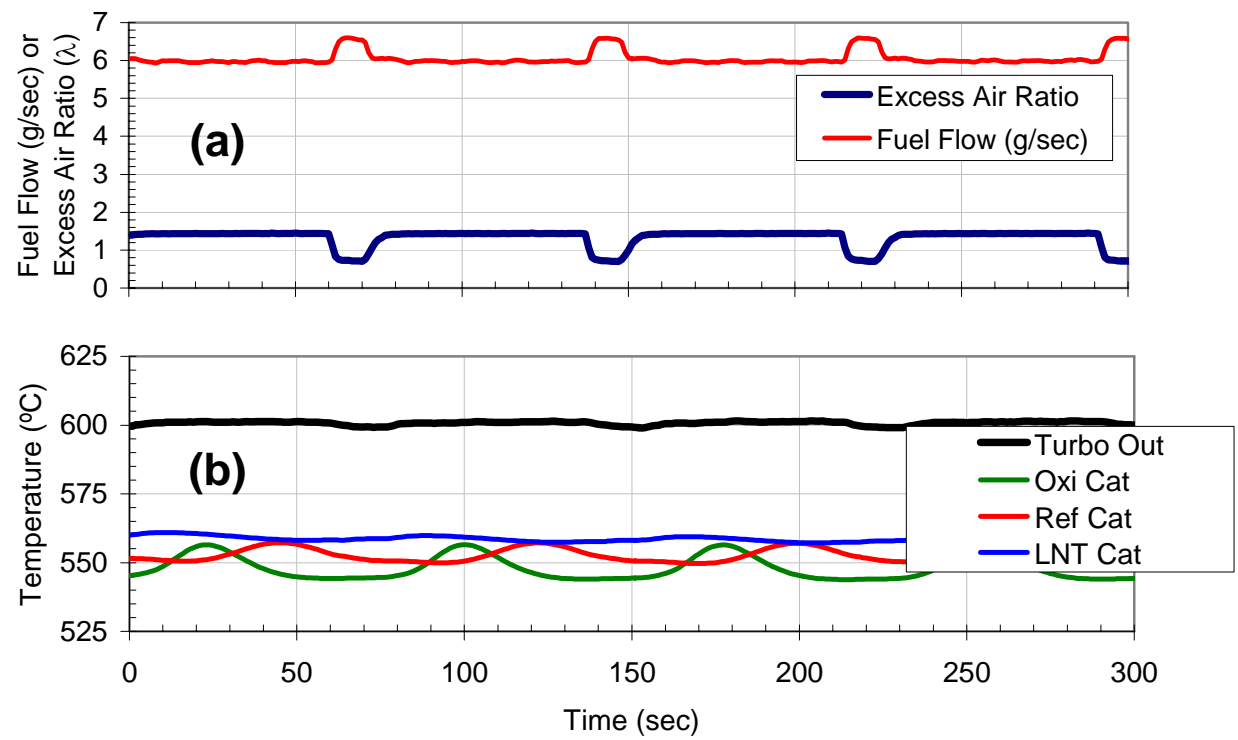

Figure 4-4. Excess air ratio, fuel flow rate, and catalyst temperatures during lean NOx trap cycling.

Fuel flow rate is also shown in Figure 4-4.a. The fuel rate required by the engine was approximately $6.0 \mathrm{~g} / \mathrm{sec}$. Additional fuel injected for catalyst regeneration is evident in the data as the total fuel flow rate (for engine and catalyst regeneration) increases momentarily to 6.6 $\mathrm{g} / \mathrm{sec}$. Although the instantaneous fuel requirement for catalyst regeneration increases the total 
fuel rate to $10 \%$ above the fuel rate of the engine, the amount of natural gas required for regeneration of the lean NOx trap catalyst for the data shown in Figure 4-3 and Figure 4-4 was only $1.32 \%$ of the fuel used for the engine when averaged over the sorption and regeneration cycle. Thus, the valved exhaust system minimizes the fuel penalty resulting from natural gas injection for catalyst regeneration.

The fuel penalty increases operating cost and affects the commercial potential of the LNT technology. Therefore, the method of calculating fuel penalty is important and will be defined here. Fuel use by the engine ( $\left.\mathrm{F}_{\text {engine }}\right)$ was calculated by averaging the fuel rate during the sorption period (lean engine operation with no injection of fuel for catalyst regeneration). Fuel use for catalyst regeneration $\left(\mathrm{F}_{\text {catalyst }}\right)$ was calculated by averaging the fuel rate during the regeneration period (lean engine operation with injection of fuel for catalyst regeneration) and subtracting the average fuel rate during sorption $\left(\mathrm{F}_{\text {engine }}\right)$. The fuel penalty is calculated by dividing the catalyst fuel use by the engine fuel use and is expressed as a percentage as shown in Equation 4-3.

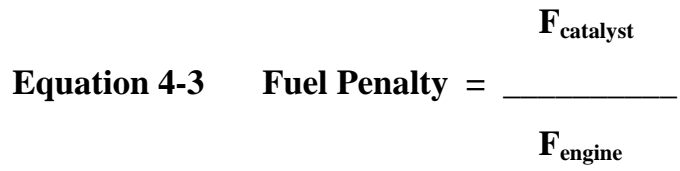

It is important to note that this method of calculating fuel penalty does not include any fuel penalty due to the backpressure of the catalyst system. The average exhaust system backpressure for the data shown in Figure 4-4 was $1.6 \mathrm{psi}(11 \mathrm{kPa})$. No effort was made to design the test system for minimal backpressure, and translating backpressure data to larger engine exhaust systems is not straightforward. Thus, only the fuel penalty from fuel injected for catalyst regeneration is presented in this study. Another source of fuel penalty is electrical and other power sources required for valve operation and control electronics; however, these requirements are most likely negligible relative to engine fuel use. Note that the fuel penalty defined here represents the fuel penalty required to regenerate a single LNT catalyst chamber; fuel penalties for multi-chamber systems would be higher in proportion to the number of chambers and duty cycles employed.

Exhaust and catalyst temperatures are shown in Figure 4-4.b. over the catalyst cycle. Some temperature drop occurs between the turbocharger outlet and the catalysts due to heat loss in the exhaust pipe. The catalyst temperatures oscillate with the same period as the catalyst cycle as exothermic heat from the combustion of natural gas occurs on the catalyst during regeneration. The heat generated does not contribute to power production and, thus, contributes to the fuel penalty unless some form of heat recovery is employed on the engine. Although heat release during the regeneration is clearly evident, the temperature changes are not greater than $20^{\circ} \mathrm{C}$. The reduction of exhaust mass flow during regeneration via the exhaust brake valve substantially reduces the exotherm as $\mathrm{O}_{2}$ and fuel mass flows are greatly reduced. 


\section{Optimization of Performance}

\subsection{Methane Oxidation Efficiency}

Since the $\mathrm{CH}_{4}$ fuel injected into the catalyst system for catalyst regeneration results in a fuel penalty, it is important to understand the utilization of $\mathrm{CH}_{4}$ for catalyst regeneration so that catalysts and regeneration processes can be optimized. The first chemical step in regeneration is the oxidation of $\mathrm{CH}_{4}$ with $\mathrm{O}_{2}$ in the catalyst chamber (from the engine exhaust leaking through the exhaust brake valve). $\mathrm{CH}_{4}$ is typically difficult to oxidize catalytically due to the stability of the $\mathrm{C}-\mathrm{H}$ bond; $\mathrm{CH}_{4}$ consists of four $\mathrm{C}-\mathrm{H}$ bonds in a tetrahedral structure.

A simple test was performed to characterize the $\mathrm{CH}_{4}$ oxidation efficiency of the oxidation catalyst in lean exhaust to determine the temperature where catalyst light-off (significant $\mathrm{CH}_{4}$ oxidation) occurs. The engine speed was held constant at $1800 \mathrm{rpm}$ while the engine load was ramped up slowly; the increasing load resulted in higher exhaust and catalyst temperatures. Note that space velocity and $\mathrm{CH}_{4}$ concentration also varied with engine load. $\mathrm{CH}_{4}$ concentration was measured before and after the oxidation catalyst at exhaust sample positions Oxi Cat In and Oxi Cat Out, respectively. The resulting data (see Figure 5-1) shows the $\mathrm{CH}_{4}$ oxidation efficiency (percentage of $\mathrm{CH}_{4}$ oxidized on the oxidation catalyst) as a function of catalyst temperature. Results show $\mathrm{CH}_{4}$ oxidation beginning to occur in the temperature range of 450 to $500^{\circ} \mathrm{C}$ with generally low oxidation efficiencies $(\sim 25 \%)$ at catalyst temperatures above $500^{\circ} \mathrm{C} . \mathrm{CH}_{4}$ oxidation catalysts are known to degrade in performance under exhaust exposure even during short time periods, which may have resulted in the limited oxidation efficiencies observed. Nevertheless, the data show that $\mathrm{CH}_{4}$ oxidation efficiency improves dramatically with temperature until $500^{\circ} \mathrm{C}$ where performance becomes stable.

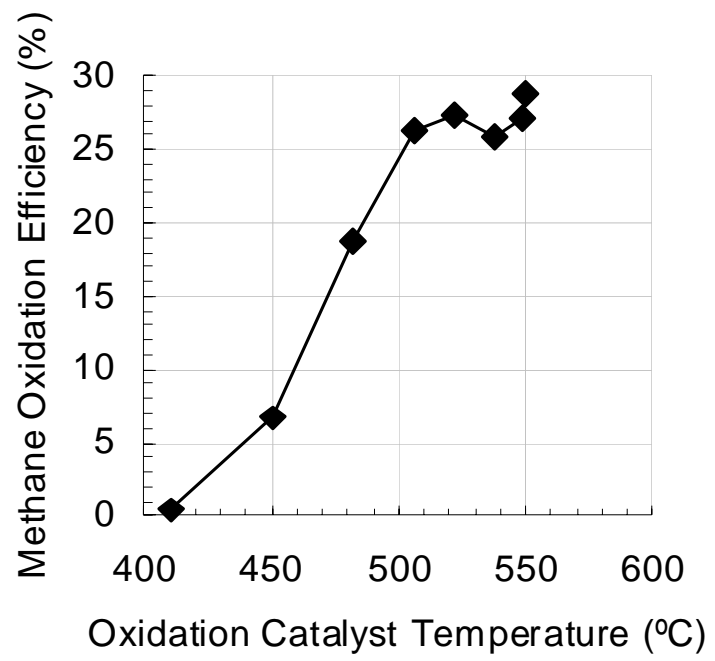

Figure 5-1. $\mathrm{CH}_{4}$ oxidation efficiency of the oxidation catalyst as a function of catalyst temperature.

The data shown in Figure 5-1 were obtained under lean exhaust conditions. During regeneration, characterization of $\mathrm{CH}_{4}$ oxidation efficiency was difficult due to the high concentration of $\mathrm{CH}_{4}$ present; however, $\mathrm{O}_{2}$ was measured before and after the oxidation catalyst to determine if $\mathrm{CH}_{4}$ oxidation and $\mathrm{O}_{2}$ depletion occurred. $\mathrm{O}_{2}$ levels measured at the Oxi Cat Out position during regeneration showed near-zero $\mathrm{O}_{2}$ levels indicating that $\mathrm{CH}_{4}$ oxidation and thereby $\mathrm{O}_{2}$ depletion was occurring during regeneration.

In addition to the $\mathrm{CH}_{4}$ oxidation requirement for catalyst regeneration, rich combustion products $\mathrm{CO}$ and $\mathrm{H}_{2}$ must be formed for catalyst regeneration to occur. A detailed examination of 
the conversion of $\mathrm{CH}_{4}$ into $\mathrm{H}_{2}$ and $\mathrm{CO}$ is presented below in Section Error! Reference source not found.. For the purpose of performance optimization, $\mathrm{CO}$ measurements were used to indicate the presence of both rich combustion products $\mathrm{CO}$ and $\mathrm{H}_{2}$. The quantity of $\mathrm{CO}$ measured gives some indication of reduction potential regardless of whether $\mathrm{CO}$ is effective alone or as a source of $\mathrm{H}_{2}$ via the water-gas-shift reaction.

Experiments were conducted to measure the quantity of $\mathrm{CO}$ generated at various positions along the catalyst chamber during regeneration. In the experiment, $\lambda$ was varied over a wide range while holding all other parameters constant. The NOx reduction efficiency and fuel penalties measured during the experiment are shown in Figure 5-2.a. as a function of $\lambda$. Figure 5-2.b. shows the peak $\mathrm{CO}$ concentration occurring during regeneration as a function of excess air ratio. The experiment was performed at an engine load of 50\% and engine speed of $1800 \mathrm{rpm}$ which resulted in catalyst temperatures of $\sim 550^{\circ} \mathrm{C}$; thus, $\mathrm{CH}_{4}$ is readily oxidized for catalyst regeneration. Sorption and regeneration periods of $30 \mathrm{sec}$. and $17 \mathrm{sec}$., respectively, were used. Results are shown for exhaust sample positions Oxi Cat In, Oxi Cat Out, and LNT Out (see Figure 3-1). The data show that virtually no $\mathrm{CO}$ exists at the Oxi Cat In position as expected since $\mathrm{CH}_{4}$ and $\mathrm{O}_{2}$ do not chemically interact at these low gas temperatures without catalyst assistance. $\mathrm{CO}$ does occur in the Oxi Cat Out position and increases as the fuel mixture entering the catalyst becomes richer. An interesting effect occurs as $\mathrm{CO}$ concentrations appear to stabilize at excess air ratios less than 0.7. CO does not exist at the LNT Out position for $\lambda=0.9$, which indicates all $\mathrm{CO}$ produced by the oxidation and reforming catalysts is consumed by the LNT catalyst during regeneration. Note that for the $\lambda=0.9$ case, NOx reduction efficiencies of only $40 \%$ were obtained, indicating that catalyst regeneration was not complete. Also, a large surplus of $\mathrm{CH}_{4}$ was present in the catalyst chamber during regeneration at $\lambda=0.9$, but $\mathrm{CH}_{4}$ did not effectively regenerate the catalyst. At a richer excess air ratio of $\lambda=0.8, \mathrm{CO}$ levels increase, and NOx reduction efficiencies greater than $90 \%$ were obtained in conjunction with observations of $\mathrm{CO}$ at the LNT out position. Adding more fuel to obtain richer conditions $(\lambda<0.8)$ gave little improvement in NOx reduction efficiency but increased the fuel penalty per regeneration event. The data show that $\mathrm{CH}_{4}$ is being utilized for LNT regeneration; however, $\mathrm{CH}_{4}$ is not shown be the LNT catalyst reductant. $\mathrm{CH}_{4}$ enables $\mathrm{O}_{2}$ depletion and $\mathrm{CO}$ and $\mathrm{H}_{2}$ production which regenerates the LNT catalyst.
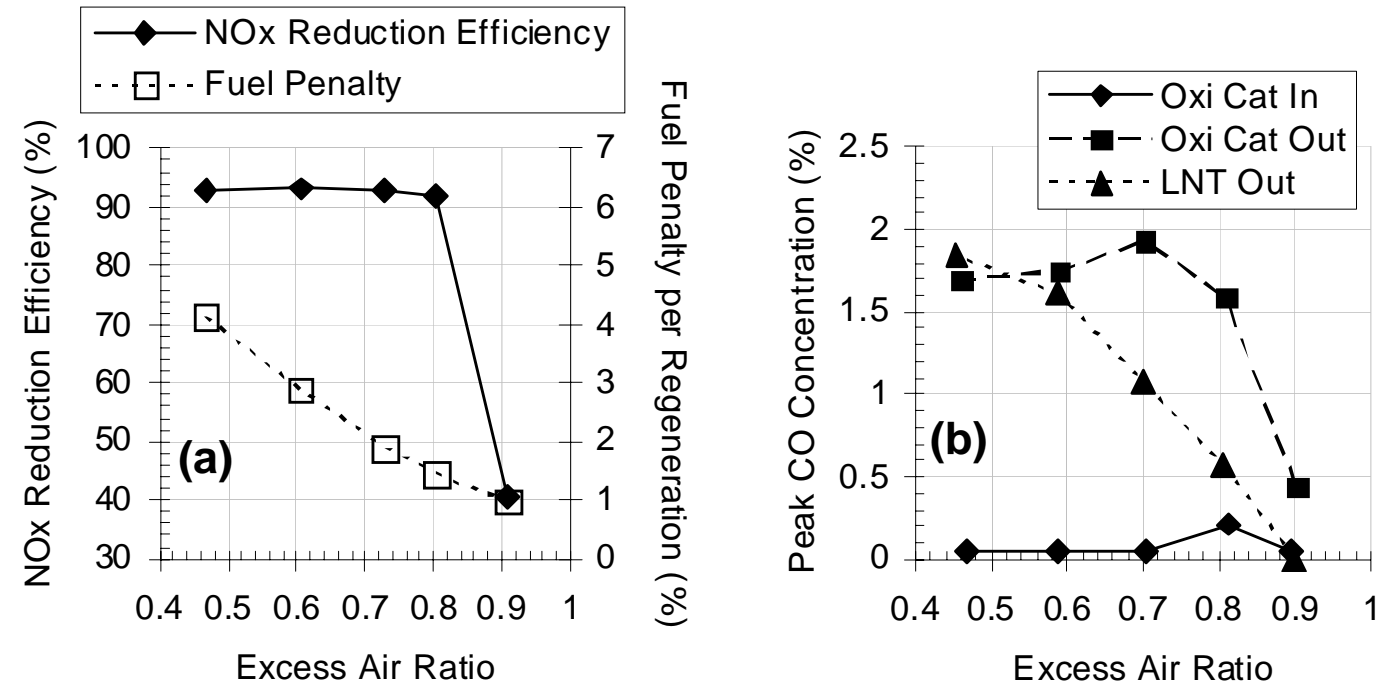

Figure 5-2. NOx performance, fuel penalty, and reductant production as a function of excess air ratio. 
Studies of catalyst performance as a function of the excess air ratio during regeneration give important information for optimization of catalyst operation in addition to an understanding of the chemistry occurring during regeneration. For the conditions shown in Figure 5-2, the optimal amount of $\mathrm{CH}_{4}$ injection occurred at $\lambda=0.8$. Lower (leaner) fuel amounts $(\lambda=0.9)$ generated lower $\mathrm{CO}$ levels during regeneration and subsequently lower NOx reduction efficiency. Higher (richer) fuel amounts $(\lambda<0.8)$ resulted in small improvements in NOx reduction efficiency yet resulted in larger fuel penalties from the extra fuel injected. While the optimal injection setting for the example case presented here is straightforward, determining the optimal parameters can be complex as fuel penalties, NOx reduction efficiencies, and NOx storage capacities vary with excess air ratio. Often optimizing one performance parameter compromises another performance area. Prior to the conducting the experiments presented in this document, experiments at different excess air ratios were conducted for the purpose of defining the optimal excess air fuel ratio $(\lambda)$ with emphasis given to NOx reduction performance at greater than $90 \%$ levels.

\subsection{NOx Capacity vs. Temperature}

A primary focus of this study was to determine if natural gas could be the source reductant for catalyst regeneration for lean NOx trap catalysts in the exhaust temperature ranges associated with natural gas internal combustion engines. In the previous section, results showed that $\mathrm{CH}_{4}$ (generally the largest component of natural gas) can be combusted under rich $(\lambda<1)$ conditions to produce $\mathrm{CO}$ and $\mathrm{H}_{2}$ to successfully regenerate the LNT catalyst. The demonstration of NOx reduction efficiencies greater than $90 \%$ shows that $\mathrm{CH}_{4}$ is capable of being a source reductant for regenerating the LNT catalyst, but a more useful parameter for analyzing the effectiveness of the LNT catalyst in natural gas engine exhaust is NOx storage capacity.

NOx storage capacity is the amount of NOx that a catalyst can store during the lean sorption period and is usually expressed per volume of catalyst. In the study presented here, NOx storage capacity is defined as the mass of $\mathrm{NOx}\left(\right.$ as $\left.\mathrm{NO}_{2}\right)$ per volume of LNT catalyst that the catalyst can store while maintaining greater than $90 \%$ NOx reduction efficiency. The units of NOx capacity are g/liter. Engine out (Sys In) and LNT Out NOx levels combined with exhaust flow data allow measurement of the mass of NOx trapped by the catalyst. The NOx storage capacity is a measurement of performance useful for sizing catalysts for specific applications; higher storage capacities allow lower LNT catalyst volume (lower capital cost) and/or lower fuel penalty (lower operating cost). The NOx capacity of the catalyst varies with catalyst temperature, regeneration parameters, and many other conditions.

After optimizing the regeneration parameters for various operating conditions, the NOx storage capacity of the LNT catalyst was tested at different catalyst temperatures. The engine was operated at steady-state conditions at 10, 25, and 50\% loads and the catalyst was cycled between sorption and regeneration until steady-state temperatures and performance were obtained. Following the completion of a regeneration event, the catalyst was allowed to store NOx in sorption mode until the level of NOx coming out of the catalyst was more than $50 \%$ of the inlet level of NOx to the catalyst (this point is defined as the $50 \%$ breakthrough point). During sorption the catalyst temperature stabilized to the catalyst temperature associated with each engine load. Data were analyzed for NOx storage capacity for each engine load and catalyst temperature.

Figure 5-3 shows the NOx storage capacity obtained as a function of LNT catalyst temperature. For comparison, NOx storage capacities from bench flow reactor testing with simulated exhaust gases are also shown. Sorption conditions for the bench tests were $500 \mathrm{ppm}$ inlet $\mathrm{NOx}$ at 30,000/hr space velocity; regeneration was performed with $\mathrm{CH}_{4}$ in an $\mathrm{O}_{2}$ containing mixture. Not surprisingly, the bench results obtained under better controlled conditions showed higher NOx capacities. Both engine and bench reactor results show that NOx capacities decrease with increasing catalyst temperature. For the engine results, catalyst temperatures of 430, 505, 
and $560^{\circ} \mathrm{C}$ correspond with engine loads of $10 \%, 25 \%$, and $50 \%$, respectively. During regeneration, excess air ratios of $\lambda=0.7,0.6$, and 0.8 were used for engine load points $10 \%, 25 \%$, and $50 \%$, respectively based on optimization procedures shown in the previous section. Note that for the $10 \%$ load, the exhaust brake valve upstream of the catalyst chamber was left open during regeneration to provide sufficient mass flow of exhaust to obtain optimal regeneration conditions. Catalyst space velocity and engine out NOx mass emission rates varied with engine load. Evaluations at $75 \%$ and $100 \%$ loads were not performed at steady-state conditions to avoid damage to the LNT catalyst from exposure to higher temperatures. The $\mathrm{CH}_{4}$ oxidation efficiency shown in Figure 5-1 is shown in Figure 5-3 in comparison to the NOx storage capacity. The temperature range where both a high NOx storage capacity for the LNT catalyst and $\mathrm{CH}_{4}$ oxidation for the methane oxidation catalyst occur is narrow regions between 450 and $500^{\circ} \mathrm{C}$. At lower temperatures than this region, performance suffers due to poorer natural gas utilization. At higher temperatures than this region, performance becomes limited by lower NOx capacity of the LNT catalyst.

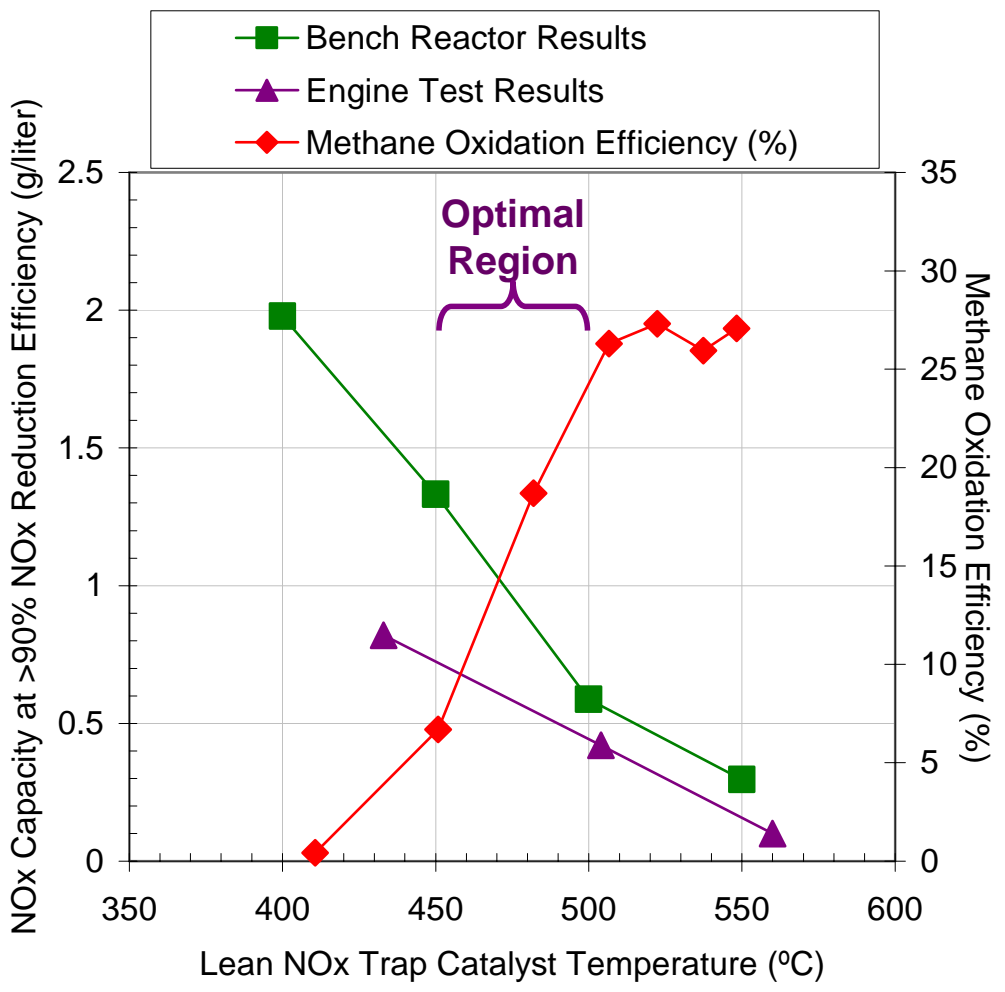

Figure 5-3. NOx storage capacity as a function of LNT catalyst temperature.

\subsection{NOx Capacity vs. NOx Rate}

After characterizing the NOx storage capacity of the LNT catalyst as a function of temperature, NOx storage capacity as a function of engine out (Sys In) NOx mass rate was characterized. Results from the capacity tests as a function of temperature indicated that catalyst temperatures of approximately $500^{\circ} \mathrm{C}$ provide a compromise between the methane oxidation efficiency of the oxidation catalyst and the NOx storage capacity of the LNT catalyst; thus, results will be presented here from tests at approximately $500^{\circ} \mathrm{C}$ under varying engine out $\mathrm{NOx}$ mass rates. The different NOx mass rates were obtained by varying the engine load during the sorption period of the LNT catalyst cycle. 
The evaluation procedure involved cycling the lean NOx trap catalyst until steady state conditions occurred for the engine and catalyst system at an engine load of $25 \%$ and speed of $1800 \mathrm{rpm}$; average catalyst temperatures of $505^{\circ} \mathrm{C}$ were obtained at the $25 \%$ load point. Then after the completion of a regeneration event, the engine was operated at loads of $10,25,50,75$, and $100 \%$ at $1800 \mathrm{rpm}$ to vary the engine out NOx mass rate, and the catalyst was allowed to store NOx in sorption mode until the $50 \%$ breakthrough point occurred. Sorption periods at all engine loads were held to less than 3 minutes to maintain a constant catalyst temperature during the test; significant NOx breakthrough occurred for all loads except the $10 \%$ load (results shown for $10 \%$ load represent unsaturated LNT performance). The experiment enabled characterization of the LNT catalyst NOx performance for different engine loads on an engine test platform while maintaining constant catalyst temperatures.

Figure 5-4 summarizes the NOx performance as a function of engine load and NOx rate at an average catalyst temperature of $505^{\circ} \mathrm{C}$. Figure 5-4.a. shows the NOx emission rate in $\mathrm{g} / \mathrm{bhp}-\mathrm{hr}$ obtained at Sys In (engine out) and LNT Out sample positions as a function of engine load. NOx reduction was obtained at all engine loads as expected, and LNT Out NOx emission levels of 0.1 $\mathrm{g} / \mathrm{bhp}$-hr were obtained at 25 and 50\% loads. The higher LNT Out emission rates obtained at 10 and $100 \%$ loads are due in part to the higher engine out (Sys In) emission rates associated with those loads. Figure 5-4.b. shows the engine out (Sys In) NOx mass rate in $\mathrm{g} / \mathrm{min}$ as a function of engine load; LNT catalyst space velocity is also shown. Both the NOx mass rate and space velocity increase with increasing load as exhaust mass flow increases. Note that the NOx mass rate at $100 \%$ load is a factor of 8 higher than at $10 \%$ load. Despite the large range in engine out NOx rate, the NOx storage capacity varied relatively less with engine load as shown in Figure 5-4.c.; however, some decrease in capacity with increasing engine load did occur, perhaps due to the increasing space velocity. NOx reduction efficiencies greater than $90 \%$ were obtained at 25 and 50\% loads as shown in Figure 5-4.c.; the lowest NOx reduction efficiency of $72 \%$ was obtained at $100 \%$ engine load due to the high engine out NOx mass rate and high space velocity. The high engine out NOx mass rate resulted in more rapid LNT catalyst saturation as expected; Figure 5-4.d. shows the time during the sorption period when greater than $90 \%$ NOx reduction efficiencies were obtained. It is important to note that NOx reduction efficiencies of greater than $90 \%$ were obtained for less than 15 seconds for $100 \%$ engine load. Since sorption periods less than 30 seconds would be difficult to implement with a valved exhaust system, more catalyst volume would be required to enable practical operation at $100 \%$ load if $90 \%$ NOx reduction is required. The fuel penalty per regeneration event was calculated based on the sorption time at greater than $90 \%$ NOx reduction efficiency levels and the engine fuel use; the results, expressed per regeneration event, are also shown in Figure 5-4.d. Fuel penalties ranged from $0.8 \%$ to $2.3 \%$, and the average fuel penalty for the five loads tested was $1.25 \%$.

Note that a system with two catalyst chambers would be required to obtain greater than $90 \%$ NOx reduction efficiency continuously; one chamber would need to be trapping NOx from the exhaust during the regeneration of the catalysts in the opposing chamber. Thus, regeneration would be required more frequently (up to a factor of 2). Thus, fuel penalties shown in Figure 5-4.d. may potentially double in a two-chamber system.

Overall, the data shown in Figure 5-4 demonstrate that high $(>90 \%)$ NOx reduction efficiencies and low exhaust emissions $(0.1 \mathrm{~g} / \mathrm{bhp}-\mathrm{hr}$ NOx $)$ can be obtained with the LNT catalyst technology at proper operating temperatures and conditions. $\mathrm{CH}_{4}$ can be used as the source reductant, and fuel penalties of approximately $2.5 \%$ are expected for a two-chamber LNT catalyst system. Limitations to NOx reduction performance occur at high engine out NOx mass rates and high space velocity; however, NOx storage capacities can provide a means to estimate the LNT catalyst volume requirements to obtain greater than $90 \%$ NOx reduction. 

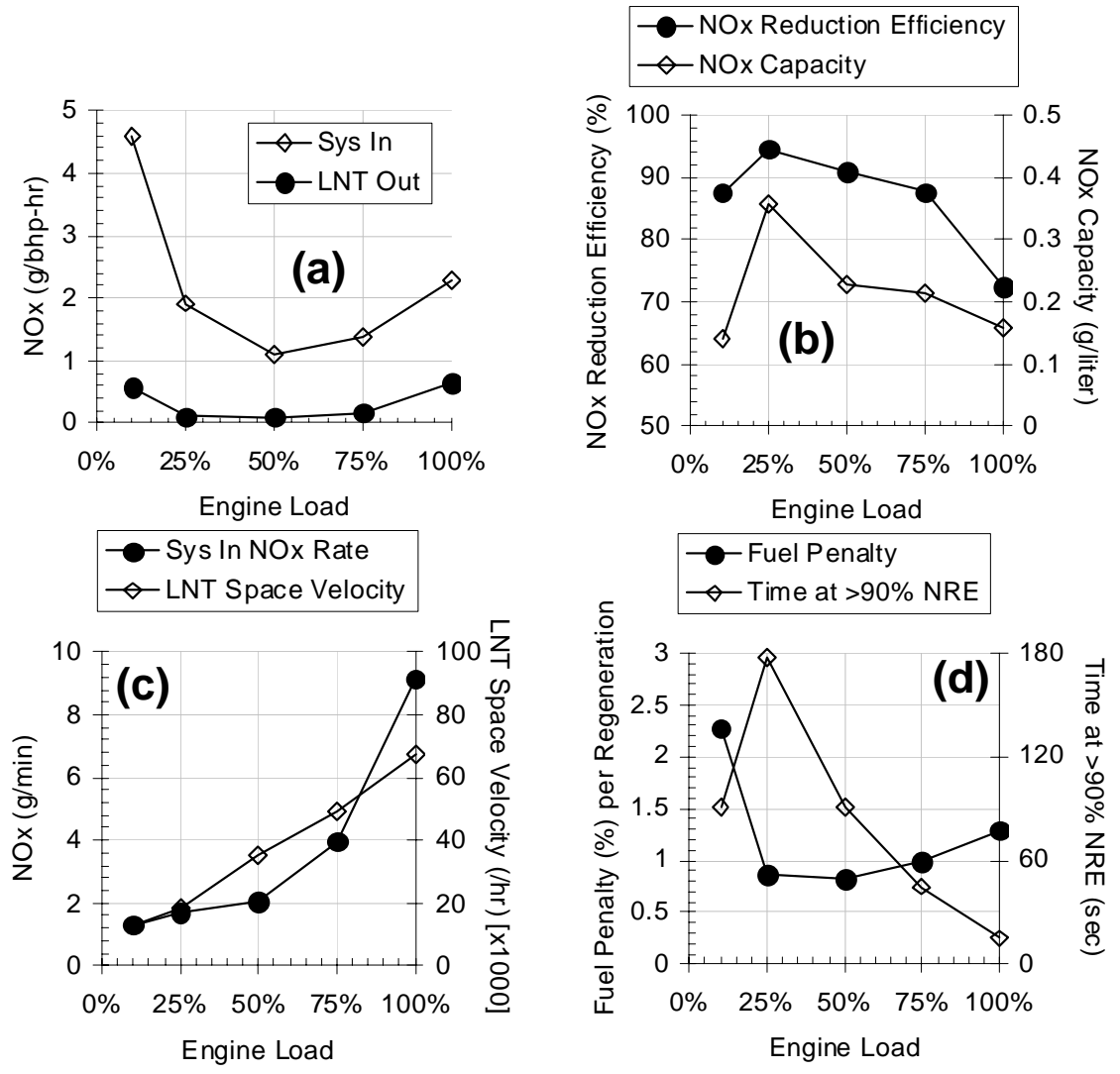

Figure 5-4. LNT performance as a function of engine conditions. 


\section{Lean NOx Trap Regeneration with Natural Gas}

\subsection{Experiment Design}

Analysis of exhaust with the analytical techniques previously described was performed for a matrix of operational conditions. The engine was operated at $1800 \mathrm{rpm}$ with different load conditions to create conditions with different catalyst temperatures. At each catalyst temperature, data were obtained for different excess air ratios used during regeneration. Here, excess air ratio $(\lambda)$ is defined as the ratio of the actual air-to-fuel ratio to the stoichiometric air-to-fuel ratio. Rich excess air ratios $(\lambda<1)$ are required to regenerate the lean NOx trap catalyst. The obtained excess air ratio was controlled by adjusting fueling rate into the exhaust system during regeneration and measured with universal exhaust oxygen sensors mounted in the exhaust directly upstream and downstream of the catalysts.

The engine loads evaluated were 29, 72.5, and $145 \mathrm{hp}$. These loads correspond with 10, 25, and $50 \%$ of full engine load at $1800 \mathrm{rpm}$, respectively. The catalyst temperatures obtained by operating at these engine loads were approximately 420,500 , and $560^{\circ} \mathrm{C}$, respectively. Experiments at higher loads were not conducted since the lean NOx trap catalyst performance declines rapidly above $550^{\circ} \mathrm{C}$ and exhaust temperatures for lean large bore natural gas engines normally do not exceed $550^{\circ} \mathrm{C}$. Actual catalyst temperatures varied during the lean-rich cycling of the lean NOx trap and varied with excess air ratio. Target excess air ratios were varied to determine the ideal fueling rate during regeneration at each load; actual excess air ratios measured for the minimum air-to-fuel ratio during regeneration are reported with results.

For each experimental point, data from several lean-rich cycles were recorded. In addition, the data were recorded for all exhaust sample points prior to changing the experimental parameters of excess air ratio. Furthermore, all excess air ratios were evaluated prior to changing engine load (temperature). This procedure arrangement allowed for minimal fluctuations of conditions between characterization at the different exhaust sample positions and optimal reproducibility of results.

For all data acquired, the lean NOx trap cycle was cycled the same. The cycle consisted of 30 seconds of lean operation for NOx sorption (engine exhaust flow through catalyst leg only) followed by 30 seconds for regeneration (engine exhaust flow through bypass leg). The regeneration process was subdivided into three sections: (1) a 1 second delay to allow exhaust flows to stabilize after exhaust valve actuation, (2) an 18 second fuel injection period, and (3) an 11 second delay after fuel injection to allow the injected fuel to purge through the catalysts.

\subsection{NOx Reduction and Fuel Penalty}

The lean NOx trap system was operated with different fueling rates during regeneration for all engine loads evaluated. NOx reduction efficiencies obtained for the different fueling rates are shown in Figure 6-1. As fueling rates increased, the minimum excess air ratio during regeneration decreased. NOx reduction efficiencies generally increased as more fuel was added during regeneration, but performance became level as excess fuel was added. NOx reduction efficiencies greater than $90 \%$ were obtained for the 10 and $25 \%$ loads, but the NOx reduction efficiency at 50\% load was approximately $70-75 \%$. The higher NOx emission rate from the engine coupled with the lower NOx storage of the lean NOx trap catalyst at $560^{\circ} \mathrm{C}$ caused the lower NOx reduction performance at 50\% load.

The fuel penalty associated with the excess air ratios obtained during regeneration is shown in Figure 6-2. As expected, the fuel penalty increases with increasing fueling rate and decreasing excess air ratio. The fuel penalty required to obtain a given excess air ratio is a function of the oxygen mass flow into the catalyst leg during regeneration as well as the amount of fuel injected into the catalyst system. The oxygen mass flow into the catalyst leg varies with engine load due 
to differences in exhaust composition and exhaust backpressures that lead to different leakage rates through the exhaust valve. Furthermore, the fuel penalties reported represent the fraction of fuel injected into the exhaust system per regeneration event relative to the engine fueling rate; thus, fuel penalties differ for different engine loads due to a variety of issues.

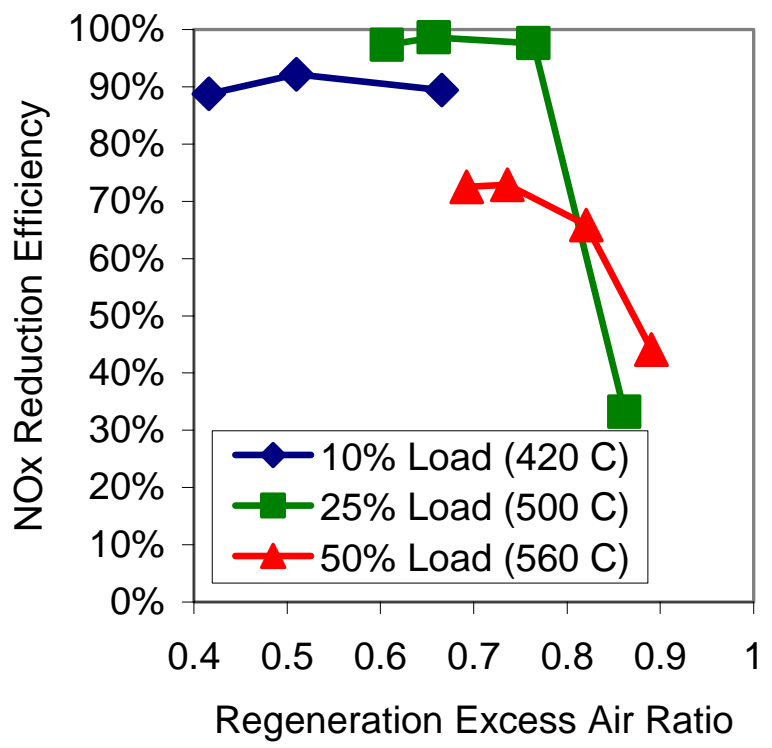

Figure 6-1. NOx reduction efficiency as a function of excess air ratio $(\lambda)$ during regeneration.

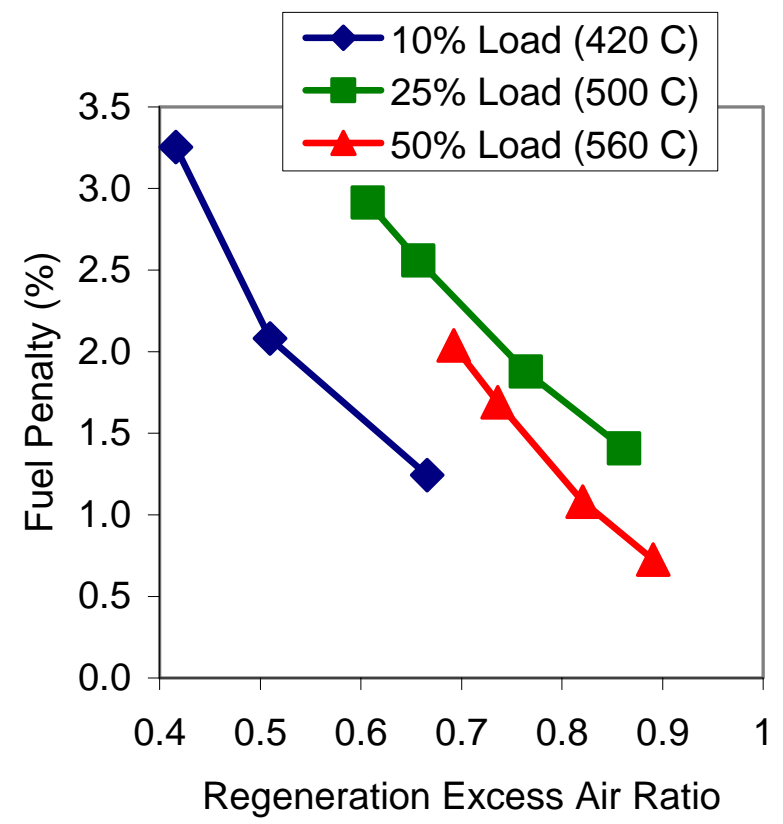

Figure 6-2. Fuel penalty as a function of excess air ratio $(\lambda)$ during regeneration. 
Figure 6-3 shows the cycle average catalyst temperatures for all three catalysts in the system as a function of engine load. A slight increase in catalyst temperature between the oxidation and lean NOx trap catalysts appears for all engine loads as a result of the exothermic process of methane oxidation over the catalysts; however, catalyst temperature differences due to exhaust temperature changes with engine load are more significant.

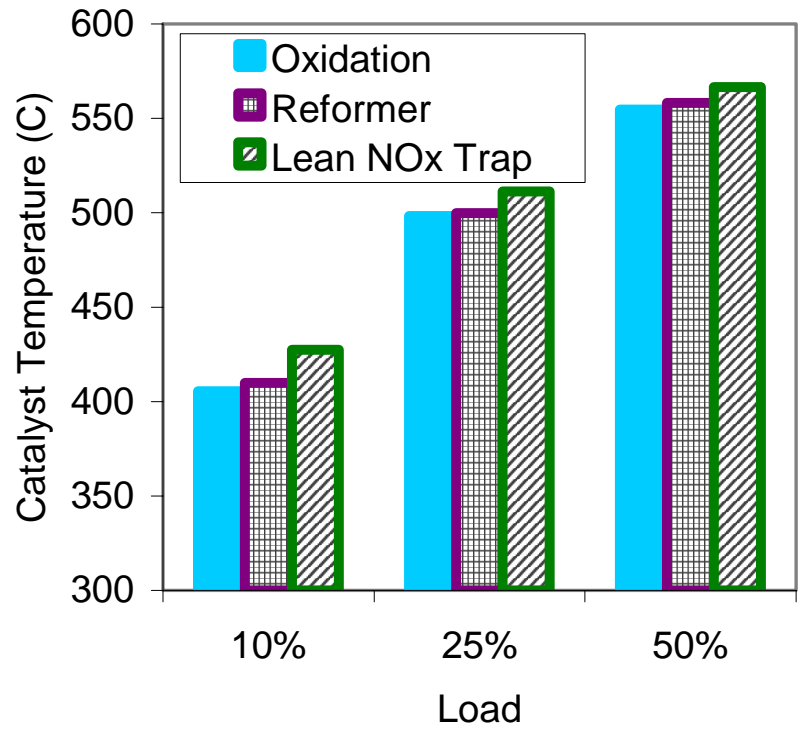

Figure 6-3. Catalyst temperatures as a function of engine load.

\subsection{Nitrogen Selectivity}

During experiments analyzing the performance effects of the minimum excess air ratio during regeneration, the exhaust chemistry was analyzed for ammonia $\left(\mathrm{NH}_{3}\right)$ and nitrous oxide $\left(\mathrm{N}_{2} \mathrm{O}\right)$ with an FTIR gas cell to determine if any non- $\mathrm{N}_{2}$ products are created during LNT operation. NOx trapped by the LNT catalyst is preferably converted to $\mathrm{N}_{2}$, and the efficiency for conversion of NOx to $\mathrm{N}_{2}$ is known as " $\mathrm{N}_{2}$ selectivity". Previous studies have been conducted on the $\mathrm{N}_{2}$ selectivity of LNT catalysts and have shown that $\mathrm{NH}_{3}$ and $\mathrm{N}_{2} \mathrm{O}$ can be formed under certain conditions. ${ }^{21}$ In these studies primarily focused on diesel engine applications, selectivity toward $\mathrm{NH}_{3}$ is a strong function of the reductant quantity supplied to the LNT catalyst during regeneration. Results observed in the natural gas application presented here were consistent with diesel engine application results.

Figure 6-4 shows $\mathrm{NH}_{3}$ and $\mathrm{N}_{2} \mathrm{O}$ measured at various points in the LNT catalyst system during lean-rich cycling with a 60 -second period. The engine was operated at $1800 \mathrm{rpm}$ and $50 \%$ load during the experiment, and the minimum excess air ratio during regeneration was $0.68(\lambda=0.68)$. $\mathrm{NH}_{3}$ is observed at the Oxi Cat Out position and continues to grow in magnitude through the reformer and LNT catalysts. The highest $\mathrm{NH}_{3}$ level was observed at the LNT Out position indicates that the largest contributor to $\mathrm{NH}_{3}$ formation is the LNT catalyst. The presence of $\mathrm{NH}_{3}$ only occurs during the rich regeneration period. There is a slow decaying $\mathrm{NH}_{3}$ signal at the Oxi Cat In position that is due to $\mathrm{NH}_{3}$ remaining in the analytical system; $\mathrm{NH}_{3}$ is known to stick to sample tubing and in general slowly travel through analytical systems. $\mathrm{N}_{2} \mathrm{O}$ only occurs at the LNT Out position and occurs at a much smaller magnitude than $\mathrm{NH}_{3}$. 


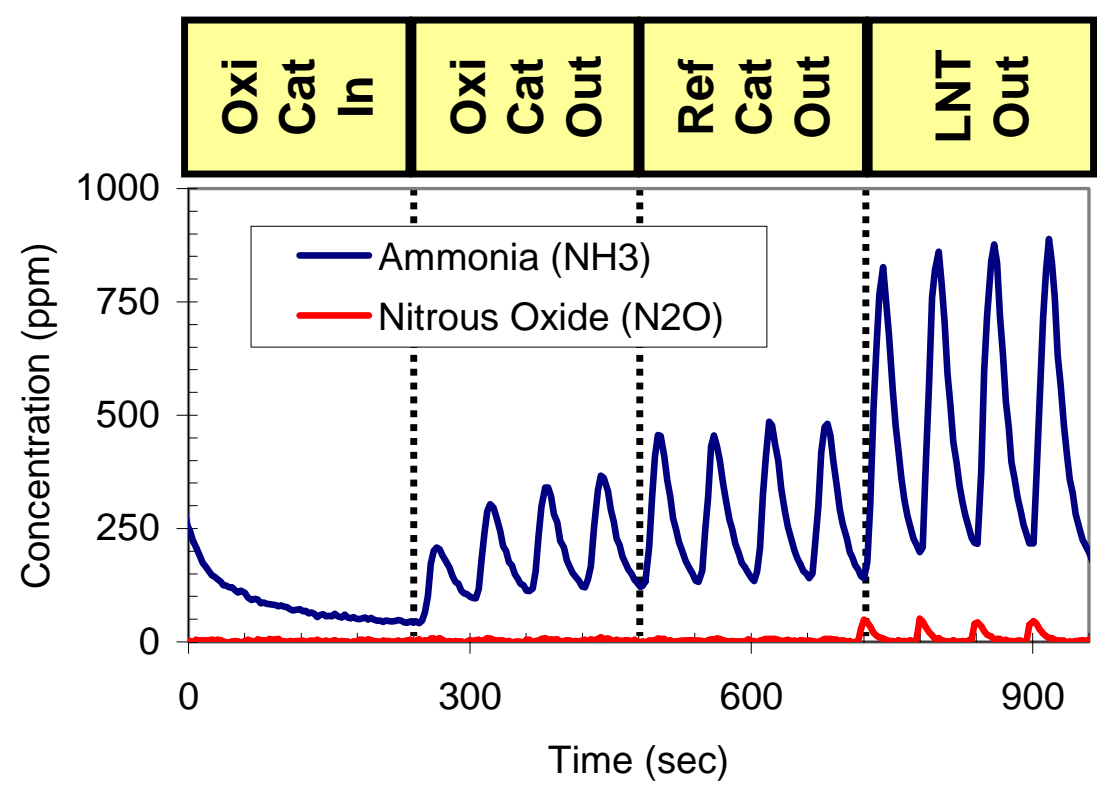

Figure 6-4. Example raw data showing $\mathrm{NH}_{3}$ and $\mathrm{N}_{2} \mathrm{O}$ measured at Oxi Cat In, Oxi Cat Out, Ref Cat Out, and LNT Out sample positions in the catalyst system. The 60-second period of the signals is due to the 60-second lean-rich cycle for lean NOx trap operation; one tick on the $x$-axis label represents 60 seconds.

The example data shown in Figure 6-4 represents a case of high $\mathrm{NH}_{3}$ emissions and is shown to illustrate the position and timing of the $\mathrm{NH}_{3}$ occurrence in the system. Although the concentration of $\mathrm{NH}_{3}$ appears high in the data, the actual total mass of $\mathrm{NH}_{3}$ emissions is relatively lower since the $\mathrm{NH}_{3}$ is emitted during the low flow regeneration event and the emission is confined to the regeneration time frame. Nonetheless, the $\mathrm{NH}_{3}$ emissions can be significant if not properly controlled. $\mathrm{NH}_{3}$ emissions from LNT catalysts are a strong function of reductant quantity delivered during regeneration and, thereby, are a function of the minimum excess air ratio during regeneration. Figure 6-5 shows peak $\mathrm{N}_{2} \mathrm{O}$ and $\mathrm{NH}_{3}$ concentrations occurring at the LNT Out position as a function of the excess air ratio; data from two catalyst temperatures are shown. $\mathrm{NH}_{3}$ emissions are a strong function of the excess air ratio at both temperatures investigated. As less reductant is delivered to the LNT catalyst, less $\mathrm{NH}_{3}$ is formed. Thus, during optimization of the LNT regeneration strategy, minimization of $\mathrm{NH}_{3}$ formation by minimizing fuel delivery must be considered in addition to the minimization of fuel penalty and maximization of NOx reduction efficiency. 

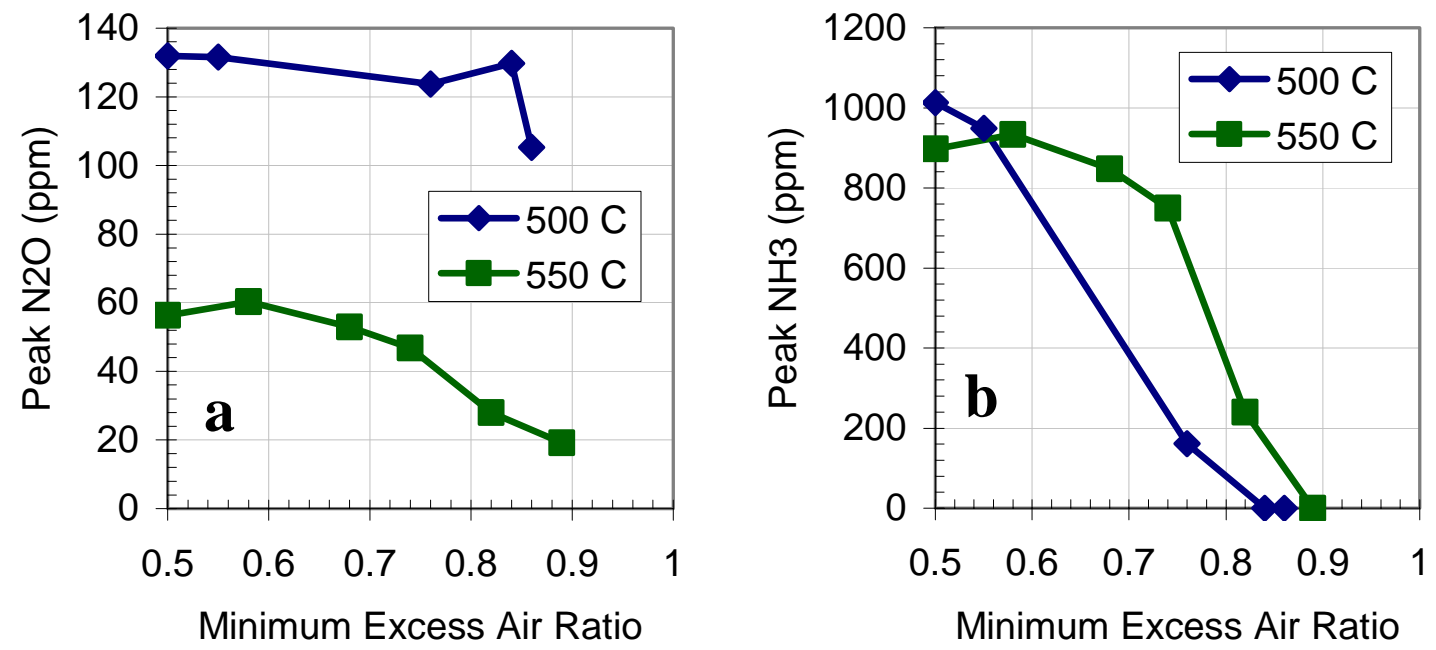

Figure 6-5. $\mathrm{N}_{2} \mathrm{O}$ (a) and $\mathrm{NH}_{3}$ (b) peak concentration measured at the LNT Out position as a function of minimum excess air ratio during regeneration.

\subsection{Methane Utilization}

Full exhaust species data $\left(\mathrm{H}_{2}, \mathrm{CO}, \mathrm{CH}_{4}, \mathrm{O}_{2}, \mathrm{CO}_{2}, \mathrm{H}_{2} \mathrm{O}\right)$ as a function of catalyst temperature and excess air ratio were obtained during lean-rich cycling of the lean NOx trap catalyst. An example of the raw data is shown in Figure 6-6. Here the engine was operated at $1800 \mathrm{rpm}$ and $25 \%$ load. The catalyst temperatures were approximately $500^{\circ} \mathrm{C}$. The LNT catalyst system was cycled with 30 seconds for NOx trapping under lean conditions and 30 seconds for the regeneration process. Fuel was injected into the catalyst system for 18 seconds during the regeneration process; the target minimum air-to-fuel ratio for this regeneration series of data was 13:1. The data in Figure 6-6 shows data obtained over four LNT cycles for each sample position where exhaust samples were obtained. The sample positions were Oxi Cat In, Oxi Cat Out, Ref Cat Out, and LNT Out in sequential order (see Figure 3-1).

A closer view of the data in Figure 6-6 is shown in Figure 6-7. Here data from one regeneration period for each exhaust sample position are shown. As observed in the data, methane and oxygen are the only constituents going into the oxidation catalyst as expected (Figure 6-7.a.). Then methane is partially oxidized (Equation 2-3 and Equation 2-4) over the oxidation catalyst, and $\mathrm{CO}$ and $\mathrm{H}_{2}$ are produced at the same time that $\mathrm{O}_{2}$ is depleted (Figure 6-7.b.). The reformer catalyst increases the $\mathrm{H}_{2}$ level in the exhaust dramatically, indicating that reforming processes (Equation 2-5, Equation 2-6, and Equation 2-7) are occurring (Figure 6-7.c.). $\mathrm{CO}$ is also increased over the reformer catalyst, indicating some partial oxidation may also be occurring over the reformer catalyst. Finally, $\mathrm{CO}$ and $\mathrm{H}_{2}$ are partially depleted over the lean $\mathrm{NOx}$ trap catalyst as these reductants are consumed in the process of NOx reduction (Equation 2-2) over the lean NOx trap catalyst (Figure 6-7.d.). 

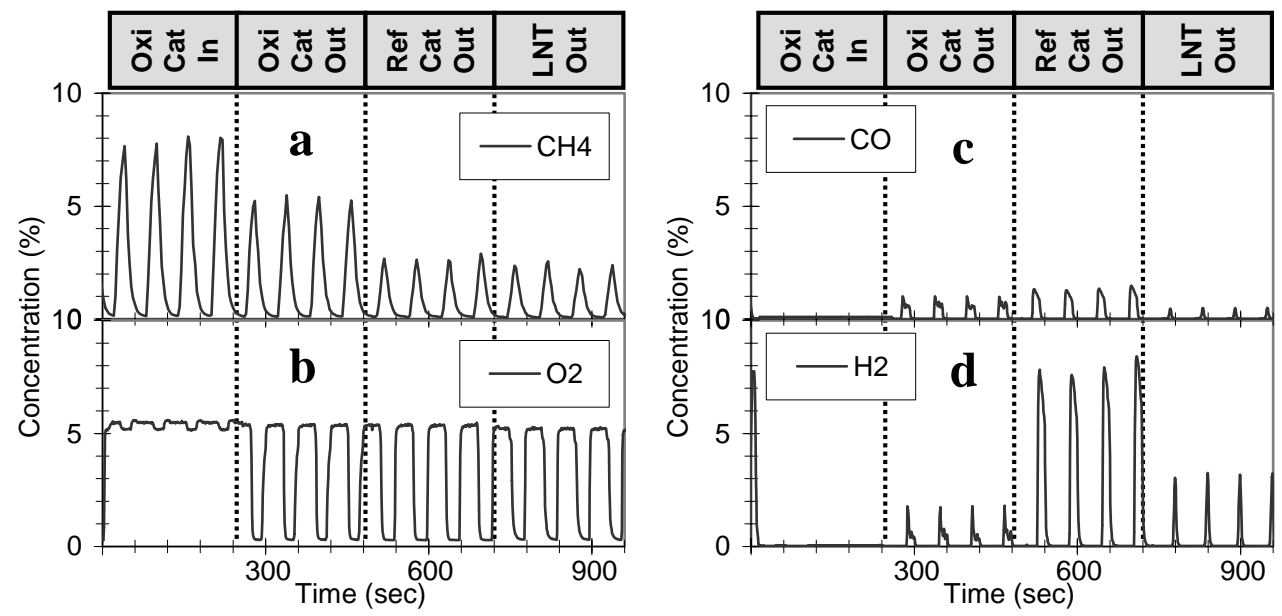

Figure 6-6. Example raw data showing (a) $\mathrm{CH}_{4}$, (b) $\mathrm{O}_{2}$, (c) $\mathrm{CO}$, and (d) $\mathrm{H}_{2}$ measured at Oxi Cat In, Oxi Cat Out, Ref Cat Out, and LNT Out sample positions in the catalyst system. The 60-second period of the signals is due to the 60-second lean-rich cycle for lean NOx trap operation; one tick on the $x$-axis label represents 60 seconds.

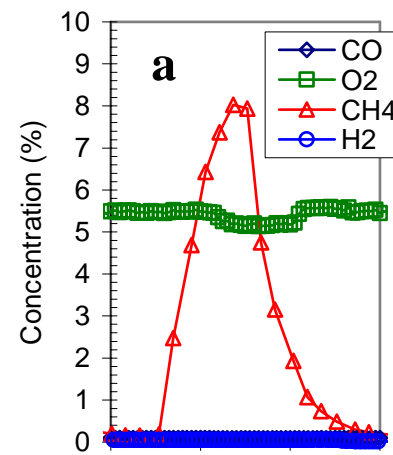

Time (sec)

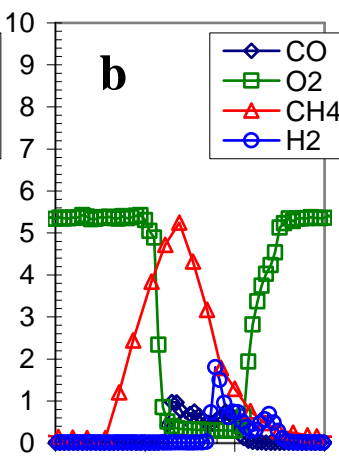

Time (sec)

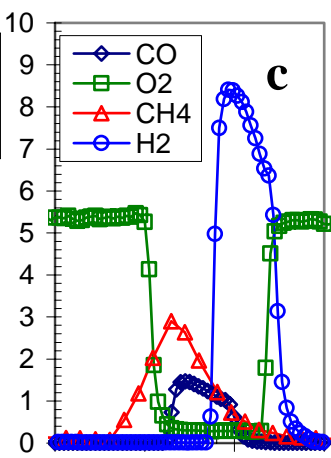

Time (sec)

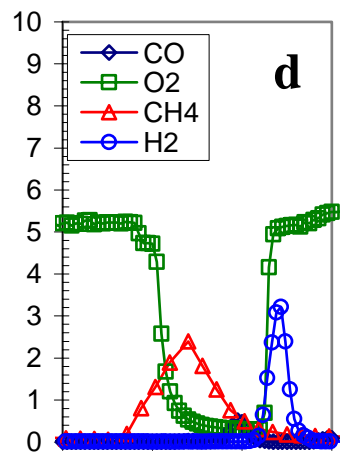

Time (sec)

Figure 6-7. Exhaust species data obtained at (a) Oxi Cat In, (b) Oxi Cat Out, (c) Ref Cat Out, and (d) LNT Out sample positions. The $x$-axis for all plots is time in seconds with a range of 0-60. The $y$-axis represents concentration and is the same scale for all plots.

Raw data as shown in Figure 6-7 were analyzed by integrating the peak signals for each reductant chemistry. The integrated data represents a better view of the chemistry occurring over each catalyst in the system. Figure 6-8 shows the integrated data for the three catalyst temperatures (engine loads) examined. The excess air ratios during regeneration were $0.67,0.76$, and 0.74 for temperatures 420,500 , and $560^{\circ} \mathrm{C}$, respectively. These excess air ratios gave optimal NOx reduction performance per fuel added for regeneration.

At $420^{\circ} \mathrm{C}$ (Figure 6-8.a.), methane levels decrease across all catalysts to some degree, indicating oxidation or reforming functions occur for all catalysts, and there is a significant increase in $\mathrm{H}_{2}$ produced by the reformer catalyst. The specific increase of $\mathrm{H}_{2}$ relative to $\mathrm{CO}$ suggests reforming processes are occurring on the reformer catalyst. Furthermore, the magnitude of the rise in $\mathrm{H}_{2}$ corresponding with a significant drop in $\mathrm{CH}_{4}$ suggests that steam reforming is occurring (Equation 2-6). In contrast, at $560^{\circ} \mathrm{C}$ (Figure 6-8.c.), methane oxidation only occurs across the oxidation catalyst, and only a small increase in $\mathrm{H}_{2}$ occurs over the reformer catalyst. Here the rise in $\mathrm{H}_{2}$ level corresponds (Equation 2-7) with a decline in $\mathrm{CO}$, which suggests water gas shift reforming is occurring. At $500^{\circ} \mathrm{C}$ (Figure 6-8.b.), the maximum production of $\mathrm{H}_{2}$ occurs 
with a sharp increase in $\mathrm{H}_{2}$ observed after the reformer catalyst. For all catalyst temperatures, total methane conversion is similar. Higher temperatures cause more rapid methane conversion via oxidation in the oxidation catalyst, and lower catalyst temperatures convert methane via a combination of oxidation and reforming processes throughout all catalysts in the system. Although the total methane conversion is similar for all catalyst temperatures, the efficiency of methane conversion into useful products for LNT regeneration differs. The reforming function of the reformer catalyst appears to peak in efficiency at $500^{\circ} \mathrm{C}$, where the greatest concentration of $\mathrm{H}_{2}$ is produced.
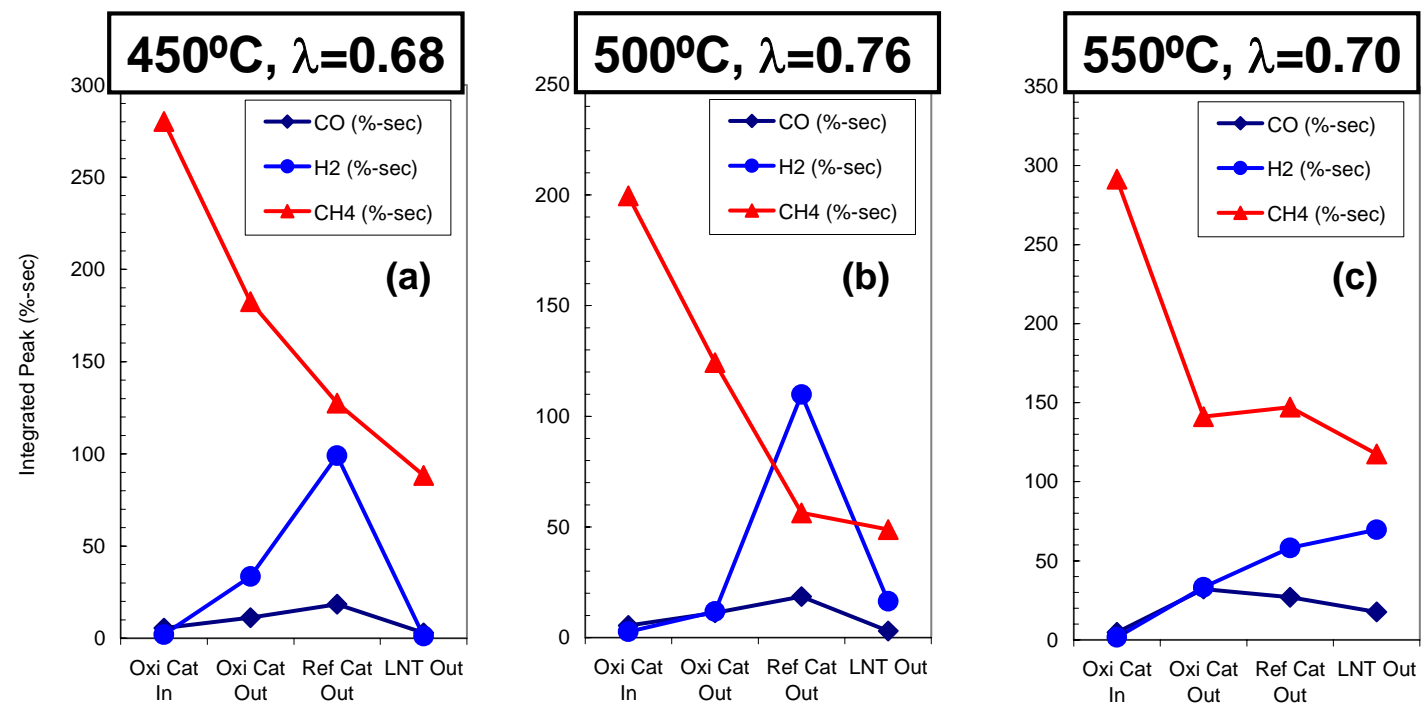

Figure 6-8. Integrated reductant peaks obtained at catalyst temperatures of (a) $420^{\circ} \mathrm{C},(b) 500^{\circ} \mathrm{C}$, and (c) $560^{\circ} \mathrm{C}$. Note the different scale for the $y$-axis in each plot.

A drop in $\mathrm{H}_{2}$ level occurs across the LNT catalyst at 420 and $500^{\circ} \mathrm{C}$, indicating that the $\mathrm{H}_{2}$ is being used to regenerate the lean NOx trap. The absence of a drop in $\mathrm{H}_{2}$ across the LNT catalyst at $560^{\circ} \mathrm{C}$ is likely due to the fact that low amounts of NOx are stored on the LNT at that temperature. Overall, the results indicate that both oxidation and reforming processes are important in producing reductant streams suitable for regeneration of lean NOx trap catalysts, and the oxidation and reforming processes are highly dependent on catalyst temperature.

\subsection{Non-Methane Hydrocarbons}

Non-methane hydrocarbons (NMHC) are another potential pollutant emission from lean natural gas engines, but NMHCs differ significantly from methane in their path through the system. First, since natural gas is primarily composed of methane, the NMHC emissions from the engine are much less than methane on mass and concentration bases. However, some NMHC emissions are generated by the combustion process and need to be minimized by exhaust emission control devices. Fortunately, catalytic oxidation of NMHCs is generally more efficient than catalytic oxidation of methane due to the strong $\mathrm{C}-\mathrm{H}$ bonds in the methane molecule. Thus, catalysts are capable of controlling NMHC emissions.

To investigate the path of NMHC in the engine and lean NOx trap catalyst system, FTIR gas spectroscopy was used to measure ethylene $\left(\mathrm{C}_{2} \mathrm{H}_{4}\right)$ at various points in the catalyst system. Although other NMHC species were also measured by the FTIR analyzer, $\mathrm{C}_{2} \mathrm{H}_{4}$ was chosen to present here since $\mathrm{C}_{2} \mathrm{H}_{4}$ is a common NMHC emitted by combustion processes and because of the potential damaging effect of $\mathrm{C}_{2} \mathrm{H}_{4}$ on plants. The potential problem of $\mathrm{C}_{2} \mathrm{H}_{4}$ damaging plants was raised by EmeraChem, the industrial catalyst supplier and partner in the project; there is 
commercial interest in natural gas generator set usage in greenhouse settings where the exhaust can be pumped into the greenhouse for heating and $\mathrm{CO}_{2}$ uptake by plants. $\mathrm{C}_{2} \mathrm{H}_{4}$ is a natural hormone for plants, but under certain conditions of $\mathrm{C}_{2} \mathrm{H}_{4}$ concentration and temperature, $\mathrm{C}_{2} \mathrm{H}_{4}$ can be injurious to plants. ${ }^{22}$

Figure 6-9 shows $\mathrm{C}_{2} \mathrm{H}_{4}$ emissions measured in the exhaust system; for reference, methane emissions are also shown. The engine was operated at 50\% load at $1800 \mathrm{rpm}$, and the minimum excess air ratio was $0.74(\lambda=0.74)$. The catalyst temperature was $\sim 550^{\circ} \mathrm{C}$. The lean-rich cycle was 60 seconds. $\mathrm{C}_{2} \mathrm{H}_{4}$ emissions are between 50 and $60 \mathrm{ppm}$ exiting the engine and entering the catalyst system as shown in the Oxi Cat In data. Downstream of the oxidation catalyst at the Oxi Cat Out sample position, virtually no $\mathrm{C}_{2} \mathrm{H}_{4}$ is observed during lean operation; however, peaks of $\mathrm{C}_{2} \mathrm{H}_{4}$ do occur as products of the partial oxidation of methane over the oxidation catalyst. These $\mathrm{C}_{2} \mathrm{H}_{4}$ peaks, that are simultaneous to the methane pulses during regeneration, are still present downstream of the reformer catalyst (Ref Cat Out) but ultimately are consumed by the LNT catalyst. After passing through all catalysts (LNT Out), there is virtually no detectable $\mathrm{C}_{2} \mathrm{H}_{4}$ in the exhaust; the error on the measurement is $5 \mathrm{ppm}$. Although $\mathrm{C}_{2} \mathrm{H}_{4}$ can be generated by the engine during combustion and by catalysts during partial oxidation and reforming processes, all of the catalysts oxidize $\mathrm{C}_{2} \mathrm{H}_{4}$ under lean conditions, and the LNT catalyst can consume $\mathrm{C}_{2} \mathrm{H}_{4}$ during rich conditions. Thus, the catalysts are effective as a whole at reducing $\mathrm{C}_{2} \mathrm{H}_{4}$ emissions to extremely low levels.

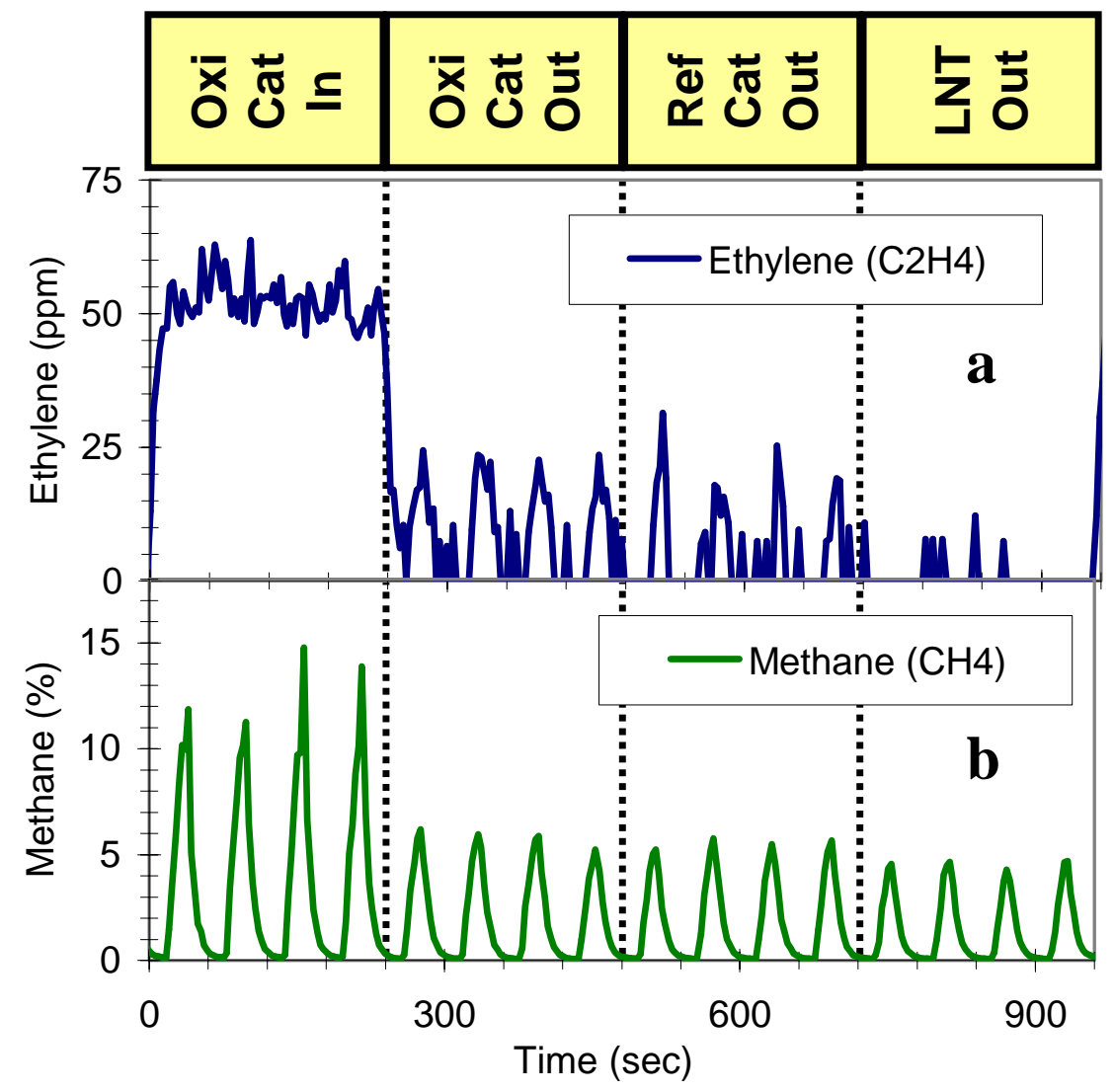

Figure 6-9. Example raw data showing (a) $\mathrm{C}_{2} \mathrm{H}_{4}$ and (b) $\mathrm{CH}_{4}$ measured at Oxi Cat In, Oxi Cat Out, Ref Cat Out, and LNT Out sample positions in the catalyst system. The 60-second period of the signals is due to the 60-second lean-rich cycle for lean NOx trap operation; one tick on the $\mathrm{x}$-axis label represents 60 seconds. 
Other NMHC species were also measured by the FTIR during the experiment. $\mathrm{C}_{2} \mathrm{H}_{4}$ was the most prominent NMHC emitted by the engine, but ethane $\left(\mathrm{C}_{2} \mathrm{H}_{6}\right)$ and propane $\left(\mathrm{C}_{3} \mathrm{H}_{8}\right)$ were the most prominent NMHCs generated in the exhaust system during the regeneration process since $\mathrm{C}_{2} \mathrm{H}_{6}$ and $\mathrm{C}_{3} \mathrm{H}_{8}$ were in the natural gas fuel injected for regeneration. Data for $\mathrm{C}_{2} \mathrm{H}_{6}$ and $\mathrm{C}_{3} \mathrm{H}_{8}$ are shown in Figure 6-10. The conditions of the experiment are the same as the $\mathrm{C}_{2} \mathrm{H}_{4}$ data in Figure 6-9, but the minimum excess air ratio was 0.82 . The peak profiles in the Oxi Cat In data show that the source of the $\mathrm{C}_{2} \mathrm{H}_{6}$ and $\mathrm{C}_{3} \mathrm{H}_{8}$ is the natural gas injected into the catalyst system for regeneration. The $\mathrm{C}_{3} \mathrm{H}_{8}$ is completely consumed by the oxidation catalyst, and the $\mathrm{C}_{2} \mathrm{H}_{6}$ is greatly reduced by the oxidation catalyst. The $\mathrm{C}_{2} \mathrm{H}_{6}$ exiting the LNT is still measurable but is very small as a mass emission level.

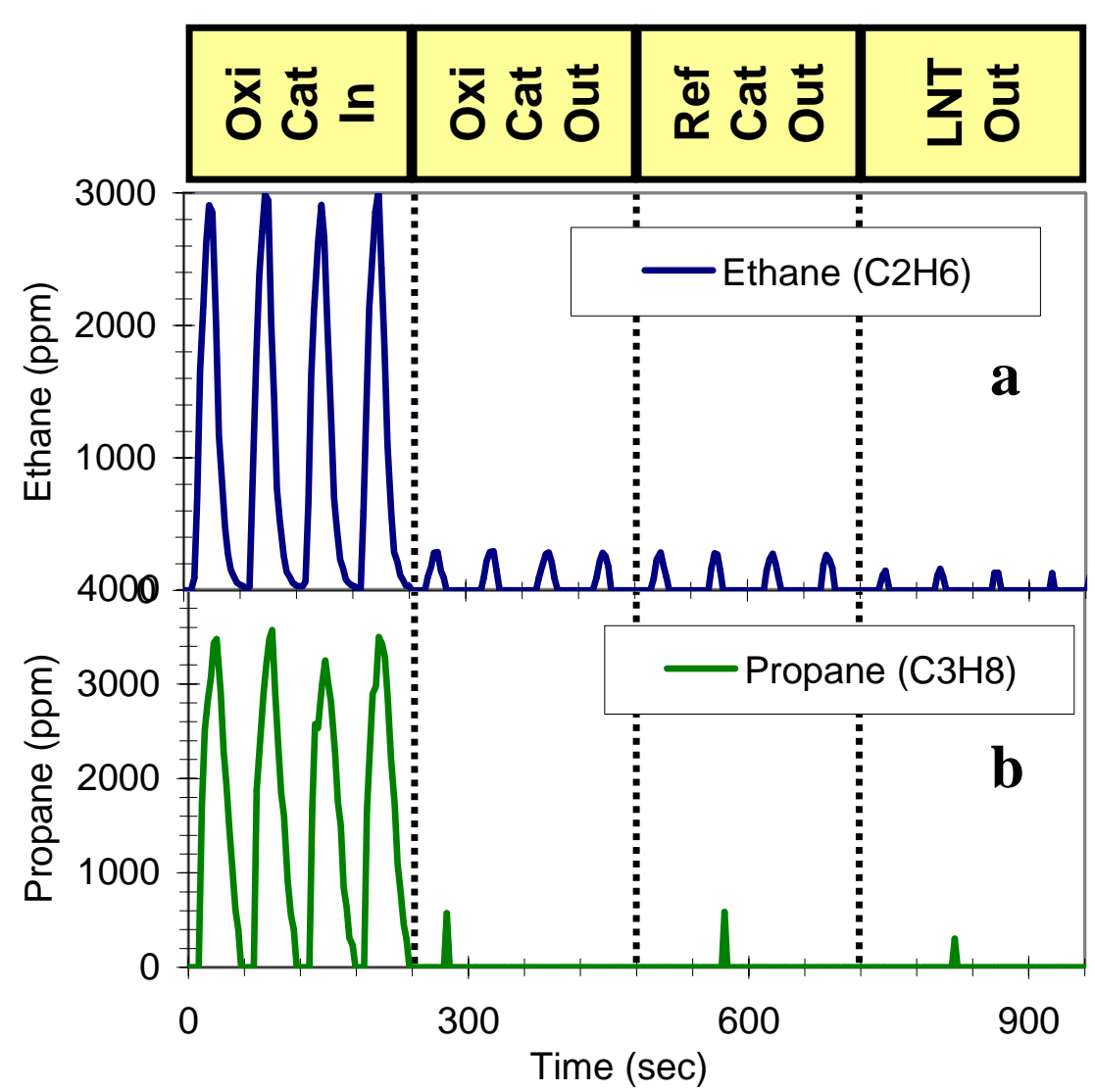

Figure 6-10. Example raw data showing (a) $\mathrm{C}_{2} \mathrm{H}_{6}$ and (b) $\mathrm{C}_{3} \mathrm{H}_{8}$ measured at Oxi Cat In, Oxi Cat Out, Ref Cat Out, and LNT Out sample positions in the catalyst system. The 60-second period of the signals is due to the 60-second lean-rich cycle for lean NOx trap operation; one tick on the $\mathrm{x}$-axis label represents 60 seconds.

In general, NMHCs are catalytically consumed in the LNT catalyst system. The catalytic consumption is effective for NMHCs emitted by the engine during combustion or generated during the regeneration process. Under conditions where excess fuel is injected into the catalyst system for regeneration, NMHC emissions downstream of the LNT can become significant, but under normal conditions, the catalysts control NMHCs effectively. 


\subsection{Summary}

Natural gas injected directly into exhaust can be utilized to regenerate lean NOx trap catalysts. The high methane content of natural gas requires catalytic treatment of the methane to generate suitable reductants for the lean NOx trap such as carbon monoxide and hydrogen. Characterization of exhaust samples obtained downstream of methane oxidation and reformer catalysts in a lean NOx trap system shows that carbon monoxide and hydrogen are produced at significant levels. Furthermore, after initial partial oxidation of methane by the oxidation catalysts, a significant amount of hydrogen is produced in reforming processes across the reformer catalyst. Both oxidation and reformer catalysts contribute significantly to the lean NOx trap regeneration process, and both processes are dependent on temperature.

Other gas species can become a concern during the regeneration process. In particular, ammonia and nitrous oxide were observed to be generated during lean NOx trap regeneration; however, their production can be minimized by minimizing reductant delivery which is consistent with minimization of fuel penalty. Non-methane hydrocarbons were also observed as products of the engine combustion process and from injection of natural gas for catalyst regeneration. In general, the catalysts were effective at reducing non-methane hydrocarbons to low levels at the tailpipe position.

The lean NOx trap catalyst technology must meet cost and durability targets for successful commercialization in lean natural gas engine applications. Based on the results presented here, the fuel requirements for catalyst operation are minimized by the fuel processing occurring on the oxidation and reforming catalysts in the system. Thus, optimization for minimal operating cost indicates the additional capital costs of the oxidation and reforming catalysts are worthwhile. 


\section{Durability}

\subsection{Catalyst Degradation Mechanisms}

There are many catalyst degradation mechanisms that affect the durability of catalysts in practice. An excellent review of the possible degradation mechanisms is given by Bartholomew. $^{23}$ A summary of Bartholomew's categories of catalyst degradation mechanisms including a brief description is given in Table 7-1 (Table 1 in Bartholomew reference ${ }^{23}$ ). For the application of interest here, catalysts for large stationary natural gas engines, different mechanisms will have different probabilities of occurring. Since natural gas engine exhaust does not contain significant particulate matter or liquid fuel components, fouling is not likely to occur at significant levels. Likewise, since the catalytic system is stationary and can be vibration isolated from the engine, attrition/crushing is not probable (in comparison to automotive applications). Vapor formation and vapor-solid and solid-solid reactions are unique chemical reactions that can occur under unique conditions, but these mechanisms are not likely to occur either. The most likely degradation mechanisms for lean NOx trap catalysts in stationary natural gas engine applications are thermal degradation and poisoning.

Table 7-1. Mechanisms of Catalyst Deactivation (Source: Bartholomew ${ }^{23}$ )

\begin{tabular}{|lll|}
\hline Mechanism & Type & Brief definition/description \\
\hline Poisoning & Chemical & $\begin{array}{l}\text { Strong chemisorption of species on catalytic sites, } \\
\text { thereby blocking sites for catalytic reaction }\end{array}$ \\
\hline Fouling & Mechanical & $\begin{array}{l}\text { Physical deposition of species from fluid phase onto the } \\
\text { catalytic surface and in catalyst pores }\end{array}$ \\
\hline Thermal degradation & Thermal & $\begin{array}{l}\text { Thermally induced loss of catalytic surface area, support } \\
\text { area, and active phase-support reactions }\end{array}$ \\
\hline Vapor formation & Chemical & $\begin{array}{l}\text { Reaction of gas with catalyst phase to produce volatile } \\
\text { compound }\end{array}$ \\
\hline $\begin{array}{l}\text { Vapor-solid and } \\
\text { solid-solid reactions }\end{array}$ & Chemical & $\begin{array}{l}\text { Reaction of fluid, support, or promoter with catalytic } \\
\text { phase to produce inactive phase }\end{array}$ \\
\hline Attrition/crushing & Mechanical & $\begin{array}{l}\text { Loss of catalytic material due to abrasion. Loss of } \\
\text { internal surface area due to mechanical-induced crushing } \\
\text { of the catalyst particle }\end{array}$ \\
\hline
\end{tabular}

Thermal degradation occurs when high temperatures induce migration and sintering of active components or when high temperatures cause surface area loss of the support material. Thermal degradation can occur slowly over time or rapidly under catastrophic high temperature exposure. Typical thermal degradation occurs slowly over time as catalysts are exposed to high temperatures. If the temperature range of exposure does not change over time, then degradation slows over time until an equilibrium state results on the catalyst. In general, the equilibrium state achieved still enables catalytic performance to occur, but the catalyst activity is less than for an unused or "fresh" catalyst. Thus, the partial loss of performance anticipated from thermal degradation due to exposure over time to normal operating temperatures is typically accounted for by engineering design of the system to account for the expected loss. Furthermore, as material development improvements are made, those improvements can be integrated into the catalyst product to reduce the thermal degradation.

A more severe thermal degradation issue is the catastrophic degradation that can occur if the catalyst is exposed to temperatures well above the normal operating range of the catalyst. In these cases, often the washcoat or support material can chemically break down, which causes a loss of surface area. The loss of washcoat surface area directly leads to loss in active component surface area and can lead to loss of washcoat adhesion, which results in attrition. The most likely 
scenario that would create catastrophic surface area loss is the dumping of fuel into the lean exhaust stream; such an event could create an exotherm on the catalyst which could result in catalyst temperatures well above the designed performance specifications. An engineering design of the engine and catalyst system that prevents large exotherm scenarios is critical to avoiding catastrophic thermal degradation.

Poisoning is another potentially damaging degradation mechanism for the lean NOx trap catalyst and will be the primary degradation mechanism investigated in this research. Sulfur is a well known catalyst poison. Sulfur is present in fuels and lubricants, and during the combustion process sulfur is converted to sulfur dioxide $\left(\mathrm{SO}_{2}\right)$. The effect of $\mathrm{SO}_{2}$ on catalytic performance varies for different catalysts and processes. The lean NOx trap catalyst system contains two catalytic processes that are extremely sensitive to sulfur poisoning: reforming and lean NOx catalysis. Reforming performance can degrade as sulfur compounds poison precious metal sites of catalytic activity. Typically, reforming occurs in a constant reducing environment; however, in the lean NOx trap catalyst system, the catalyst is cycled from lean to rich environment. Thus, an investigation into the effects of sulfur on partial oxidation and reforming is needed.

The effects of sulfur on lean NOx trap catalysts are well known and are quite severe. $\mathrm{SO}_{2}$ in the exhaust directly competes with NOx storage by adsorbing directly onto the active alkali/alkaline earth sorbate component and forming sulfate species. Once the sulfate species are formed, the site is inactive for NOx storage, and reversal of the sulfur poisoning is challenging since the sulfate species are more thermodynamically stable than the nitrate and carbonate species (see Figure 2-1).

When sulfur poisoning of lean NOx trap catalysts occurs, the degradation is proportional to the amount of sulfur exposure. Thus, since natural gas has less sulfur than other fuels such as gasoline and diesel, lean NOx trap catalysts are well suited for natural gas applications. However, the stationary power generation application demands long hours of operation and thereby large volumes of fuel use. Over time, the lean NOx trap catalyst is exposed to significant levels of sulfur, and sulfur poisoning of the lean NOx trap catalyst is the primary degradation mechanism of concern.

\subsection{Effect of Sulfur on Oxidation and Reformer Catalysts}

\subsubsection{Sulfur Exposure Experiment}

To determine the effects of sulfur on the durability of the oxidation and reformer catalysts, the catalysts were exposed to sulfur in controlled experiments. Sulfur exposure was performed by adding sulfur in the form of sulfur dioxide $\left(\mathrm{SO}_{2}\right)$ into the exhaust system; a bottled gas tank of $1 \% \mathrm{SO}_{2}$ in $\mathrm{N}_{2}$ was the $\mathrm{SO}_{2}$ source. The $\mathrm{SO}_{2}$ was added downstream of the engine turbocharger and downstream of an air-to-liquid heat exchanger in the exhaust system. The $\mathrm{SO}_{2}$ added to the system passed through a curved section of exhaust prior to entering the catalyst system; this allowed mixing of the $\mathrm{SO}_{2}$ to occur prior to catalyst exposure. Measurement of the $\mathrm{SO}_{2}$ in the exhaust was performed by sampling a small ( 1-2 liter/min) amount of exhaust just prior to the catalyst system. The concentration of $\mathrm{SO}_{2}$ was measured in chilled exhaust with an $\mathrm{SO}_{2}$ analyzer (Ametek Model 922). During the sulfur exposure experiments, the lean NOx trap catalysts were removed from the system; this study focused on the sulfur effects on the oxidation and reformer catalysts.

During the experiments, the engine load and speed were kept constant at $180 \mathrm{hp}$ or $134 \mathrm{~kW}$ ( $\sim 75 \%$ load) and $1800 \mathrm{rpm}$, respectively. The catalysts were cycled in a lean-rich manner typical of operation for a lean NOx trap system. The cycle parameters were held constant throughout the experiment; the cycle was composed of 45 seconds of lean operation (main exhaust flow through catalyst leg) and 15 seconds regeneration that included transition of the exhaust control valves (main exhaust flow through bypass leg with catalyst leg becoming rich for LNT regeneration). 
Thus, each cycle lasted 1 minute total. The space velocity of the exhaust for the oxidation and reformer catalysts varied during the lean-rich cycle. During lean operation with full exhaust flow the space velocity was $102,000 / \mathrm{hr}$ for each catalyst, but during the lower flow rich operation, the space velocity was $7,000 / \mathrm{hr}$ for each catalyst. The rich mode exhaust flow was determined by measuring $\mathrm{O}_{2}$ dilution during addition of a known flow rate of $\mathrm{N}_{2}$ to the exhaust. During the 15 second regeneration period, fuel was injected into the catalyst chamber upstream of the oxidation catalyst for 10 seconds; the remaining time allowed the fuel to be purged from the catalyst chamber prior to the influx of lean exhaust. A small flow of exhaust from the engine passed through the catalyst chamber during regeneration which carried the injected fuel through the catalysts. Flow of fuel through the injectors was controlled to attain a target excess air ratio $(\lambda)$ of 0.75 during the regeneration period; $\lambda$ was monitored with UEGO sensors in the system. In general, the catalysts were cycled before, during, and after $\mathrm{SO}_{2}$ exposure; however, some periods of lean only operation were purposely practiced to determine if lean vs. rich operation allows recovery of lost performance due to $\mathrm{SO}_{2}$ exposure.

The flow of $\mathrm{SO}_{2}$ was controlled to attain different levels of additional $\mathrm{SO}_{2}$ exposure: concentrations of 3,15 , and $40 \mathrm{ppm} \mathrm{SO}_{2}$ entering the catalyst system. Here the term "additional $\mathrm{SO}_{2}$ exposure" points out that a small level $(<1 \mathrm{ppm})$ of $\mathrm{SO}_{2}$ is already in the exhaust due to sulfur in the fuel and oil. It is important to note that the levels of $\mathrm{SO}_{2}$ artificially imposed in this study are much greater than typical levels of $\mathrm{SO}_{2}$ experienced in natural gas engine applications. The higher $\mathrm{SO}_{2}$ levels were used to accelerate any effects from sulfur so that those effects could be measured practically in a controlled experiment. The exposure times varied but were less than 1 hour. Originally, longer exposure times were planned, but it was observed that reactions to $\mathrm{SO}_{2}$ exposure were rapid with performance quickly approaching steady-state conditions. Thus, experiments focused on characterizing the reaction of the catalysts to the $\mathrm{SO}_{2}$ exposure until steady-state conditions occurred. Then, after $\mathrm{SO}_{2}$ exposure was complete, the performance of the catalysts was again monitored to determine if recovery from the negative effects of $\mathrm{SO}_{2}$ exposure would occur.

Catalyst temperatures were controlled with the upstream air-to-liquid heat exchanger and were generally stable during the experiments. Typically, the average oxidation and reformer catalyst temperatures were between 520 and $525^{\circ} \mathrm{C}$. Note that during the catalyst cycle, the catalyst temperature fluctuated due to exotherms produced as fuel was oxidized over the catalyst in the transition from lean to rich conditions. A typical range of temperatures experienced by the catalysts during a cycle was typically $514-536^{\circ} \mathrm{C}$ for the oxidation catalyst and $518-533^{\circ} \mathrm{C}$ for the reformer catalyst; here the oxidation temperature range is greater since more fuel is oxidized over the oxidation catalyst. For the $40-\mathrm{ppm} \mathrm{SO}_{2}$ exposure, a second catalyst temperature range was used with average oxidation and reformer catalyst temperatures of 460 to $465^{\circ} \mathrm{C}$; in this case, typical ranges of temperature were $455-473^{\circ} \mathrm{C}$ and $458-470^{\circ} \mathrm{C}$ for the oxidation and reformer catalysts, respectively.

\subsubsection{Results}

Reactions of the oxidation and reformer catalyst performance to a typical $\mathrm{SO}_{2}$ exposure experiment are shown in Figure 7-1 which shows data from 15-ppm $\mathrm{SO}_{2}$ exposure. Peak $\mathrm{CO}$ and $\mathrm{H}_{2}$ downstream of the oxidation and reformer catalysts are plotted vs. time in minutes, which is also equivalent to the number of cycles (since each cycle lasted one minute); the peak concentrations of the reductant species are shown in this graph. The phases of the exposure include a pre- $\mathrm{SO}_{2}$ phase, the 15-ppm $\mathrm{SO}_{2}$ exposure, a lean period, and a recovery period with lean-rich cycling but no $\mathrm{SO}_{2}$ added. During all phases, the engine load and speed were kept constant at $75 \%$ and $1800 \mathrm{rpm}$, respectively. During the pre- $\mathrm{SO}_{2}$ phase, the catalysts were cycled with the parameters detailed above; the parameters are typical of normal cycling during

lean NOx trap system operation. At time $=20$ minutes, the flow of $\mathrm{SO}_{2}$ at a 15 -ppm concentration 
began, and immediately, the oxidation and reforming processes lost efficiency due to the $\mathrm{SO}_{2}$ exposure. After approximately 10 cycles/minutes, the performance had decreased to a steadystate level and did not change with additional $\mathrm{SO}_{2}$ exposure time. At this point (time $=70$ minutes), the $\mathrm{SO}_{2}$ exposure was stopped, and the catalyst was left in a lean (oxygen rich) state to determine if $\mathrm{SO}_{2}$ chemisorbed on the catalyst would desorb under lean conditions with exhaust flowing over the catalysts. Then, after 30 minutes, lean-rich cycling was restarted without $\mathrm{SO}_{2}$ addition; this phase is called "recovery" since performance does recover here. No recovery of lost performance due to $\mathrm{SO}_{2}$ exposure was observed after the 30 minute lean period based on the performance at the initiation of the lean-rich cycling at time $=100$ minutes. However, during the lean-rich cycling of the recovery phase, reductant concentration rose, and performance did recover. All of the initial performance was recovered within the experimental precision. The fact that the recovery occurred during lean-rich cycling but not during lean operation suggests that $\mathrm{SO}_{2}$ is being desorbed from the catalysts during rich operation (most likely in the form of $\mathrm{H}_{2} \mathrm{~S}$ ). The Ref Cat Out $\mathrm{H}_{2}$ data suggest that performance after recovery was actually higher than the pre- $\mathrm{SO}_{2}$ level; however, the lower initial results were most likely due to an incomplete recovery from the previous experiment conducted with 40-ppm $\mathrm{SO}_{2}$ exposure on the previous day (recovery from 40-ppm exposure is apparently slower as discussed below).

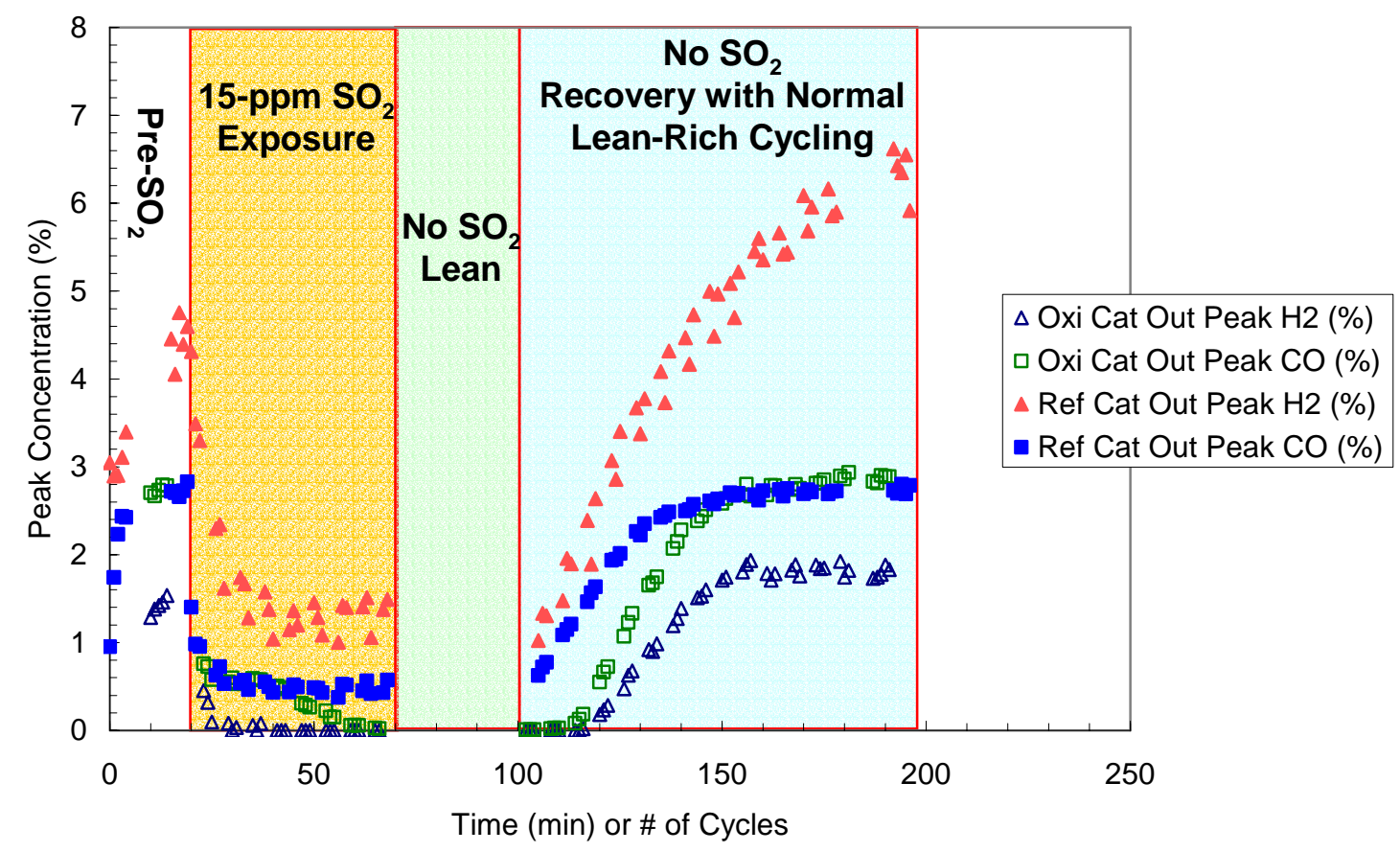

Figure 7-1. $\mathrm{CO}$ and $\mathrm{H}_{2}$ as a function of time and cycles before, during, and after exposure to $15 \mathrm{ppm}$ $\mathrm{SO}_{2}$.

Data from exposure to $3 \mathrm{ppm} \mathrm{SO}_{2}$ (shown in Figure 7-2) followed a similar pattern to the 15ppm data. Again, $\mathrm{CO}$ and $\mathrm{H}_{2}$ downstream of the oxidation and reformer catalysts are shown as a function of time. During $\mathrm{SO}_{2}$ exposure, performance degraded to a steady-state level. No significant recovery in performance was observed in the following lean period, but once lean-rich cycling was commenced without $\mathrm{SO}_{2}$ addition, recovery in performance was observed. Thus, the same general pattern was observed for both the 15-ppm and 3-ppm $\mathrm{SO}_{2}$ data: performance degradation to a steady-state level during $\mathrm{SO}_{2}$ exposure followed by performance recovery during lean-rich cycling without $\mathrm{SO}_{2}$ addition. The differences in the data from 15-ppm and 3-ppm $\mathrm{SO}_{2}$ exposure were the rate of change in performance and the level of steady-state performance attained. In general, the degradation rate was slower and the recovery rate was faster for the 
lower (3-ppm) $\mathrm{SO}_{2}$ exposure. In addition, the steady-state level of performance attained after exposure was generally higher (greater reductant concentration) for lower level $\mathrm{SO}_{2}$ exposure. Thus, the qualitative nature of the $\mathrm{SO}_{2}$ poisoning is similar for different $\mathrm{SO}_{2}$ concentrations, but the quantitative results for rates of change and performance levels differed.

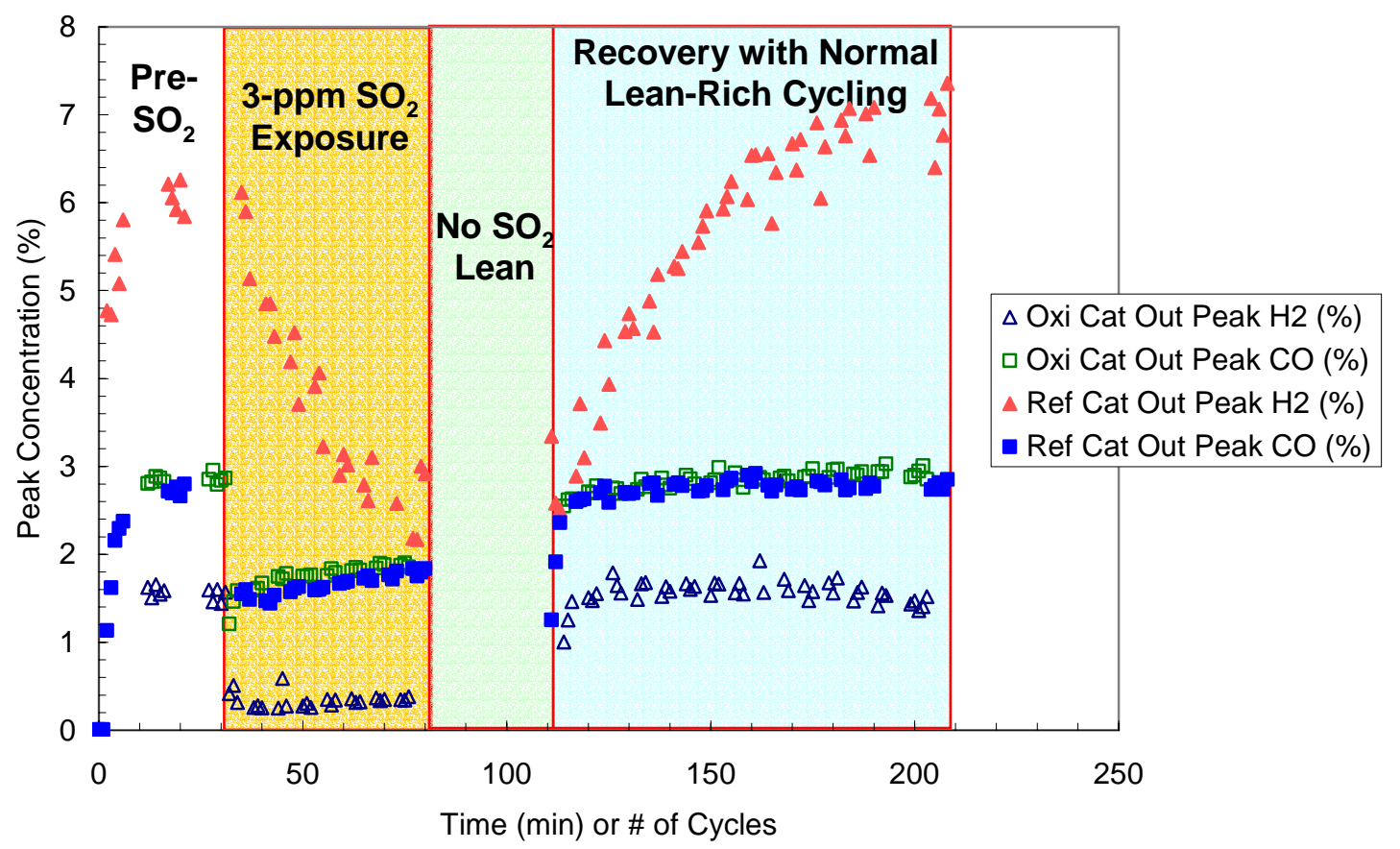

Figure 7-2. $\mathrm{CO}$ and $\mathrm{H}_{2}$ as a function of time and cycles before, during, and after exposure to $3 \mathbf{p p m}$ $\mathrm{SO}_{2}$.

Another interesting finding from the 3-ppm $\mathrm{SO}_{2}$ data shown in Figure 7-2 relates to the comparative degradation and recovery rates among sample position and reductant type. The decrease in $\mathrm{CO}$ and $\mathrm{H}_{2}$ downstream of the oxidation catalyst was very rapid. For the reformer catalyst, $\mathrm{CO}$ decreased rapidly, but $\mathrm{H}_{2}$ degradation occurred at a relatively slower rate. Likewise, during recovery, $\mathrm{H}_{2}$ at the reformer catalyst out position again occurred at the slowest rate. The cause of the slower reaction of the reformer catalyst out $\mathrm{H}_{2}$ data is confounded by the fact that the reforming chemistry (Equation 2-5, Equation 2-6, and Equation 2-7) must follow the oxidation reactions (Equation 2-3 and Equation 2-4). The rate of recovery of performance is an even stronger function of $\mathrm{SO}_{2}$ concentration during $\mathrm{SO}_{2}$ exposure when comparing results for 3-, 15-, and 40-ppm $\mathrm{SO}_{2}$ (Figure 7-3). The effect does not appear to be linear as the 40-ppm $\mathrm{SO}_{2}$ concentration performance takes much longer to recover from the $\mathrm{SO}_{2}$ exposure. 


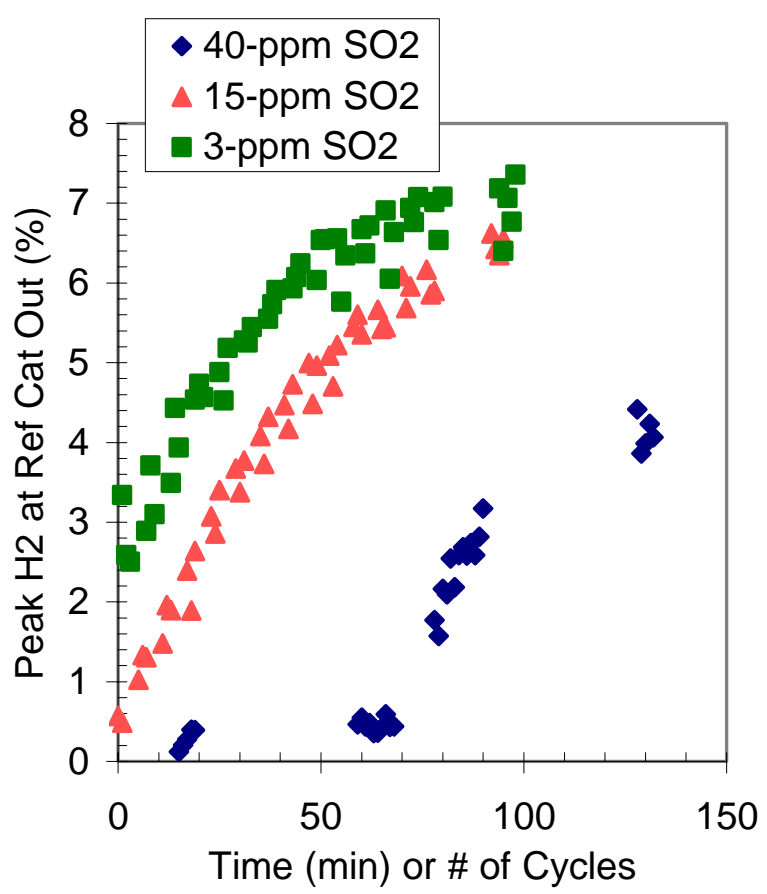

Figure 7-3. Recovery of $\mathrm{H}_{2}$ downstream of the reformer catalyst after exposure to $\mathrm{SO}_{2}$.

A comparison of data from all levels of $\mathrm{SO}_{2}(3,15$, and $40 \mathrm{ppm})$ is shown in Figure 7-4 for the $520^{\circ} \mathrm{C}$ catalyst temperature. The results show that recovery occurs for all concentrations of $\mathrm{SO}_{2}$ used during exposure. There is slightly less $\mathrm{H}_{2}$ for the $40-\mathrm{ppm}^{\mathrm{SO}} \mathrm{O}_{2}$ reformer catalyst out case (Figure 7-4.d.); however, the performance was still increasing at the end of the data collection. The 40-ppm $\mathrm{SO}_{2}$ case did not show any significantly interesting effects in comparison to the 3- and 15-ppm cases. Degradation was essentially complete for the 40-ppm case, but recovery did occur.
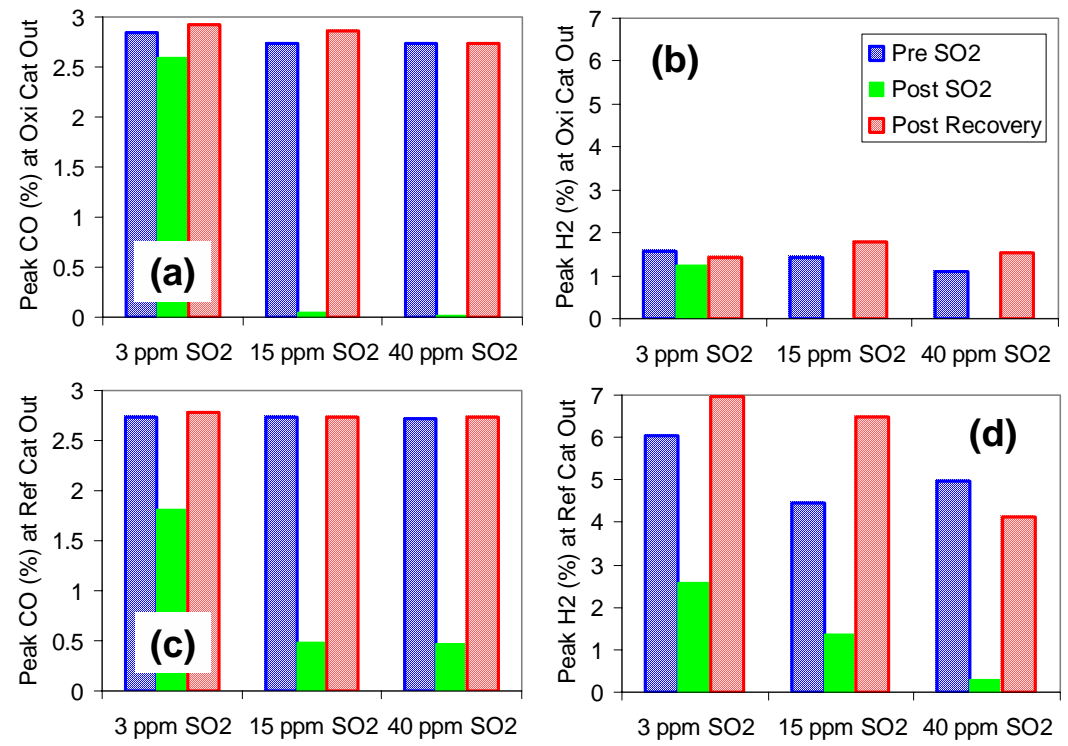

Figure 7-4. Comparison of pre-SO ${ }_{2}$, post- $\mathrm{SO}_{2}$, and post-recovery reductant concentrations for 3-, 15, and 40-ppm $\mathrm{SO}_{2}$ exposure experiments; peak reductant concentrations shown for (a) Oxi Cat Out CO, (b) Oxi Cat Out $\mathrm{H}_{2}$, (c) Ref Cat Out CO, and (d) Ref Cat Out $\mathrm{H}_{2}$. 
Figure 7-5 shows a comparison of data from $40 \mathrm{ppm} \mathrm{SO}_{2}$ exposure for two catalyst temperatures: 460 and $520^{\circ} \mathrm{C}$. The results show that complete recovery does occur after lean-rich cycling in the recovery phase regardless of the catalyst temperature. The oxidation and reforming processes have different efficiencies for the two different temperatures, but both temperatures show recovery of performance occurring. Degradation for the lower temperature case where the partial oxidation is less efficient even for the cases without $\mathrm{SO}_{2}$ was significant enough to result in no reductant production downstream of the reformer catalyst.
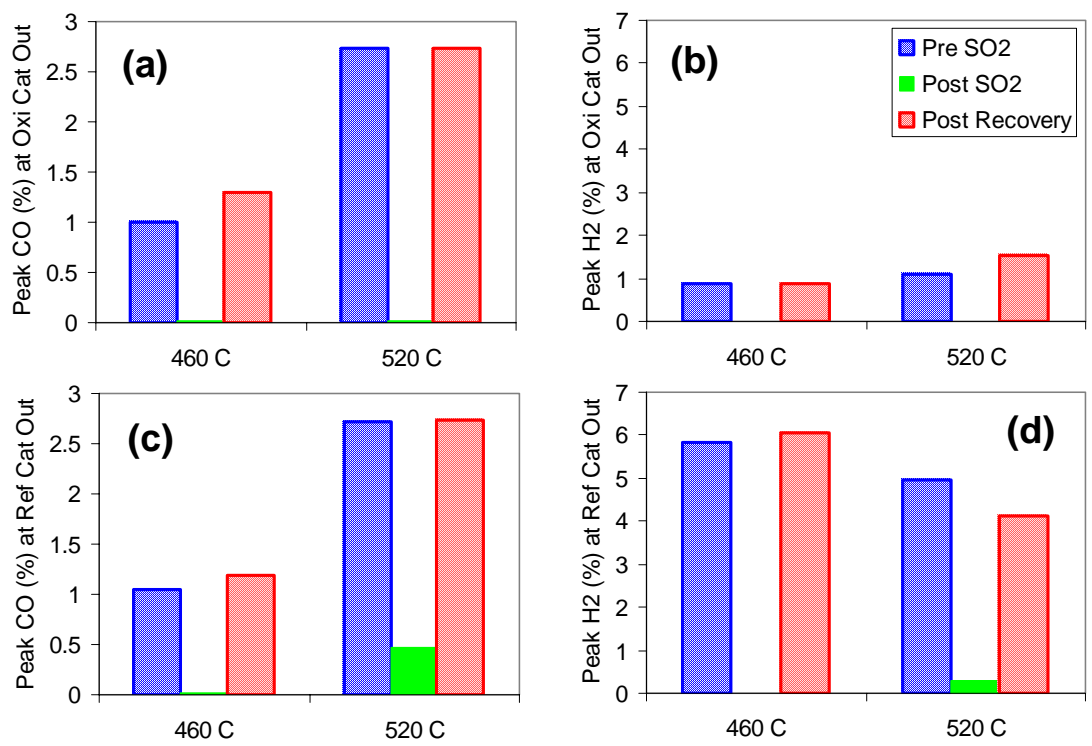

Figure 7-5. Comparison of pre-SO ${ }_{2}$, post- $\mathrm{SO}_{2}$, and post-recovery reductant concentrations for 460 and $520^{\circ} \mathrm{C}$ catalyst temperatures for $40-\mathrm{ppm} \mathrm{SO}_{2}$ exposure; peak reductant concentrations shown for (a) Oxi Cat Out CO, (b) Oxi Cat Out $\mathrm{H}_{2}$, (c) Ref Cat Out CO, and (d) Ref Cat Out $\mathrm{H}_{2}$.

\subsubsection{Discussion: Implications of the Results}

The results for different $\mathrm{SO}_{2}$ concentrations consistently showed that degradation of oxidation and reforming processes occurs with $\mathrm{SO}_{2}$ exposure, but full recovery also occurs during normal lean-rich cycling once $\mathrm{SO}_{2}$ exposure is stopped. It is worth repeating that the $\mathrm{SO}_{2}$ concentrations used in these studies were orders of magnitude higher than $\mathrm{SO}_{2}$ concentrations commonly found in natural gas engine exhaust. Sulfur levels in natural gas fuel are typically less than $10 \mathrm{ppm}$, and since fuel and air are mixed in the combustion process, $\mathrm{SO}_{2}$ levels in exhaust are typically $<1$ $\mathrm{ppm}$ (including contributions from sulfur in combusted oil). At these low levels of $\mathrm{SO}_{2}$, degradation from sulfur poisoning is unlikely to be significant as long as the catalysts are cycled in a lean-rich fashion since the rich operation causes any accumulated sulfur poisons to be released.

For applications where higher levels $(>1 \mathrm{ppm})$ of sulfur are present in the natural gas (for example, gas compression engines at an oil field), the effect of sulfur will be dependent on the magnitude of $\mathrm{SO}_{2}$ in the exhaust with increasing $\mathrm{SO}_{2}$ content causing a decrease in catalytic performance. Brief exposure to high $\mathrm{SO}_{2}$ concentrations can be tolerated since the lean-rich cycling is continually removing sulfur from the catalysts as well. Actual performance will be determined by the steady-state equilibrium established by the quantity of $\mathrm{SO}_{2}$ in the exhaust and the rate at which the $\mathrm{SO}_{2}$ is removed from the catalysts by the periodic rich operation. In cases where oxidation and reformer catalyst performance is not sufficient, partial oxidation of methane by operating a reciprocating engine rich is a possible replacement technique; however, at $\mathrm{SO}_{2}$ levels where the oxidation and reformer catalysts do not perform well, the lean NOx trap catalyst is likely to suffer even greater performance loss. 
In the lean NOx trap application where the oxidation and reformer catalysts are cycled between lean and rich conditions, the sulfur exposure effect is primarily dependent on the concentration of sulfur exposure as opposed to the total mass of sulfur exposure. In contrast, typical reformer catalyst applications, where the catalyst is operated continuously under rich conditions, experience degradation primarily proportional to the total mass of sulfur exposure (regardless of sulfur concentration). The lean-rich cycle changes the rich-only model by enabling oxidation of chemisorbed sulfur species $\left(\mathrm{H}_{2} \mathrm{~S}, \mathrm{COS}\right.$, etc.) over the catalyst during lean operation and reduction and release of chemisorbed sulfur species $\left(\mathrm{SO}_{2}\right)$ during lean operation. The kinetics of these oxidation and reduction reactions dictates the amount of sulfur removal from the catalyst and becomes a factor in the overall sulfur accumulation rate under lean-rich cycling. Thus, the accumulated mass of sulfur exposure is still a primary factor but is primarily determined by the rate of sulfur accumulation (concentration dependent) and the rate of sulfur release (kinetic dependent).

\subsubsection{Summary}

Studies related to the durability of a lean NOx trap catalyst system were conducted on a lean natural gas reciprocating engine platform. Experiments focused on the effect of sulfur on the oxidation and reformer catalysts of the lean NOx trap system. The catalysts were exposed to $\mathrm{SO}_{2}$ at different concentrations, and the ability of the catalysts to produce $\mathrm{CO}$ and $\mathrm{H}_{2}$ reductants through partial oxidation of methane and reforming processes was characterized.

Upon exposure to $\mathrm{SO}_{2}$, a rapid loss in reductant production occurred; however, once $\mathrm{SO}_{2}$ exposure was stopped, performance recovered to initial levels under normal lean-rich cycling conditions. The recovery occurs during rich operation since no recovery was observed after lean operation. Similar effects were observed for different levels of $\mathrm{SO}_{2}$ during exposure, but the magnitude of the effects varied. Performance during $\mathrm{SO}_{2}$ exposure decreased to a steady-state level of performance; higher levels of steady-state performance were associated with lower levels of $\mathrm{SO}_{2}$ concentration during exposure.

The results indicate that sulfur will not significantly affect the critical oxidation and reforming processes for most applications where low levels $(<1 \mathrm{ppm})$ of sulfur occur and the catalysts are cycled in a lean-rich manner typically associated with lean NOx trap catalysts. For higher levels of sulfur that may be experienced in some applications, performance of the oxidation and reformer catalysts may be hampered with the magnitude of the effect proportional to the level of sulfur in the exhaust, but the effect should not be permanent with performance recovering once sulfur levels decrease. These results specifically address the oxidation and reformer catalyst portions of the lean NOx trap system; the effect of sulfur on lean NOx trap catalyst durability is severe and will need to be addressed in future work.

\subsection{Mitigation of Sulfur Effects on Lean NOx Trap Catalysts}

In general there are three process-based strategies for mitigating degradation from sulfur poisoning of the lean NOx trap catalyst: reduction of sulfur exposure, desulfation, and sorbate reapplication. The first strategy, reduction of sulfur exposure, is to minimize the amount of sulfur entering the exhaust system. Sources of sulfur include fuel and oil. The sulfur in the oil is critical to oil performance, but control of oil systems to minimize oil combustion will reduce sulfur from the oil source. Natural gas fuels have varying levels of sulfur depending on their source and processing. While natural gas from oil fields contains larger amounts of sulfur present in the oil well, commercial natural gas supply tends to have low amounts of sulfur content, and typically, the sulfur-based odorant added to natural gas is the primary sulfur-containing component. Thus, reducing the odorant additive concentration can reduce sulfur in the fuel.

Another technique practiced in automotive applications for minimizing degradation from sulfur poisoning is desulfation. Desulfation is a process that removes the sulfur from the sorbate 
component and renews the site for NOx storage. Since the sulfate species are more thermodynamically stable, reduction of the catalyst under higher catalyst temperatures is required to remove the sulfur. The exposure to higher temperatures can cause thermal degradation to occur. Since the catalyst system is much larger in the stationary natural gas application, control of catalyst temperatures would be difficult; thus, desulfation was not considered for this research study.

The third technique for minimizing degradation from sulfur poisoning is sorbate reapplication. Sorbate reapplication is a catalyst service that is conducted at intervals after significant sulfur exposure occurs. The lean NOx trap catalyst is removed from the system and the sulfur poisoned sorbate sites are removed in an aqueous based solution. Then, new sorbate component is added. Such a technique is also referred to as "washing" in the catalyst industry. The sorbate reapplication is a low cost service that does not affect the precious metal component of the catalyst significantly; the technique is practiced commercially on natural gas turbine applications. Research of the effectiveness of sorbate reapplication for natural gas reciprocating engine applications will be presented here.

\subsubsection{Sorbate Reapplication Procedure}

The lean NOx trap catalysts were treated with aqueous-based solutions to remove and reapply the K sorbate component. Often in the industry, aqueous-based processes for servicing catalysts are referred to as "washing" or "wash" procedures. The first step in the sorbate reapplication procedure was sorbate removal. The catalysts were submerged in deionized $\mathrm{H}_{2} \mathrm{O}$ for 15 minutes; then, the catalysts were drained and the excess $\mathrm{H}_{2} \mathrm{O}$ was removed. The $\mathrm{H}_{2} \mathrm{O}$ wash was repeated three times to ensure that all of the $\mathrm{K}$ compounds were removed. After sorbate removal, the new $\mathrm{K}$ sorbate was applied by submerging the catalysts in a $\mathrm{K}_{2} \mathrm{CO}_{3}$ solution. The concentration of the $\mathrm{K}_{2} \mathrm{CO}_{3}$ solution was $10 \%$ by mass, and the catalysts were submerged in the solution for 17 minutes. After the soak in the $\mathrm{K}_{2} \mathrm{CO}_{3}$ solution, the catalysts were drained and excess solution was removed. The catalysts were allowed to dry in room conditions for more than 24 hours prior to use. During the drying process, the $\mathrm{K}_{2} \mathrm{CO}_{3}$ is left on the catalyst to form the active component for NOx adsorption.

\subsubsection{Experiment Design}

The basic outline of the experiment was to characterize the lean NOx trap catalysts prior to sulfur exposure, after sulfur exposure, and after sorbate reapplication. To begin the study, lean NOx trap catalysts that had been used previously in engine experiments were processed with the sorbate reapplication procedure. The choice of catalysts with an engine exhaust exposure history was made in order to isolate the sulfur and sorbate reapplication effects which were the focal points of the study. Since the catalysts had already been exposed to engine exhaust and the thermal cycling associated with operation of a lean NOx trap, the catalysts were degreened and slightly aged on the engine, and the precious metal active surface area had stabilized. The sorbate reapplication procedure should have minimal impact on the precious metal component of the catalysts; so, use of the pre-aged catalysts insured that any changes observed in the performance would be due to the sulfur poisoning and sorbate changes.

The performance of the lean NOx trap catalysts was characterized prior to sulfur exposure. Various operational conditions were employed to characterize the lean NOx trap performance. Specific details of the characterization will be given in parallel with the results which will be shown below.

The catalysts were exposed to sulfur in a controlled manner by adding $\mathrm{SO}_{2}$ from a bottle gas source to the exhaust upstream of the catalysts. The source of $\mathrm{SO}_{2}$ was $1 \% \mathrm{SO}_{2}$ in a $\mathrm{N}_{2}$ balance. The flow of $\mathrm{SO}_{2}$ gas was controlled to obtain a level of 3.0-3.5 ppm $\mathrm{SO}_{2}$ in the exhaust which is a level at least one order of magnitude higher than levels commonly found in natural gas engine 
exhaust. During the sulfur exposure, the engine speed and load were held constant at $1800 \mathrm{rpm}$ and $200 \mathrm{hp}(149 \mathrm{~kW})$, respectively, and the catalyst system was operated in four different modes. The four modes of operation for the catalyst system consisted of two lean-rich cycle conditions and two exhaust temperatures controlled by the heat exchanger. These four modes of operation provided a duty-cycle simulation for the sulfur exposure and allowed the performance of the catalysts to be monitored during the exposure process at different operating conditions. The details of the four modes of operation will be given in parallel with the results which will be shown below.

The catalysts were exposed to sulfur for a total of 348 minutes. Over the course of the exposure, the pressure drop in the bottled gas of $1 \% \mathrm{SO}_{2}$ was monitored. The total $\mathrm{S}$ consumed was determined to be $23.5 \mathrm{~g}$ based on the tank volume and pressure loss in the tank. In comparison, the $\mathrm{S}$ exposure can also be calculated based on the concentration of $\mathrm{SO}_{2}$ measured in the exhaust and the exhaust flow. Using $3.25 \mathrm{ppm} \mathrm{SO}_{2}$ (the middle of the controlled range) and an exhaust flow of 14,273 slpm (determined by intake air flow measurement and measured air-tofuel ratio with a universal exhaust gas oxygen sensor), a $\mathrm{S}$ exposure of $23.0 \mathrm{~g}$ was calculated with this method. Both measurements agree well.

After sulfur poisoning occurred, the performance of the lean NOx trap catalysts were characterized again with the same techniques and parameters used before. Then, the lean NOx trap catalysts were removed from the system, and the sorbate component was reapplied with the procedure described above. After the sulfur exposure and after the sorbate reapplication, small core samples were collected from the catalysts for future evaluation of physical properties. The overall volume of catalyst samples collected was negligible compared with the total volume of catalysts in the system. After sorbate reapplication, the catalysts were reinstalled in the exhaust system, and again, the performance of the lean NOx trap catalysts were characterized with the same techniques and parameters.

\subsubsection{Results}

The lean NOx trap catalyst can adsorb more than $90 \%$ of the NOx emitted by the engine, but as the catalyst sorption sites are filled with NOx the trapping efficiency decreases. Typical data from lean NOx trap operation are shown in Figure 7-6. NOx concentration changes as a function of time as the catalyst is filled with NOx. The analyzed exhaust gas was sampled downstream of the catalyst system ("Sys Out" in Figure 3-1); at this sample location, the exhaust is primarily engine out exhaust during catalyst regeneration. During the sorption phase of the lean NOx cycle process, the engine exhaust flows through the catalyst only, and the system out NOx concentration is reduced. Figure 7-6 shows three cycles of the lean NOx trap at $1800 \mathrm{rpm}$ and $200 \mathrm{hp}$ (about $75 \%$ of max load at $1800 \mathrm{rpm}$ ); the sorption phase of the cycle is 60 seconds. The catalyst temperature was approximately $460^{\circ} \mathrm{C}$ at this point. The shaded regions represent the regeneration phase where engine exhaust is bypassed around the lean NOx trap. During these phases the NOx concentration is approximately $100 \mathrm{ppm}$. The NOx profiles for the sorption phase of operation show the characteristic loading curve of the lean NOx trap. Initially, right after regeneration, the NOx levels are low; then, as the catalyst sites become filled with NOx, the system out NOx levels rise. Since the lean NOx trap brings the NOx concentration levels down to less than $10 \mathrm{ppm}$, the NOx trapping efficiencies are $>90 \%$. 


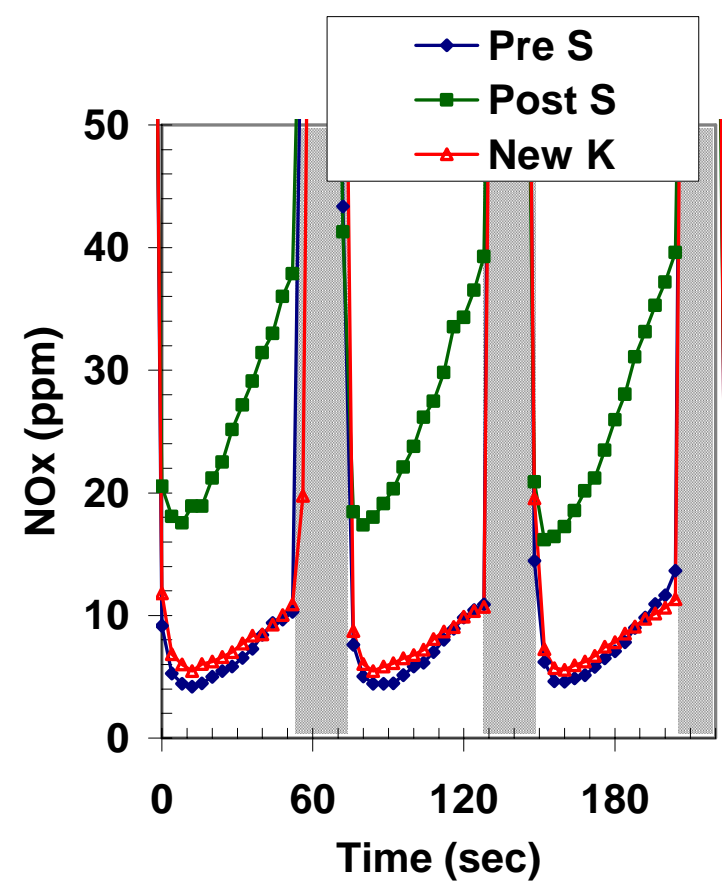

Figure 7-6. NOx sorption profiles for the lean NOx trap catalyst before and after sulfur exposure and after new sorbate has been applied. The shaded regions represent regeneration phases.

Three curves are shown in Figure 7-6 representing specific points in the study. The "Pre S" data show the NOx performance prior to the sulfur exposure. The "Post S" data show the NOx performance after sulfur exposure. Finally, the "New K" data show the NOx performance after new K sorbate has been applied with the sorbate reapplication process described above. The NOx performance exhibited by the catalyst prior to sulfur exposure (Pre S) is excellent with $>90 \%$ NOx reduction demonstrated. After sulfur exposure (Post S), the NOx performance decreases as more NOx slips through the catalyst; however, note that the catalyst is still functioning with the regeneration process continuing to renew the catalyst for more NOx trapping. After the sorbate has be reapplied (New K), the original NOx performance is attained again; the performance under these operational conditions is very similar for the Pre S and New K states.

NOx concentration data shown in Figure 7-6 are analyzed to obtain the cycle-based "NOx reduction efficiency" which is defined as the percentage of NOx entering the catalyst over a complete catalyst sorption regeneration cycle that is reduced to $\mathrm{N}_{2}$. A related value is the "peak NOx reduction efficiency" and is defined as the maximum instantaneous NOx reduction from engine out NOx levels that occurs over a single catalyst cycle.

Figure 7-7 and Figure 7-8 show the cycle-based NOx reduction efficiency and the peak NOx reduction efficiency per cycle for the four modes of operation of the lean NOx trap catalyst during the experiment. In all cases, the engine was operated at a steady state speed and load of $1800 \mathrm{rpm}$ and $200 \mathrm{hp}(149 \mathrm{~kW})$, respectively. The operation modes differed in the sorption phase period of catalyst operation and the catalyst temperature as controlled by the upstream heat exchanger. The combinations of these variables were: 30 second sorption period at $520^{\circ} \mathrm{C}$ catalyst temperature, 60 second sorption period at $520^{\circ} \mathrm{C}$ catalyst temperature, 60 second sorption period at $460^{\circ} \mathrm{C}$ catalyst temperature, and 30 second sorption period at $460^{\circ} \mathrm{C}$ catalyst temperature. Here the catalyst temperature reported was measured with a Type $\mathrm{K}$ thermocouple inserted into the first lean NOx trap catalyst monolith. Temperatures fluctuated with time as the catalyst cycled; the temperatures listed are cycle-average temperatures. The catalyst capacity for NOx storage is higher at $520^{\circ} \mathrm{C}$ vs. $460^{\circ} \mathrm{C}$; so, the $520^{\circ} \mathrm{C}$ temperature points are more challenging. 
Since longer sorption periods require more NOx storage by the catalyst, the longer 60 second sorption periods are more challenging.

The period in the study where sulfur exposure occurred and the point where new sorbate was reapplied to the catalysts are noted in Figure 7-7 and Figure 7-8. NOx performance for all modes is relatively stable prior to sulfur exposure and after sorbate reapplication as expected. During sulfur exposure, the NOx performance degrades over time. The degree of degradation is different for each mode of operation. The $520^{\circ} \mathrm{C}$ modes showed a larger loss in performance relative to the $460^{\circ} \mathrm{C}$ modes as the sulfur poisoning of storage sites was more severe for the lower NOx capacity at the higher temperature. The sorption period had a much smaller effect on the degradation magnitude as both the 30 and 60 second cycles degraded at similar rates and with similar magnitudes of lost performance.

After sulfur exposure stopped, performance increased slightly, which may have been due to desulfation of the upstream oxidation and reforming catalysts. As shown above the oxidation and reforming catalytic processes are impacted by sulfur exposure but recover through desulfation processes. The recovery of oxidation and reforming efficiency leads to more reductant supply to the lean NOx trap catalyst which can improve regeneration of the catalyst for more NOx storage.

The profile of performance loss as a function of sulfur exposure time is similar for the cycle average NOx reduction efficiency (Figure 7-7) and the peak NOx reduction efficiency (Figure 7-8), but the peak NOx reduction efficiency does not decrease to the same level. The degree of sulfation that is tolerable is dependent on the emission regulation that is required.

The sorbate reapplication was effective at restoring the lost performance. The level of NOx reduction after sorbate reapplication is essentially the same as the performance prior to sulfur exposure for the four modes examined. To analyze the performance over the course of study more closely, experiments were conducted at various points in the study to more broadly measure NOx performance of the catalysts. In these examinations, important differences were discovered that are not apparent from the four mode data shown in Figure 7-7 and Figure 7-8.

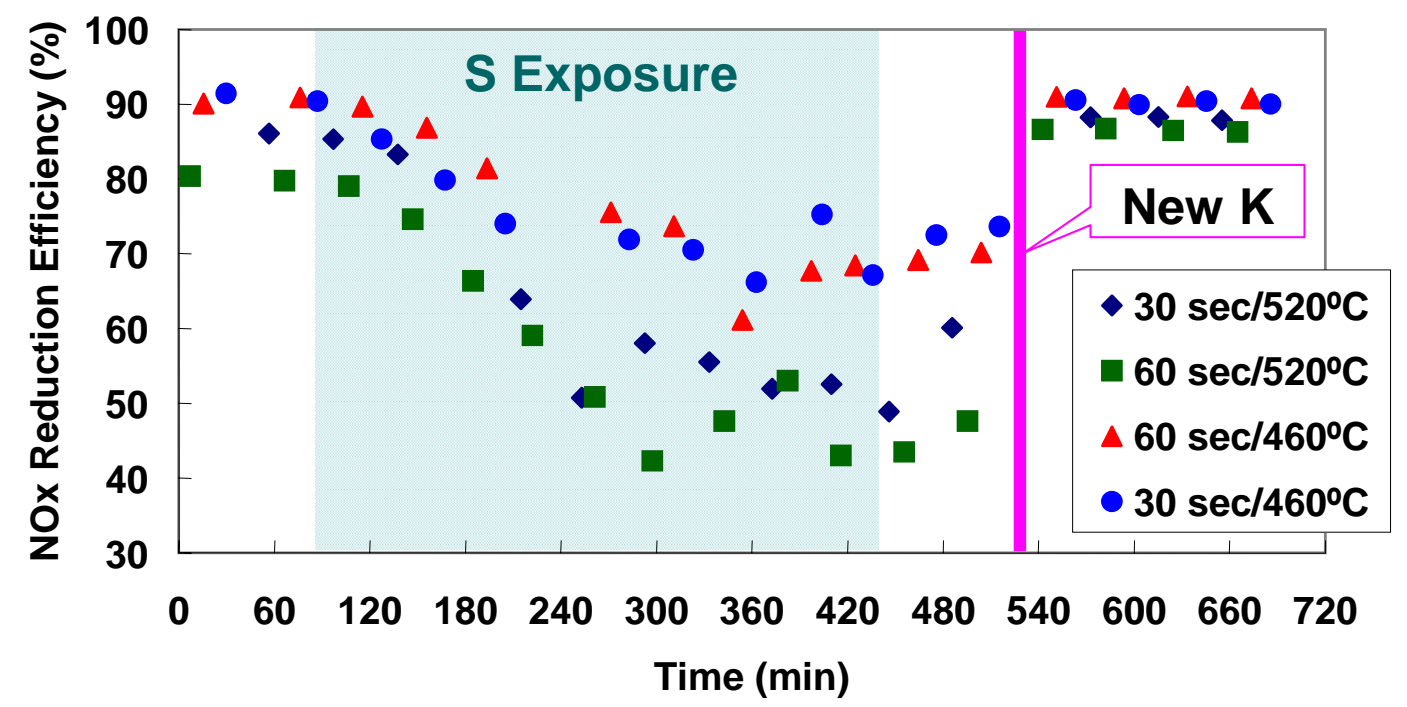

Figure 7-7. Cycle average NOx reduction efficiency for four operational modes over the course of the study. 


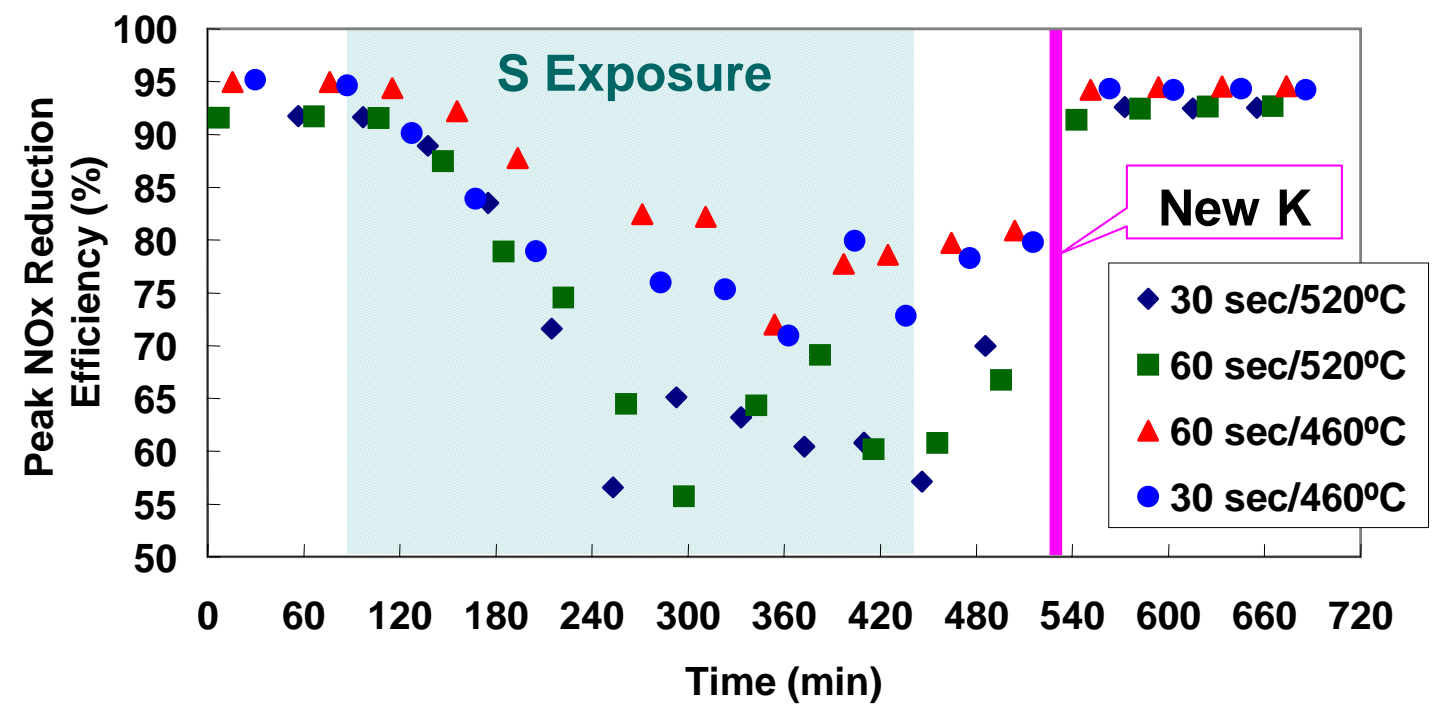

Figure 7-8. Peak NOx reduction efficiency for four operational modes over the course of the study.

An experiment was conducted to measure the NOx reduction efficiency performance as a function of catalyst temperature by maintaining constant engine operating conditions while varying the catalyst temperature with the heat exchanger upstream of the catalyst system. Again, the engine was operated at a speed and load of $1800 \mathrm{rpm}$ and $200 \mathrm{hp}(149 \mathrm{~kW})$, respectively. A sorption period of 30 seconds was used. The data Figure 7-9 and Figure 7-10 show the cycle average NOx reduction efficiency and peak NOx reduction efficiency as a function of the lean NOx trap catalyst temperature from these experiments; the evaluations were conducted prior to sulfur exposure (Pre S), after sulfur exposure (Post S), and after application of new K sorbate (New K) as noted before.

As Figure 7-9 shows, although the NOx reduction efficiency above $450^{\circ} \mathrm{C}$ is the same for the Pre $\mathrm{S}$ and New $\mathrm{K}$ cases, there are significant differences in the temperature range from $350^{\circ} \mathrm{C}$ to $450^{\circ} \mathrm{C}$. In this temperature range, the NOx performance is dictated by the efficiency at which the methane injected for regeneration of the catalysts is oxidized and reformed into reductants $\mathrm{CO}$ and $\mathrm{H}_{2}$ for reduction of the lean NOx trap catalysts. Apparently, a non-recoverable loss of oxidation and reforming performance occurred over the course of the sulfur exposure and sorbate reapplication processes. The Post $\mathrm{S}$ data show a loss for all temperatures relative to the Pre $\mathrm{S}$ case; thus, performance loss over sulfur exposure was due to lost NOx capacity (apparent from $>450^{\circ} \mathrm{C}$ temperatures) and lost oxidation and reforming efficiency (apparent form losses below $450^{\circ} \mathrm{C}$ ). The peak NOx reduction efficiency data in Figure 7-10 show similar results. 


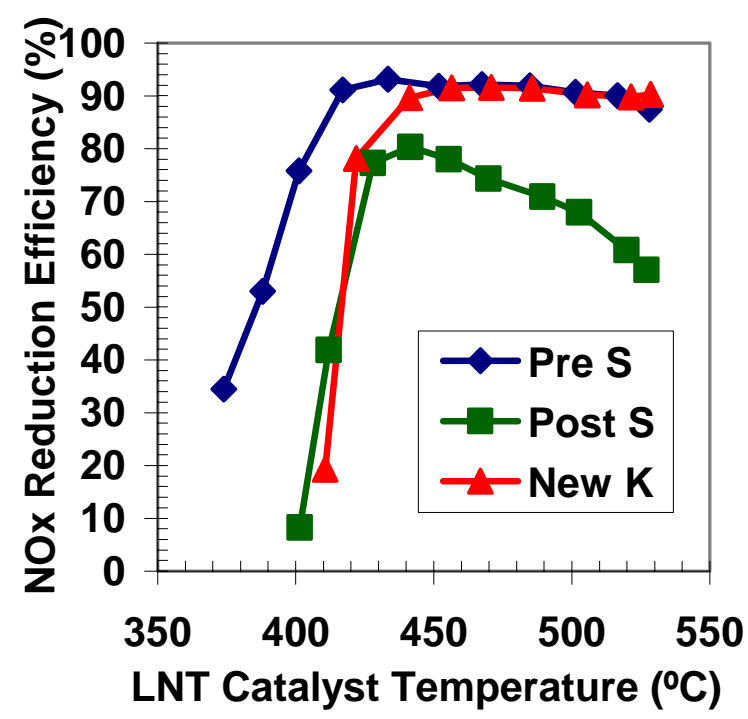

Figure 7-9. NOx reduction efficiency as a function of temperature before and after sulfur exposure and after new sorbate application.

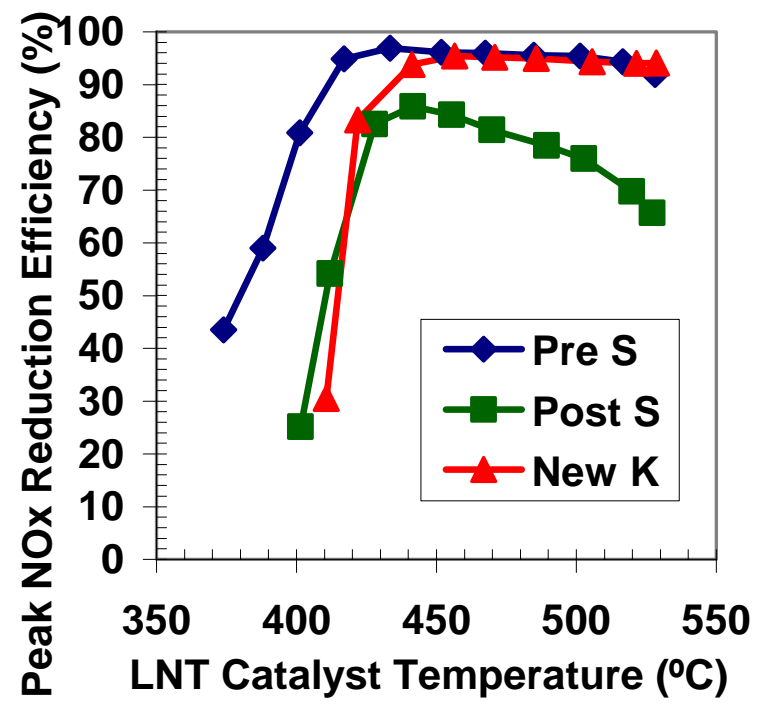

Figure 7-10. Peak NOx reduction efficiency as a function of temperature before and after sulfur exposure and after new sorbate application.

Another measure of the NOx performance can be expressed by calculating the mass of NOx stored per volume of lean NOx trap catalyst; this value is called "NOx capacity" and is shown in Figure 7-11. The data were collected at the same engine and temperature conditions used for the data shown in Figure 7-9 and Figure 7-10, but the catalyst was allowed to saturate with NOx for an extended period to measure total NOx storage capacity. In the Figure 7-11 data, the capacity is calculated based on the point where the catalyst out emissions rise above $50 \%$ of the engine out NOx emissions; this trigger point for the integration window in the data analysis allows a consistent means of comparing capacities based on a certain emission level set point. As Figure 7-11 shows, the loss in performance due to sulfur exposure is more dramatic when comparing NOx capacity. Furthermore, the recovery in performance from the sorbate reapplication 
processes is relatively more impressive in Figure 7-11 as compared with Figure 7-9 and Figure 7-10. The performance below $450^{\circ} \mathrm{C}$ is not fully recovered in the New $\mathrm{K}$ data.

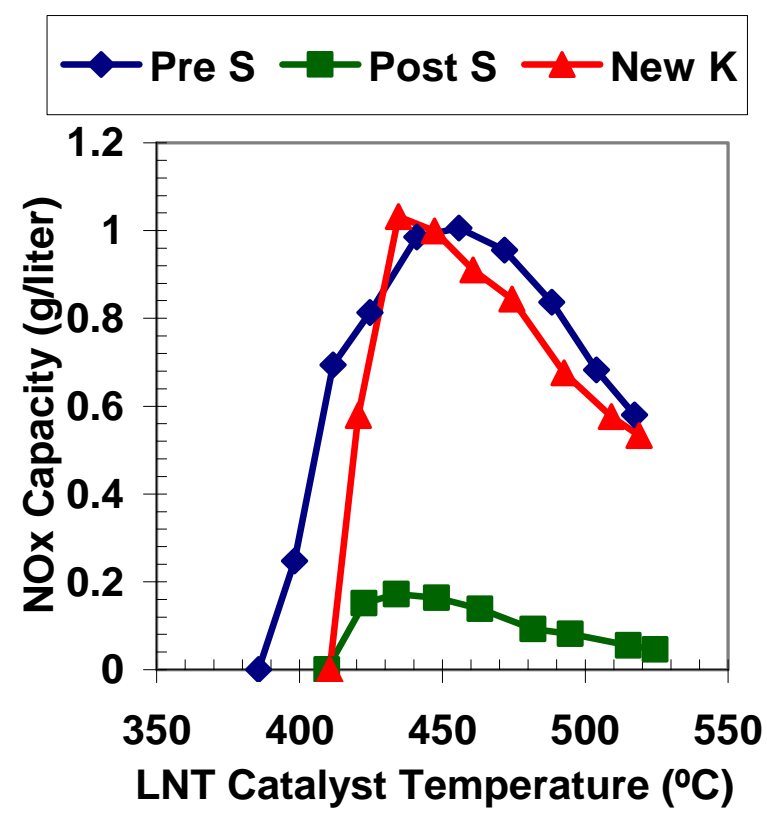

Figure 7-11. NOx storage capacity as a function of temperature before and after sulfur exposure and after new sorbate application.

\subsubsection{Summary}

Experiments were conducted on a lean natural gas engine platform to study the effects of sulfur exposure on a lean NOx trap catalyst system. Sulfur exposure caused degradation in NOx reduction efficiency as expected; however, a treatment of the lean NOx trap catalyst to reapply new sorbate material was effective in restoring lost NOx performance. The recovery of lost NOx performance was not complete for all temperature ranges. At temperatures where performance is capacity limited (above $450^{\circ} \mathrm{C}$ ), full recovery occurred. In contrast, at temperatures where performance is limited by the efficiency of methane oxidation and reforming (below $450^{\circ} \mathrm{C}$ ), performance does not recover fully.

The sorbate reapplication process is an effective means of recovering NOx reduction performance for most of the operating window of the catalyst. The technique is inexpensive since precious metal components are not removed or reapplied in the process. The process is appropriate for safe water soluble sorbate components such as potassium based materials. The frequency required for the process to enable suitable performance by the catalysts is dependent on a number of factors including the emission requirements for the application of interest. 


\section{Application of Lean NOx Trap Catalysis for Natural Gas Applications}

\subsection{ISO 8178 Emission Test Cycle}

In the sections above, several important aspects of lean NOx trap catalysis for lean natural gas reciprocating engines have been discussed. In this section, lean NOx trap catalyst performance relative to emission regulation cycles will be presented. Although capital cost and operating costs are the two most important factors in power generation installation, emission regulations are the second priority factor since they influence cost and often determine the feasibility of a particular project. Thus, the performance of the lean NOx trap catalyst system relative to emission regulations is discussed here.

There are several emission test cycles for stationary reciprocating engines. The authors chose the ISO 8178 emission test cycle to represent NOx emission performance from the lean NOx trap catalyst system. The ISO 8178 (published by the International Organization for Standardization) is an internationally recognized test cycle commonly used in many countries. ${ }^{24,25}$ The test cycle is composed of three to eleven steady-state engine operation modes depending on the specific application (designated by "Type"). For the large natural gas power generation application, Type D2, a constant speed test cycle, is often used. This emission test cycle is composed of five modes at rated speed. Each mode is weighted, and the combined emissions from the weighted five modes results in a single emission level for the engine expressed in units of $\mathrm{g} / \mathrm{bhp}-\mathrm{hr}$ or $\mathrm{g} / \mathrm{kW}-\mathrm{hr}$. The normalization of the emissions to power allows for easy comparison of emissions from various size engines. It is important to note that the Type D2 ISO 8178 emission test cycle is similar to other stationary and off-road engine test cycles such as the U. S. Environmental Protection Agency's Code of Federal Regulations (CFR) 40 Part 89 Subpart E (89.407). ${ }^{26}$

Table 8-1 gives a summary of the ISO 8178 Type D2 emission test cycle. There are five modes in the test cycle corresponding with engine loads of $10,25,50,75$, and $100 \%$ which are weighted with factors of $0.10,0.30,0.30,0.25$, and 0.05 , respectively. The order of testing is from the highest load to the lowest, and the engine must be operated for specific time periods at each mode. A speed of $1800 \mathrm{rpm}$ was used for the evaluations presented here. Typical power levels for each mode for the engine used in this study are listed in the table for reference.

Table 8-1. ISO 8178 Emission Test Cycle Type D2

\begin{tabular}{|c|c|c|c|c|}
\hline Mode & Torque (\%) & Weighting Factor & Engine Speed (rpm) & Engine Power (hp) \\
\hline 1 & 100 & 0.05 & 1800 & 248 \\
\hline 2 & 75 & 0.25 & 1800 & 186 \\
\hline 3 & 50 & 0.30 & 1800 & 124 \\
\hline 4 & 25 & 0.30 & 1800 & 62 \\
\hline 5 & 10 & 0.10 & 1800 & 24.8 \\
\hline
\end{tabular}

In this section, emissions measured by conducting the ISO 8178 Type D2 emission test cycle will be presented for the lean NOx trap catalyst system. The emissions were measured downstream of the single catalyst chamber system described in Figure 3-1, which allows engine exhaust to pass untreated through the bypass leg during the regeneration phase of operation. However, the emission rates presented in this section will represent a dual catalyst chamber system in which the engine exhaust is treated at all times. The dual catalyst chamber system emission rates were estimated by simply using the sorption phase emission rate from the single catalyst chamber system data; the dual chamber estimate is conservative since untreated exhaust 
leakage through the bypass leg significantly contributes to the emissions measured at the system out position during the sorption phase.

When conducting the ISO 8178 Type D2 test, the temperatures of the catalysts were allowed to stabilize prior to recording the NOx emission data. At each mode point, the sorption cycle period was allowed to increase in increments of 30 seconds approximately every five lean-rich cycles until significant NOx breakthrough occurred during the sorption phase. This technique enables a simple performance optimization to be performed for each mode. During data analysis, the sorption period with the best combined fuel penalty and NOx emissions was selected for reporting in the ISO 8178 emission value.

\subsection{Details of Modal Data}

Engines are engineered to provide optimal power and efficiency over a broad range of operating conditions. Air and fuel flow are the primary engine controls that can be adjusted by engine controllers to allow for optimal performance. Since test cycles like ISO 8178 require low emissions over a broad range, engine controls must minimize emissions over a broad range as well, but naturally, variations in emission rates will occur for different engine loads and speeds. The particular engine used in this study has a turbocharger and intercooler that enable higher air intake rates. Other main controls on the engine include fueling, spark timing, and the intake throttle. In general for this engine, leaner air-to-fuel mixtures are used as engine load increases. A summary of the fueling rate and air-to-fuel ratio expressed as excess air ratio (defined in Equation 4-2) for the engine loads representing the five modes of the ISO 8178 test cycle are shown in Figure 8-1. Fueling rate increases with engine load as expected. Excess air ratios are higher for the 50,75 , and $100 \%$ loads in comparison to the 10 and $25 \%$ loads, but the excess air ratio does not vary much in the low (10-25\%) and high (50-100\%) load ranges.

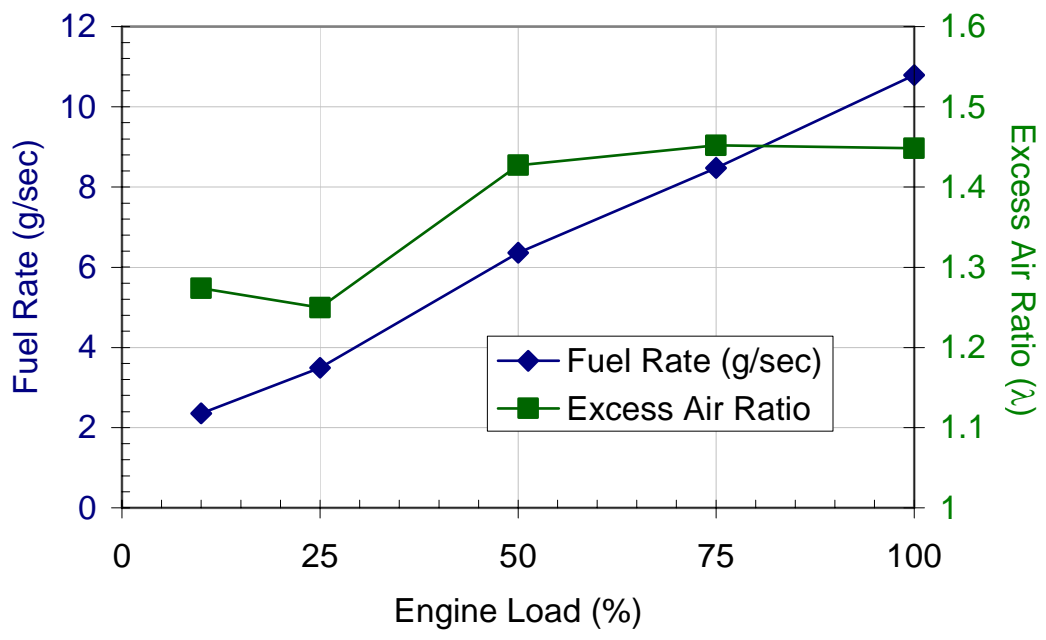

Figure 8-1. Fueling rate and excess air ratio for engine loads measured during the ISO 8178 test cycle.

Fueling rate and excess air ratio have a strong influence on NOx emissions. In general, as fueling rate increases, NOx emissions increase, and as excess air ratio increases, NOx emissions decrease. Thus, the general increases in fuel rate and excess air ratio shown in Figure 8-1 have conflicting impacts on the amount of NOx emissions. The actual NOx emissions from the modes of the ISO 8178 test cycle are shown in Figure 8-2. Here three plots are shown which illustrate the factors influencing NOx emission rates on a mass per power basis. 

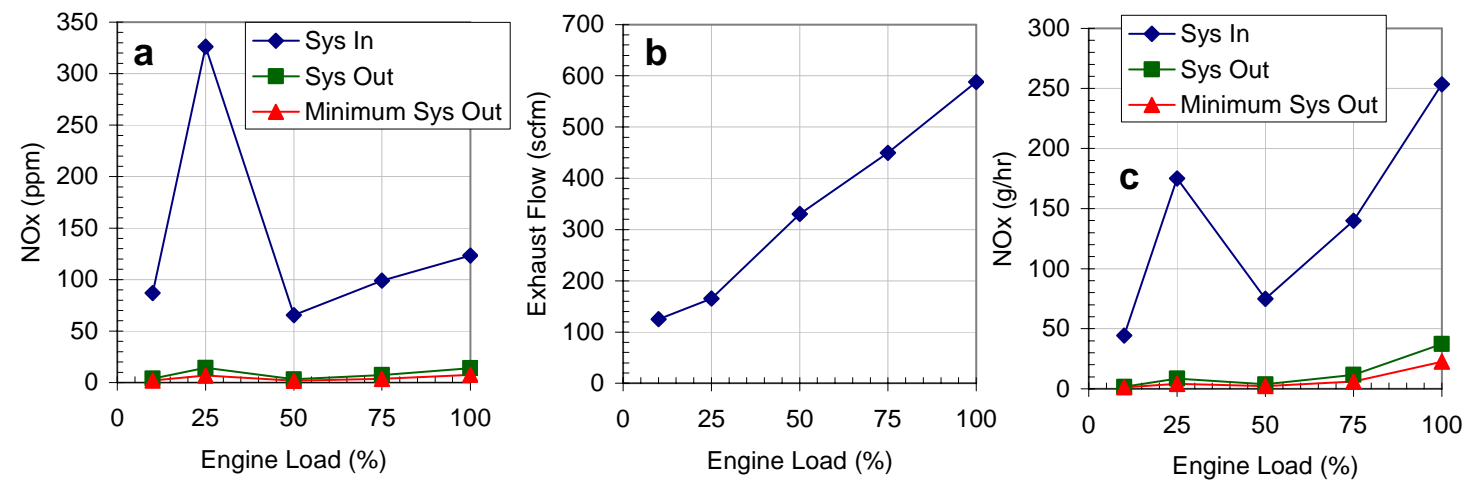

Figure 8-2. NOx concentration (a), exhaust flow (b), and NOx mass emission rate (c) for the five modes of the ISO 8178 test cycle.

Figure 8-2.a. shows NOx concentration expressed in ppm units in the exhaust at Sys In (engine out) and Sys Out (catalyst system out) positions (see Figure 3-1). The emission data are average emissions over three lean-rich cycles of operation of the lean NOx trap catalyst. In addition to the cycle average data, the minimum emissions observed during the cycle are shown as well as "Minimum Sys Out". The combined effects of fueling rate and excess air ratio on emissions creates a localized maximum of engine out NOx concentration at the $25 \%$ load point. As shown by the data, the catalyst system is effective at reducing the NOx concentration at all load points, but higher engine out NOx concentrations do lead to slightly higher catalyst system out NOx concentrations.

Figure 8-2.b. shows the exhaust flow in units of scfm as a function of engine load. The exhaust flow increases by a factor of five between the 10 and $100 \%$ load points. The NOx emissions expressed in $\mathrm{g} / \mathrm{bhp}$-hr (Figure 8-2.c.) are a function of the NOx concentration data (Figure 8-2.a.) and the exhaust flow data (Figure 8-2.b.). The mass NOx emissions in g/bhp-hr show that the highest rate of NOx emissions on a power basis occurs at the highest load point $(100 \%)$. The corresponding catalyst system out (Sys Out) emissions are also at the highest load, but again, the lean NOx trap catalyst is effective at reducing the NOx emissions dramatically at all load points.

Table 8-2 summarizes the NOx emissions obtained in the ISO 8178 data results shown in Figure 8-2; in addition, fuel penalty and catalyst temperature data are also shown in the table. Although the engine out NOx emissions vary by more than a factor of five over the test, the NOx reduction efficiency ("NRE") of the catalyst system is high ( $>88 \%)$ for all modes. The weighted result for the system out NOx emissions is $0.08 \mathrm{~g} / \mathrm{bhp}-\mathrm{hr}$, which is less than the ARES target of $0.1 \mathrm{~g} / \mathrm{bhp}-\mathrm{hr}$, and represents a $93.2 \%$ reduction from the engine out NOx emissions of $1.11 \mathrm{~g} / \mathrm{bhp}-$ hr (Figure 8-3). The weighted average NOx reduction for all five modes was $94.2 \%$.

Table 8-2. ISO 8178 Data

\begin{tabular}{|c|c|c|c|c|c|c|c|c|}
\hline Mode & $\begin{array}{c}\text { Engine } \\
\text { Load } \\
(\%)\end{array}$ & $\begin{array}{c}\text { Engine } \\
\text { Out NOx } \\
(\mathrm{g} / \mathrm{hr})\end{array}$ & $\begin{array}{c}\text { System } \\
\text { Out NOx } \\
(\mathrm{g} / \mathrm{hr})\end{array}$ & $\begin{array}{c}\text { Engine } \\
\text { Out NOx } \\
\text { (g/bhp-hr) }\end{array}$ & $\begin{array}{c}\text { System } \\
\text { Out NOx } \\
\text { (g/bhp-hr) }\end{array}$ & $\begin{array}{c}\text { NRE* }^{*} \\
(\%)\end{array}$ & $\begin{array}{c}\text { Fuel } \\
\text { Penalty } \\
(\%)\end{array}$ & $\begin{array}{l}\text { LNT Catalyst } \\
\text { Temperature } \\
\left({ }^{\circ} \mathrm{C}\right)\end{array}$ \\
\hline 1 & 100 & 253.4 & 28.6 & 1.05 & 0.12 & 88.7 & 3.8 & 512.2 \\
\hline 2 & 75 & 139.8 & 11.2 & 0.77 & 0.06 & 92.0 & 2.2 & 498.9 \\
\hline 3 & 50 & 74.8 & 3.6 & 0.61 & 0.03 & 95.3 & 1.4 & 469.4 \\
\hline 4 & 25 & 175.0 & 8.2 & 2.95 & 0.14 & 95.2 & 2.7 & 439.6 \\
\hline 5 & 10 & 44.4 & 1.7 & 1.89 & 0.07 & 96.4 & 3.2 & 364.6 \\
\hline \multicolumn{4}{|c|}{ Weighted Result } & 1.11 & 0.08 & 94.2 & 2.3 & 459.5 \\
\hline
\end{tabular}

*NRE=NOx Reduction Efficiency 


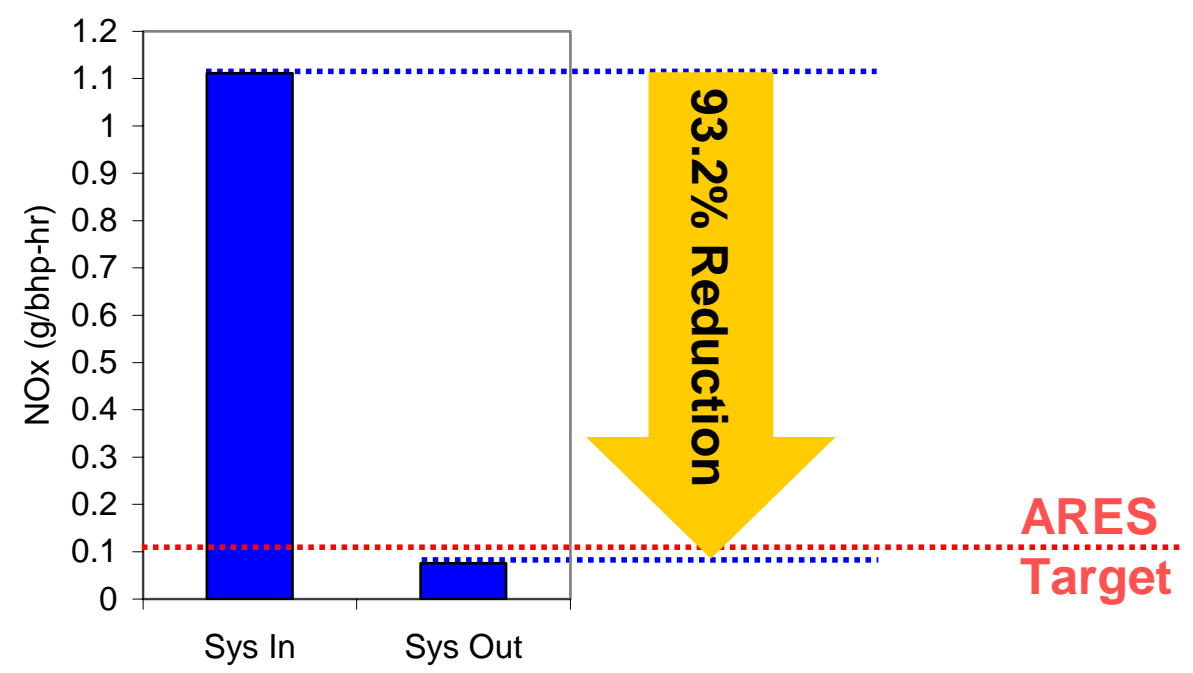

Figure 8-3. Engine out and system out NOx measured during the ISO 8178 emission test cycle.

The fuel penalties shown in Table 8-2 range between 1.4 and 3.8\%. These fuel penalties represent the amount of fuel required to regenerate both catalyst chambers of a dual-chamber lean NOx trap system; the percentage is relative to the amount of fuel being consumed by the engine to produce power. The fuel penalty data were determined from a fuel flow signal with significant noise; the coefficient of variation of the data for the fuel penalties was $33 \%$. The data represent the expected range of fuel penalty for a dual-chamber system. This level of fuel penalty is not negligible from an operating cost view, but the level is significantly less than the $\sim 12 \%$ fuel benefit associated with operating the engine lean (as compared with stoichiometric operation). Thus, the benefits of the lean natural gas engine are maintained while the NOx emissions are reduced by the lean NOx trap system.

\subsection{Temperature Effect on Performance}

The lean NOx trap catalyst temperature decreases with engine load and covers a wide range of temperatures over the five mode test. Since catalyst temperature plays a large role in performance, the ISO 8178 emission test cycle was performed with different catalyst temperature ranges to study the temperature effect. The heat exchanger upstream of the catalyst system was controlled to vary the catalyst temperature range. For a complete ISO 8178 test, the heat exchanger was not adjusted; thus, the thermal management of the system represents passive thermal management that could be integrated into the catalyst system design process (as opposed to "active" thermal management where control occurs during system operation). Data from three heat exchanger set points ("HEX Point") are shown in Table 8-3. The ISO 8178 weighted emission factor is given, and the lean NOx trap catalyst temperature expressed as a weighted average is shown as well.

Table 8-3. ISO 8178 Emission Test Cycle Results vs. Catalyst Temperature

\begin{tabular}{|c|c|c|}
\hline HEX Point & System Out NOx (g/bhp-hr) & LNT Catalyst Temperature $\left({ }^{\circ} \mathrm{C}\right)$ \\
\hline 1 & 0.11 & 484.1 \\
\hline 2 & 0.08 & 459.5 \\
\hline 3 & 0.09 & 437.7 \\
\hline
\end{tabular}

Figure 8-4 shows data for the specific modes of the experimental results summarized in Table 8-3. HEX Point 1 had the least heat removal and, thereby, the highest overall catalyst temperatures; in contrast, HEX Point 3 had the most heat removal and the lowest overall catalyst 
temperatures. The highest NOx emissions occurred during mode 1, which is the $100 \%$ load point and had the highest catalyst temperatures. In mode 1, the system out NOx emissions varied significantly as the catalyst temperatures differed. The lowest NOx emissions occurred for the medium heat exchanger set point (HEX Point 2); the data shown in Table 8-2 were obtained at HEX Point 2.
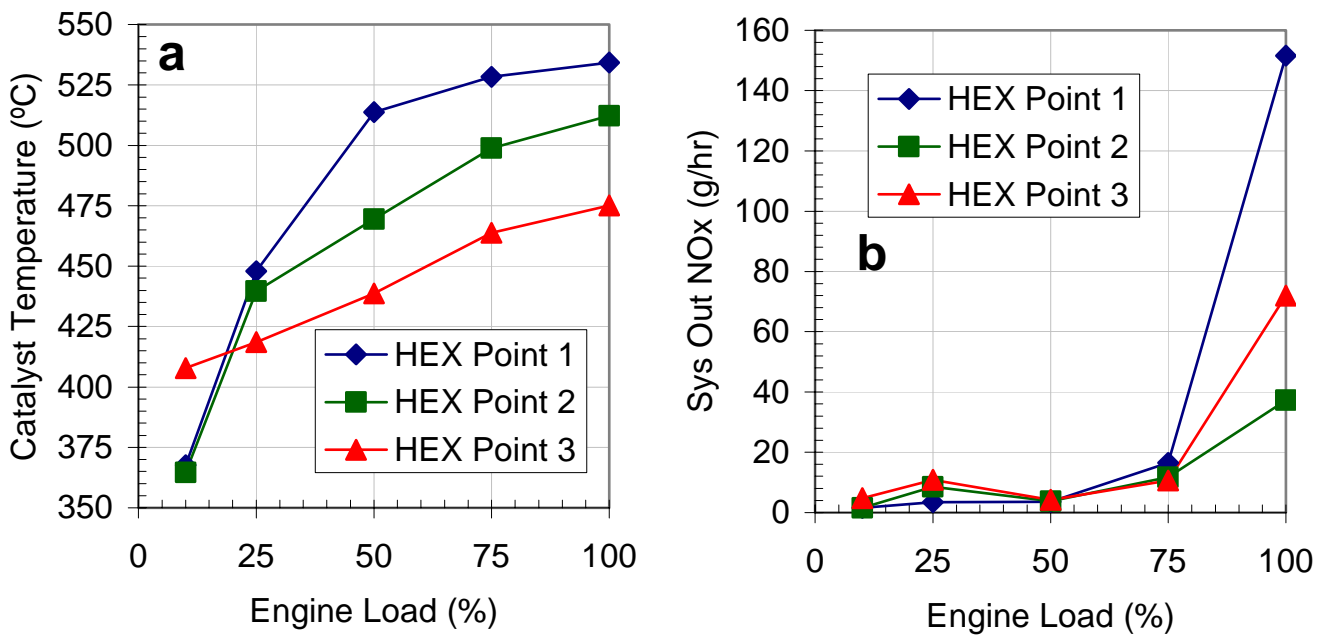

Figure 8-4. Catalyst temperature (a) and system out NOx (b) from three different temperature ranges.

The results of the ISO 8178 tests at different catalyst temperature ranges are due to the phenomena shown in Figure 5-3, Figure 7-9, and Figure 7-11. As catalyst temperatures increase, the NOx reduction performance decreases due to a decreasing capacity for NOx trapping exhibited by the lean NOx trap catalyst. As catalyst temperatures decrease, NOx reduction performance decreases as the regeneration process ceases due to the less efficient partial oxidation of methane. Thus, the optimal catalyst performance occurs where a balance between the performance losses at low and high temperatures occurs.

A summary of all of the ISO 8178 emission test cycle results is shown in Figure 8-5; NOx emissions in $\mathrm{g} / \mathrm{bhp}$-hr are shown as a function of the weighted average lean NOx trap catalyst temperature. The "Pre S" data points were results obtained prior to sulfur poisoning of the lean NOx trap catalysts; the data are the same data shown in Table 8-3 and represent degreened catalysts. The "New K" data points were obtained after sulfur poisoning had occurred and after the application of new sorbate material as described in Section 7.3. Finally, one data point notated as "Pre S (LNT Out)" represents the ISO 8178 emission level measured immediately downstream of the lean NOx trap catalyst at the "LNT Out" position; no NOx from exhaust leaked through the exhaust valve contributes to the "Pre S (LNT Out)" result which was obtained prior to sulfur poisoning.

The "Pre S" data shows graphically the relationship between performance and catalyst temperature. The curve was superimposed on the data to illustrate the optimization trend as a function of temperature which shows more NOx emissions occurring as lower and higher temperatures occur relative to the optimal performance slightly above $450^{\circ} \mathrm{C}$. For reference, the ARES target emission level of $0.1 \mathrm{~g} / \mathrm{bhp}-\mathrm{hr}$ is shown; the importance of system design for optimal performance is apparent as the temperature changes affect whether or not the target emission level is met.

Although only two data points for the "New K" case were acquired, the "New K" data points are close to the "Pre S" data points. The similarity in performance in the "New K" and "Pre S" data gives optimism that sulfur effects can be controlled via the sorbate reapplication procedure 
(Section 7.3) and that the lean NOx trap catalyst can be durable enough to meet emission regulation levels over a significant useful life period. It is important to note that the emission levels obtained in the field are subject to degradation that occurs during normal operation, catalyst and system manufacturing tolerances and variability, and environmental influences such as ambient temperature and humidity. Any of these factors can cause the NOx emission levels demonstrated in the laboratory to increase; thus, measures should be engineered into the system design to compensate for issues that are difficult to control. For the lean NOx trap catalyst technology, the most straightforward means of compensation is to add more lean NOx trap catalyst volume to the system. Although adding more catalyst volume raises capital cost, the increase in catalyst volume can greatly assist in maintaining low NOx emissions under variable circumstances.

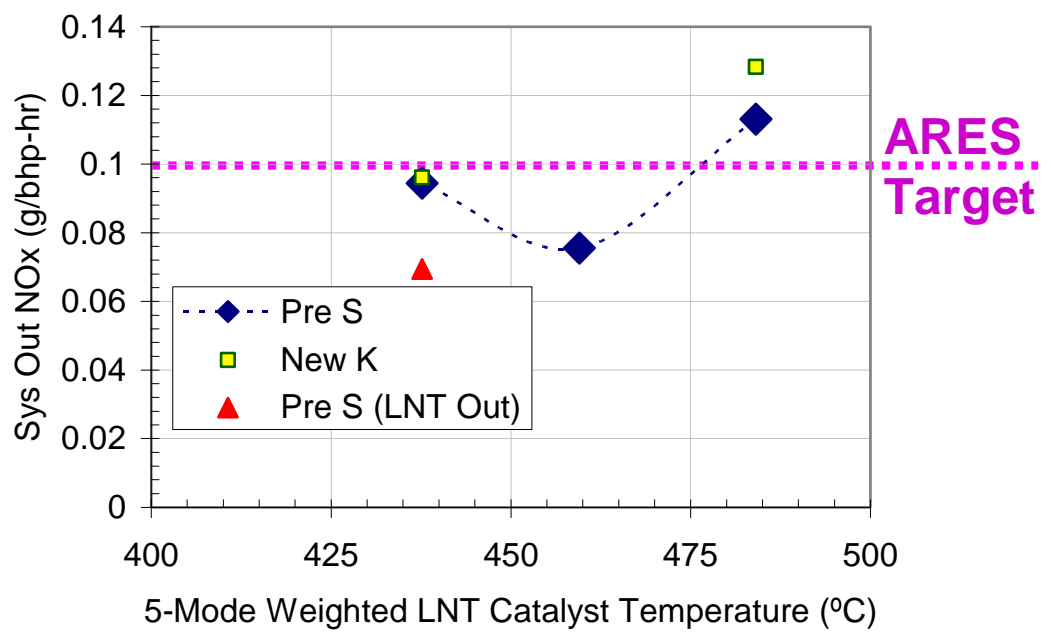

Figure 8-5. ISO 8178 emission test cycle results vs. catalyst temperature. 


\section{Future of Lean NOx Trap Catalysis for Reciprocating Engines}

As demonstrated by the results presented in this report, the lean NOx trap catalyst technology provides excellent NOx emission control in lean natural gas reciprocating engine applications. The potential for successful commercial application of the lean NOx trap technology in reciprocating engine applications will depend on several performance factors such as fuel penalty, capital and operating costs, and durability. It is expected that the potential for successful implementation of lean NOx trap catalysts in lean natural gas applications will be supported by future work in the area of lean NOx trap catalysis and in areas related to reciprocating engine development. In this section, specific future work activities that are likely to benefit lean NOx trap catalysis are presented.

\subsection{Integration with Heat Recovery Systems}

The efficiency of distributed power increases dramatically when recovery of waste heat is incorporated into the system design. Combined heat and power (CHP) systems allow recovery of waste heat energy which can be used to provide useful heat for hot water/steam systems and cooling systems via adsorption chillers. The lean NOx trap catalyst system is installed on the exhaust where most waste heat energy recovery occurs; thus, design of exhaust systems will necessarily have to consider the needs of both technologies. However, it is important to note that system design of the integration of these components provides opportunities for improved performance of the normally separate technologies.

Waste heat from a reciprocating engine is commonly recovered from oil systems, coolant systems, air intake systems (intercooler), and exhaust systems. In some cases heat can be recovered from radiant heat from the engine block; however, designs for radiant heat recovery must insure that engine overheating does not occur. A schematic of positions where waste heat can be recovered in a lean natural gas engine with a lean NOx trap catalyst system is shown in Figure 9-1.

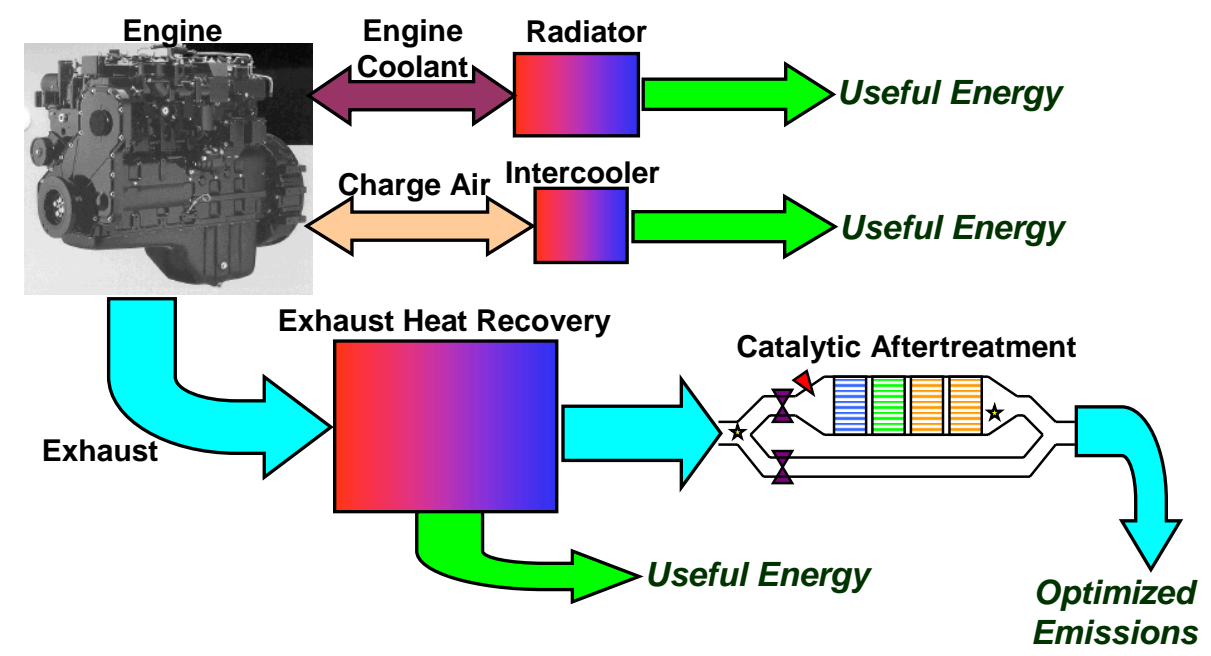

Figure 9-1. Schematic of waste heat recovery positions from an engine-catalyst system.

By controlling the amount of heat extracted from the exhaust system at the "Exhaust Heat Recovery" point shown in Figure 9-1, the performance of the downstream catalytic aftertreatment can be optimized. A simple experiment was conducted with the geometry shown in Figure 9-1. The amount of heat recovery by the heat exchanger located upstream of the lean NOx trap catalyst system was varied, and the NOx reduction efficiency was monitored. The results of the experiment presented as a function of the catalyst system inlet temperature are shown in Figure 
9-2. The NOx reduction efficiency increases as more heat recovery occurs until a catalyst system inlet temperature of $\sim 425^{\circ} \mathrm{C}$ occurs. As more heat recovery occurs, the catalyst system temperatures drop below $400^{\circ} \mathrm{C}$, and a dramatic drop in NOx reduction efficiency performance occurs. The drop is expected since the natural gas can not be partially oxidized at the lower temperatures and, thereby, prevents regeneration of the lean NOx trap catalyst. During the experiment, the engine operation was held constant; so, as expected, the thermal efficiency of the engine alone is constant. However, when including the heat energy recovered from the exhaust, the thermal efficiency of the combined heat recovery and engine system increases as more heat recovery occurs. The optimal system performance occurs where the NOx reduction efficiency and thermal efficiency are both relatively high; the optimal point for the experiment conducted here is highlighted in Figure 9-2. Essentially, the heat recovery allows optimization of the system based on the tradeoff between natural gas partial oxidation performance and NOx trapping capacity as illustrated in Figure 5-3.

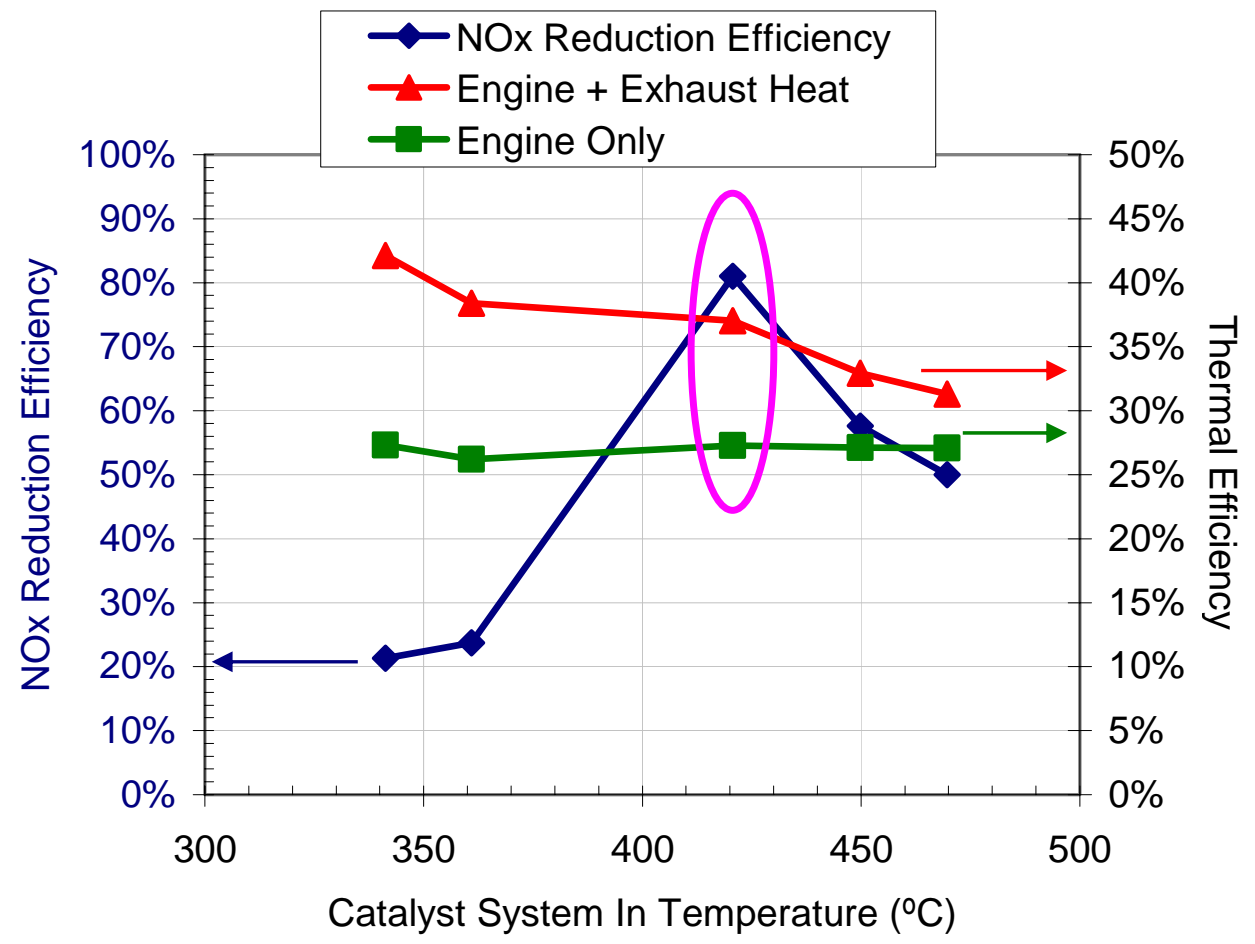

Figure 9-2. NOx reduction efficiency and thermal efficiency as heat recovery is varied.

Further optimization of a combined heat recovery and a lean NOx trap catalyst aftertreatment system can be envisioned if the lean NOx trap catalyst system can be separated into modular components. Specifically, if the partial oxidation and reforming catalysts can be separated physically from the lean NOx trap catalysts, then the oxidation and reforming could be placed upstream of heat recovery, and the lean NOx trap catalysts could remain downstream of the heat recovery. In theory, such a design would provide improved performance and increase the size of the temperature operating window. The partial oxidation and reforming processes work more efficiently at a higher temperature range, and the lean NOx trap catalysts work more efficiently in a lower temperature range. This approach is shown schematically in Figure 9-3. 
(a) System Geometry for Laboratory Studies

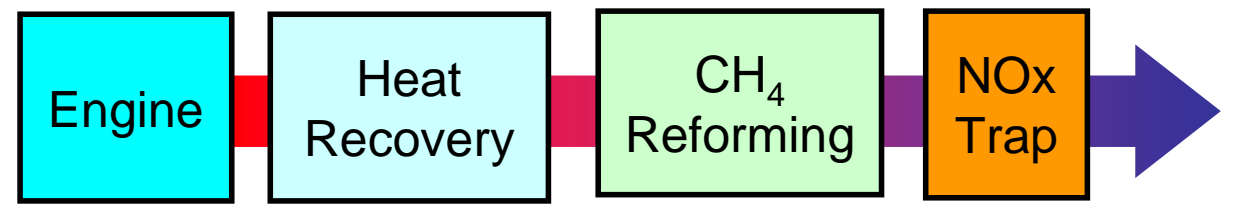

(b) Optimized System Geometry

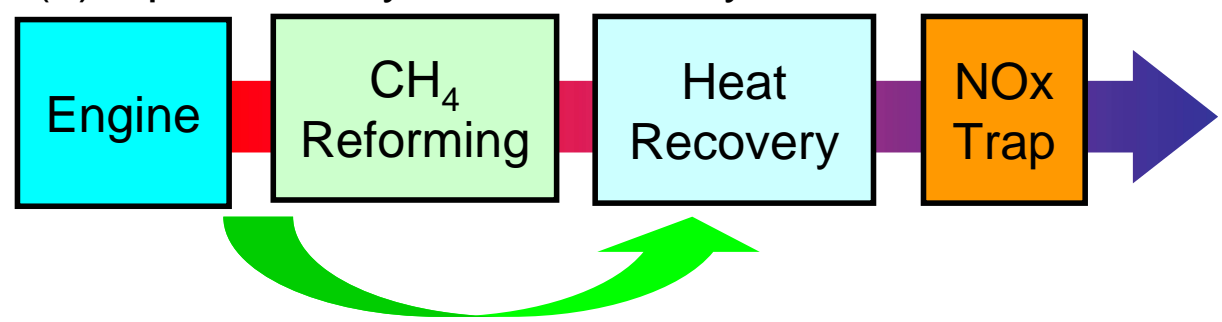

Figure 9-3. Optimization of system performance by separation of partial oxidation and reforming catalysts from the lean NOx trap catalysts.

\subsection{Engine Improvements in NOx Emissions}

Significant progress has been made by engine manufacturers to lower NOx emissions from the engine. Lean natural gas engines with NOx emission levels of $0.5 \mathrm{~g} / \mathrm{bhp}$-hr are commonly available. As NOx emission levels from engines are lowered, the lean NOx trap catalyst technology becomes more feasible since less catalyst volume is required in the system to handle the lower NOx level in the exhaust. In addition, lower NOx emissions levels are often the results of leaner operation of the engine which causes higher $\mathrm{O}_{2}$ levels in the exhaust. The lean $\mathrm{NOx}$ trap technology is capable of operating over a wide range of $\mathrm{O}_{2}$ levels in the exhaust; so, the advancement of engine technologies that lower NOx emissions will be mutually beneficial to the lean NOx trap catalyst technology.

\subsection{Hydrogen Generation}

One method demonstrated for the extension of the lean limit of combustion and thereby the lowering of NOx emissions from lean natural gas reciprocating engines is hydrogen $\left(\mathrm{H}_{2}\right)$ enrichment. ${ }^{7}$ In $\mathrm{H}_{2}$ enrichment, part of the natural gas fuel is converted into $\mathrm{H}_{2}$ gas and redirected back to the intake system of the engine. The new fuel charge which is a mixture of natural gas and $\mathrm{H}_{2}$ enables leaner combustion and lower NOx emissions. Since the lean NOx trap catalyst system generates $\mathrm{H}_{2}$ from natural gas fuel for regeneration of the catalyst, there is a synergistic opportunity to use one $\mathrm{H}_{2}$ production technology to serve the $\mathrm{H}_{2}$ needs of both the engine (for $\mathrm{H}_{2}$ enrichment to lower NOx) and the lean NOx trap catalyst (to regenerate the catalyst). A schematic of such a proposed system is shown in Figure 9-4. Here a modular device (most likely a catalytic reformer) serves to produce $\mathrm{H}_{2}$ from the natural gas stream. The $\mathrm{H}_{2}$ is then routed back to the intake system of the engine as well as the lean NOx trap catalyst system for catalyst regeneration. Exhaust emitted by the engine is lower in NOx emissions, and the lean NOx trap catalyst system can reduce the NOx emissions to even lower levels with aid from the $\mathrm{H}_{2}$ fuel for catalyst regeneration. 


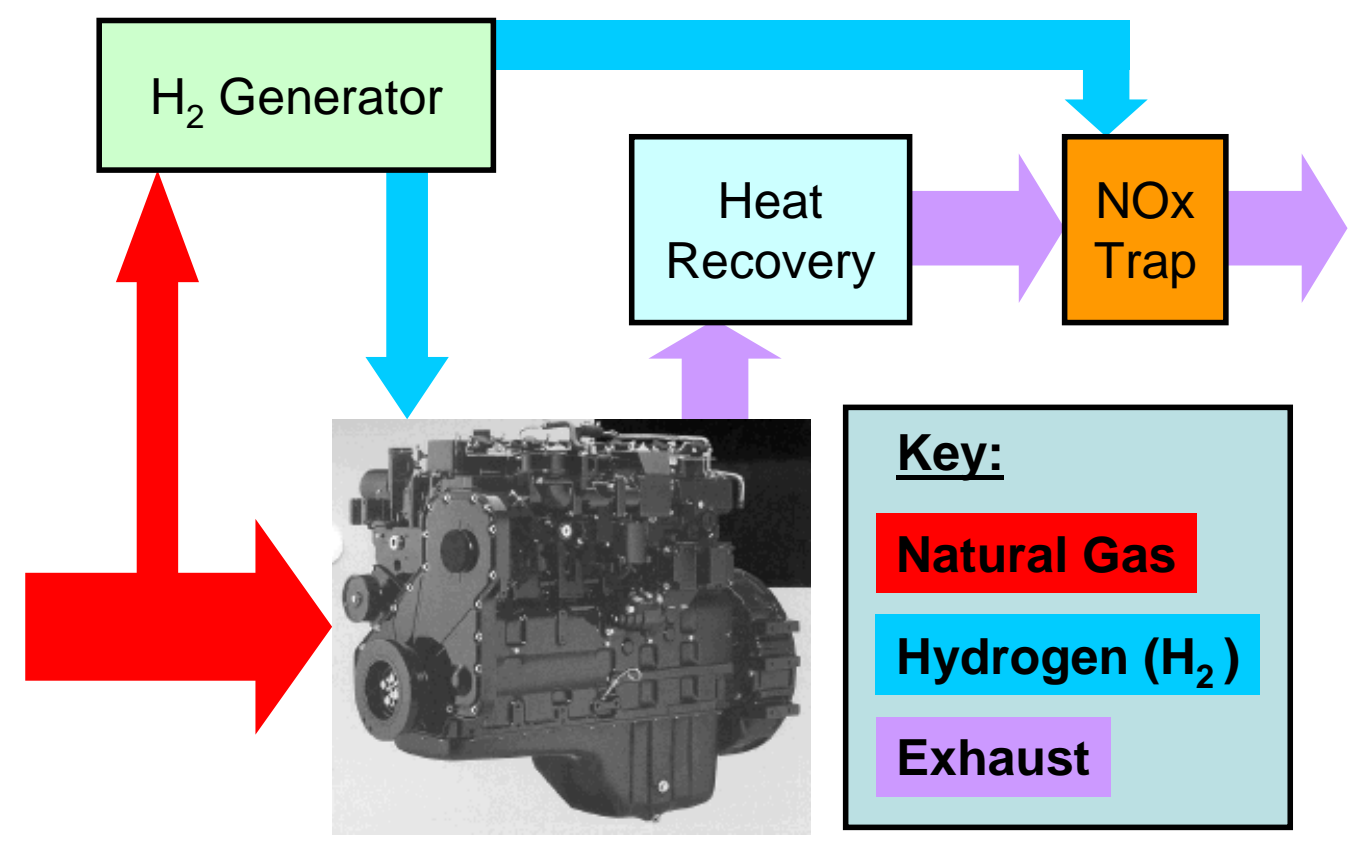

Figure 9-4. Schematic of engine and lean NOx trap system with common $\mathrm{H}_{2}$ source.

\subsection{Opportunities for Catalyst Cost Reduction}

One of largest barriers to installation of the lean NOx trap catalyst technology is cost. Unfortunately, any cost associated with aftertreatment is often viewed as excessive since no power is produced by the aftertreatment system. Opportunities to reduce the cost of the lean NOx trap catalyst do exist and are being pursued in the research and development of lean NOx trap catalysts for a variety of applications. Any general reduction in precious metal content for the lean NOx trap catalyst will help reduce catalyst cost for the lean natural gas engine application.

One specific opportunity for cost savings by precious metal reduction of the lean NOx trap catalyst occurs due to the temperature range of operation associated with the natural gas engine application. Precious metals are required in lean NOx trap catalysis for the regeneration process, but the amount of precious metal required to enable regeneration is highly dependent on temperature. At low temperatures, more precious metal is required to enable regeneration of all NOx storage sites. As catalyst temperatures increase, the effect of precious metal content becomes less dominant in catalyst performance and other factors (e.g. sorbate loading) become more dominant. Results of a bench flow reactor study of lean NOx trap catalysts with varying Pt content are shown in Figure 9-5; the NOx storage capacity of the catalysts are shown as a function of catalyst temperature under the same operating conditions. At low temperatures, a definite benefit occurs to the higher Pt content as more NOx storage increases with Pt load. However, at $400^{\circ} \mathrm{C}$, the NOx capacity for all $\mathrm{Pt}$ loads is essentially the same. In the $350-600^{\circ} \mathrm{C}$ temperature range of lean natural gas engines, excess Pt on the lean NOx trap catalyst does not give a significant performance benefit; thus, opportunities to reduce cost by lowering the Pt load of the catalyst exist. 


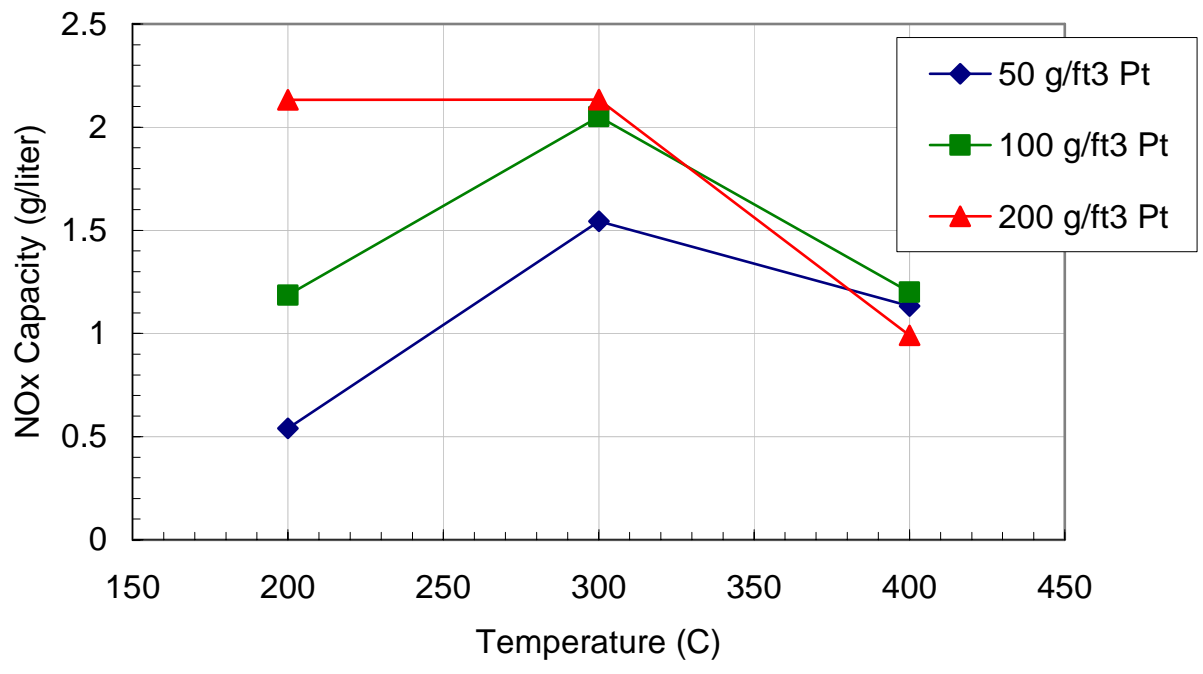

Figure 9-5. NOx storage capacity as a function of catalyst temperature for lean NOx trap catalysts with different Pt content.

\subsection{Field Studies}

Several critical issues regarding the feasibility of lean NOx trap catalyst technology for lean natural gas reciprocating engines were addressed in the research and development presented in this report. Specific positive results in critical areas were: (1) natural gas could be utilized to regenerate the lean NOx trap catalyst (via partial oxidation and reforming processes), (2) reformer catalysts impact $\mathrm{CH}_{4}$ utilization and are therefore a cost effective component of the catalyst system, (3) sulfur poisoning of the partial oxidation and reforming process can occur but is not sustained during lean-rich cycling with low sulfur content fuel, and (4) sorbate reapplication is an effective means of restoring lost performance due to sulfur poisoning of the lean NOx trap catalyst. All of the research and development on lean NOx trap catalysis presented in this report was conducted in a laboratory setting. The technology appears feasible for large natural gas engine applications based on the laboratory results; however, demonstration of the technology in field applications is needed. Field studies of a full size catalyst and engine system are needed to demonstrate the performance in a real-world setting and to establish more accurate measures for key parameters such as fuel penalty and degradation rate. 


\section{Conclusions}

Lean NOx trap catalysts have been studied as a means to reduce NOx emissions from lean natural gas reciprocating engines commonly used in distributed power generation. The research was supported by the Advanced Reciprocating Engine Systems (ARES) program of the U.S. Department of Energy. Industrial partners in the ARES program are Caterpillar, Cummins, and Waukesha. A primary goal of the ARES program is to achieve $<0.1 \mathrm{~g} / \mathrm{bhp}-\mathrm{hr}$ NOx emissions by 2010.

Research was conducted on a dynamometer-mounted Cummins 8.3-liter lean natural gas engine at Oak Ridge National Laboratory. A lean NOx trap catalyst system installed on the exhaust system of the engine successfully demonstrated NOx emission levels below $0.1 \mathrm{~g} / \mathrm{bhp}-\mathrm{hr}$. Furthermore, NOx emission levels as low as $0.08 \mathrm{~g} / \mathrm{bhp}-\mathrm{hr}$ were demonstrated in the ISO 8178 Type D2 emission test cycle commonly used for power generation applications. NOx emissions were reduced by over $90 \%$ from the emission levels emitted by the engine. Natural gas fuel from the supply line to the engine was used as the fuel to enable NOx reduction in lean exhaust; fuel penalties (fuel use for the catalyst system relative to the engine fuel use) for the ISO 8178 test modes were between $1.4 \%$ and $3.8 \%$.

Several critical aspects of the lean NOx trap catalyst technology were investigated for lean natural gas reciprocating engine applications. Research activities ranged from fundamental mechanisms involved in catalyst operation to studies of catalyst performance relative to ARES goals established by the ARES industrial representatives for commercial systems. Key findings include:

- Natural gas fuel can be used as the catalyst reductant. Natural gas containing high methane content can be used to regenerate the lean NOx trap catalyst and to reduce stored NOx to $\mathrm{N}_{2}$. Partial oxidation and reforming of the natural gas into $\mathrm{CO}$ and $\mathrm{H}_{2}$ species is required to enable catalyst regeneration. Valved exhaust systems enable catalyst regeneration to occur with low fuel penalties and dismiss the need for changes in engine operation.

- The reformer catalyst is a cost-effective component of the catalyst system. A study of the exhaust chemistry during the lean NOx trap catalyst regeneration cycle showed that both the partial oxidation and reforming catalysts contribute to the production of $\mathrm{CO}$ and $\mathrm{H}_{2}$ for catalyst regeneration. Thus, optimal utilization of the methane in natural gas for lean NOx trap catalyst regeneration incorporates the functionality of both catalysts.

- Recovery from sulfur poisoning of the oxidation and reforming catalysts occurs under normal lean-rich cycling operation. Sulfur poisoning of the oxidation and reforming catalysts can occur for elevated levels of sulfur in the exhaust; however, normal lean-rich cycling operation of the catalysts with typical sulfur content in fuel removes sulfur compounds and recovers lost performance.

- Sorbate reapplication is a low cost means of managing sulfur poisoning of the lean NOx trap catalysts. Sulfur poisoning is a well known degradation mechanism in lean NOx trap catalysis. Recovery of lost performance due to sulfur poisoning of the lean NOx trap catalysts was demonstrated with a technique where the active sorbate component of the catalysts is removed and reapplied by servicing the catalyst in an aqueous-based solution. The technique enables mitigation of sulfur poisoning in practice through a low cost service process.

- Thermal management and system integration design will be critical to commercial success. Catalyst performance was sensitive to temperature. Optimal performance for the system was achieved by balancing the need for higher temperatures to enable methane partial oxidation with the preference of lower 
temperatures for increased NOx storage capacity. Achieving the optimal balance will require careful system integration design and control.

The results from the laboratory studies conclude that lean NOx trap catalysis is a promising technology for control of NOx emissions from lean natural gas reciprocating engines. Further work is required to demonstrate the technology on full size systems in field studies which will help establish more accurate measures for key parameters such as fuel penalty and degradation rate. Advancements in the lean NOx trap technology are still occurring and should help reduce capital costs associated with the catalysts. Furthermore, advancements in engine technology should be mutually beneficial to the lean NOx trap technology as the technology becomes more cost effective with reduced engine out NOx levels. System integration with heat recovery should provide opportunities to reduce cost and improve performance of the lean NOx trap catalyst as well as improve the total efficiency of the power generation system. 


\section{Nomenclature}

LNT: Lean NOx Trap catalyst

NRE: NOx Reduction Efficiency

ORNL: Oak Ridge National Laboratory

ARES: Advanced Reciprocating Engine Systems program of the U.S. Department of Energy

ARICE: Advanced Reciprocating Internal Combustion Engines program of the California Air Resources Board

NOx: oxides of nitrogen ( $\mathrm{NO}$ and $\mathrm{NO}_{2}$ )

HC: hydrocarbons

NMHC: non-methane hydrocarbons

"Regeneration": the process of flowing a net-reducing gas over the lean NOx trap to release stored NOx and reduce the NOx to $\mathrm{N}_{2}$ which enables more NOx to be stored.

"Partial Oxidation": combustion of a fuel (methane) under rich air-to-fuel ratios to enable the consumption of oxygen and the production of $\mathrm{CO}$ and/or $\mathrm{H}_{2}$.

"Reforming": catalytic assisted shift of gas chemistries to enable more $\mathrm{CO}$ and/or $\mathrm{H}_{2}$ from methane mixtures under reducing conditions.

"Poisoning": deactivation of catalytic activity via chemisorption of molecules.

"scfm": standard cubic feet per minute (units commonly used for exhaust flow)

"cpsi”: cells per square inch (units commonly used for catalyst substrate cell density)

"g/bhp-hr": grams per brake-horsepower hour (units commonly used for emissions regulations and the units used for the ARES emission goal) 


\title{
12 Distribution
}

\author{
U.S. Department of Energy: \\ Debbie Haught \\ Pat Hoffman \\ Merrill Smith \\ Ron Fiskum (retired) \\ ARES Industrial Partner Representatives: \\ Gordon Gerber (Caterpillar) \\ Dave Montgomery (Caterpillar) \\ Edward J. Lyford-Pike (Cummins) \\ Link Brandon (Cummins) \\ Axel zur Loye (Cummins) \\ David Watson (Waukesha) \\ James Drees (Waukesha) \\ Robert Stachowicz (Waukesha) \\ EmeraChem (Catalyst Supplier in Project) Representatives: \\ Steve DeCicco \\ Lisa Mitchell \\ ORNL Internal: \\ Johney Green \\ Ron Graves \\ Dave Stinton \\ Patti Garland \\ Bob DeVault \\ Tom King \\ Tim Theiss (and other co-authors)
}




\section{References}

${ }^{1}$ Robert W. Stachowicz, David E. Watson, Donald M. Newburry, and Timothy J. Callahan, "Design and
Development of Waukesha's Stoichiometric, Cooled EGR Engine for the California ARICE Program",
Proceedings of ASME Internal Combustion Division: 2005 Fall Technical Conference ICEF2005-1329
(2005).
${ }_{2}$ Daniel L. Flowers, Joel Martinez-Frias, Francisco Espinosa-Loza, Nick Killingsworth, Salvador M. Aceves, Robert Dibble, Miroslav Kristic, and Avtar Bining, "Development and Testing of a 6-Cylinder HCCI Engine for Distributed Generation", Proceedings of ASME Internal Combustion Division: 2005 Fall Technical Conference ICEF2005-1342 (2005).

${ }^{3}$ Hongxun Gao, Ron Matthews, Sreepati Hari, and Matt Hall, "Use of Railplugs to Extend the Lean Limit of Natural Gas Engines", Proceedings of ASME Internal Combustion Division: 2004 Fall Technical Conference ICEF2004-881 (2004).

${ }^{4}$ Bipin Bihari, Sreenath B. Gupta, Raj R. Sekar, Jess Gingrich, and Jack Smith, "Development of Advanced Laser Ignition System for Stationary Natural Gas Reciprocating Engines", Proceedings of ASME Internal Combustion Division: 2005 Fall Technical Conference ICEF2005-1325 (2005).

${ }^{5}$ Azer P. Yalin, Morgan W. Defoot, Sachin Joshi, Daniel Olsen, Bryan Willson, Yuji Matsuura, and Mitsunobu Miyagi, "Laser Ignition of Natural Gas Engines Using Fiber Delivery", Proceedings of ASME Internal Combustion Division: 2005 Fall Technical Conference ICEF2005-1336 (2005).

${ }^{6}$ Gunther Herdin, Johann Klausner, Ernst Wintner, Martin Weinrotter, Josef Graf, and Kurt Iskra, "Laser Ignition: A New Concept to Use and Increase the Potentials of the Gas Engines", Proceedings of ASME Internal Combustion Division: 2005 Fall Technical Conference ICEF2005-1352 (2005).

${ }^{7}$ Gunther Herdin, Friedrich Gruber, Johann Klausner, Reinheard Robitschko, and Diethard Plohberger, "Use of Hydrogen and Hydrogen Mixtures in Gas Engines and Potentials of NOx Emissions",Proceedings of ASME Internal Combustion Division: 2005 Fall Technical Conference ICEF2005-1354 (2005).

${ }^{8}$ Kinichi Iwachido, Hiroshi Tanada, Tetsuya Watanabe, Naoto Yamada, Osamu Nakayama, Hiromitsu Ando, Masao Hori, Shigeyoshi Taniguchi, Naomi Noda, and Fumio Abe, "Development of the NOx Adsorber Catalyst for Use with High-Temperature Condition", Society of Automotive Engineers Technical Series 2001-01-1298 (2001)

${ }^{9}$ D. Gregory, R. A. Marshall, B. Eves, M. Dearth, J. Hepburn, M. Brogan, and D. Swallow, "Evolution of Lean-NOx Traps on PFI and DISI Lean Burn Vehicles", Society of Automotive Engineers Technical Series 1999-01-3498 (1999).

${ }^{10}$ T. H. Lake, R. G. Bending, G. P. Williams, A. J. Beaumont, A. Warburton, and J. Andersson, "Development of the Control and Aftertreatment System for a Very Low Emission G-DI Vehicle", Society of Automotive Engineers Technical Series 1999-01-1281 (1999).

${ }^{11}$ C. Schenk, J. McDonald, and B. Olson, "High-Efficiency NOx and PM Exhaust Emission Control for Heavy-Duty On-Highway Diesel Engines", Society of Automotive Engineers Technical Series 2001-011351 (2001).

${ }^{12}$ C. Schenk, J. McDonald, and C. Laroo, "High-Efficiency NOx and PM Exhaust Emission Control for Heavy-Duty On-Highway Diesel Engines - Part Two", Society of Automotive Engineers Technical Series 2001-01-3619 (2001).

${ }^{13}$ J. E. Parks II, G. J Wagner, W. S. Epling, M. W. Sanders, and L. E. Campbell, "Near-Zero NOx Control for Diesel Aftertreatment", Society of Automotive Engineers Technical Series 1999-01-2890 (1999).

${ }^{14}$ James E. Parks II, Aaron M. Williams, H. Douglas Ferguson III, John M. E. Storey, "Lean NOx Trap Catalysis for NOx Reduction in Natural Gas Engine Applications", Proceedings of ASME Internal Combustion Division: 2004 Fall Technical Conference ICEF2004-871 (2004).

${ }^{15}$ James E. Parks II and Jim Tassitano, "Natural Gas Partial Oxidation and Reforming for Lean NOx Trap Catalysis Regeneration", Proceedings of ASME Internal Combustion Division: 2005 Fall Technical Conference ICEF2005-1287 (2005).

${ }^{16}$ James E. Parks II and Senthil Ponnusamy, "The Effect of Sulfur on Methane Partial Oxidation and Reforming Processes for Lean NOx Trap Catalysis", Proceedings of ASME Internal Combustion Division: 2006 Fall Technical Conference ICEF2006-1535 (2006). 
${ }^{17}$ James E. Parks II, "Mitigation of Sulfur Effects on a Lean NOx Trap Catalyst by Sorbate Reapplication", Proceedings of ASME Internal Combustion Division: 2007 Fall Technical Conference ICEF2007-1628 (2007).

${ }^{18}$ William S. Epling, Larry E. Campbell, Aleksey Yezerets, Neal W. Currier, and James E. Parks II, "Overview of the Fundamental Reactions and Degradation Mechanisms of NOx Storage/Reduction Catalysts", Catalysis Reviews 46, No. 2, pp. 163-245, (2004).

${ }^{19}$ SEM Micrograph acquired by Karen More of the High Temperature and Materials Laboratory at Oak Ridge National Laboratory.

${ }^{20}$ W. P. Partridge, J. M. E. Storey, S. A. Lewis, R. W. Smithwick, G. L. DeVault, M. J. Cunningham, N. W. Currier, and T. M. Yonushonis, "Time-Resolved Measurements of Emission Transients by Mass Spectroscopy", SAE Transactions - Journal of Fuels and Lubricants 109, p. 2992, Paper No. 2000-01-2952 (2000).

${ }^{21}$ Josh A. Pihl, James E. Parks II, C. Stuart Daw, and Thatcher W. Root, "Product Selectivity During Regeneration of Lean NOx Trap Catalysts", SAE Technical Paper Series 2006-01-3441 (2006).

${ }^{22} \mathrm{http}: / /$ wihort.uwex.edu/flowers/GreenhouseGases.htm (last accessed September 26, 2007)

${ }^{23}$ Calvin H. Bartholomew, "Mechanisms of catalyst deactivation", Applied Catalysis A: General 212, pp. 17-60 (2001).

${ }^{24}$ www.dieselnet.com/standards/cycles/iso8178.html (last accessed September 26, 2007)

${ }_{25}$ International Organization for Standardization website: www.iso.org (last accessed September 26, 2007)

${ }^{26}$ www.gpoaccess.gov/cfr/index.html (last accessed September 26, 2007) 